\title{
Headspace Vapor Characterization of Hanford \\ Waste Tank 241-S-103: Results from \\ Samples Collected on 6/12/96
}

\author{
J. C. Evans \\ K. H. Pool \\ B. L. Thomas \\ K. B. Olsen \\ J. S. Fruchter \\ K. L. Silvers
}

January 1997

Prepared for Westinghouse Hanford Company under a Related Services Agreement with the U.S. Department of Energy under Contract DE-AC06-76RLO 1830

Pacific Northwest National Laboratory

Richland, Washington 99352

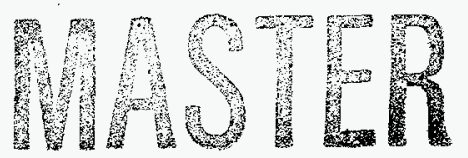




\section{DISCLAMMIR}

Portions of this document may be illegible in electronic image products. Images are produced from the best available original document. 


\section{DISCLAIMER}

This report was prepared as an account of work sponsored by an agency of the United States Government. Neither the United States Government nor any agency thereof, nor any of their employees, makes any warranty, express or implied, or assumes any legal liability or responsibility for the accuracy, completeness, or usefulness of any information, apparatus, product, or process disclosed, or represents that its use would not infringe privately owned rights. Reference herein to any specific commercial product, process, or service by trade name, trademark, manufacturer, or otherwise does not necessarily constitute or imply its endorsement, recommendation, or favoring by the United States Government or any agency thereof. The views and opinions of authors expressed herein do not necessarily state or reflect those of the United States Government or any agency thereof. 


\section{Summary}

This report describes the analytical results of vapor samples taken from the headspace of the waste storage tank 241-S-103 (Tank S-103) at the Hanford Site in Washington State. The results described in this report were obtained to characterize the vapors present in the tank headspace and to support safety evaluations and tank farm operations. The results include air concentrations of selected inorganic and organic analytes and grouped compounds from samples obtained by Westinghouse Hanford Company (WHC) and provided for analysis to Pacific Northwest National Laboratory (PNNL). Analyses were performed by the Vapor Analytical Laboratory (VAL) at PNNL. Analyte concentrations were based on analytical results and, where appropriate, sample volumes provided by WHC. A summary of the inorganic analytes, permanent gases, and total non-methane organic compounds is listed in Table S.1. The three highest concentration analytes detected in SUMMA ${ }^{\mathrm{TM}}$ canister and triple sorbent trap samples are also listed in Table S.1. Detailed descriptions of the analytical results appear in the appendices.

Table S.1. $\quad$ Summary Results of Samples to Characterize the Headspace of Tank S-103 on $6 / 12 / 96$

\begin{tabular}{|c|c|c|c|c|}
\hline Category & $\begin{array}{l}\text { Sample } \\
\text { Medium } \\
\end{array}$ & Analyte & $\begin{array}{c}\text { Vapor }{ }^{(a)} \\
\text { Concentration } \\
\end{array}$ & Units \\
\hline Inorganic Analytes ${ }^{(b)}$ & Sorbent Traps & $\begin{array}{l}\mathrm{NH}_{3} \\
\mathrm{NO}_{2} \\
\mathrm{NO} \\
\mathrm{H}_{2} \mathrm{O}\end{array}$ & $\begin{array}{c}150 \pm 4 \\
<0.16 \\
<0.16 \\
11.2 \pm 0.2\end{array}$ & $\begin{array}{l}\text { ppmv } \\
\text { ppmv } \\
\text { ppmv } \\
\mathrm{mg} / \mathrm{L}\end{array}$ \\
\hline Permanent Gases & $\begin{array}{l}\text { SUMMA }^{\mathrm{mm}} \\
\text { Canister }\end{array}$ & $\begin{array}{l}\mathrm{H}_{2} \\
\mathrm{CH}_{4} \\
\mathrm{CO}_{2} \\
\mathrm{CO} \\
\mathrm{N}_{2} \mathrm{O}\end{array}$ & $\begin{array}{r}79 \\
<50 \\
<34 \\
<34 \\
136\end{array}$ & $\begin{array}{l}\text { ppmv } \\
\text { ppmv } \\
\text { ppmv } \\
\text { ppmv } \\
\text { ppmv }\end{array}$ \\
\hline $\begin{array}{l}\text { Total Non-Methane } \\
\text { Organic Compounds (TO-12) }\end{array}$ & $\begin{array}{l}\text { SUMMA }^{\text {MM }} \\
\text { Canister }\end{array}$ & $\begin{array}{l}\text { Non-Methane } \\
\text { Organic Compounds }\end{array}$ & 1.25 & $\mathrm{mg} / \mathrm{m}$ \\
\hline $\begin{array}{l}\text { Volatile Organics } \\
\text { (TO-14) }\end{array}$ & $\begin{array}{l}\text { SUMMA }^{\mathrm{Tm}} \\
\text { Canister }\end{array}$ & $\begin{array}{l}\text { Methanol } \\
\text { Ethanol } \\
\text { Acetone }\end{array}$ & $\begin{array}{l}2.112 \\
0.574 \\
0.114\end{array}$ & $\begin{array}{l}\text { ppmv } \\
\text { ppmv } \\
\text { ppmv }\end{array}$ \\
\hline $\begin{array}{l}\text { Semi-Volatile Organics } \\
\text { (PNL-TVP-10) }\end{array}$ & Sorbent Traps & $\begin{array}{l}\text { Methanol } \\
\text { Toluene } \\
\text { 3-Methyl-Hexane }\end{array}$ & $\begin{array}{l}0.807 \\
0.282 \\
0.163 \mathrm{~N}\end{array}$ & $\begin{array}{l}\text { ppmv } \\
\text { ppmv } \\
\text { ppmv }\end{array}$ \\
\hline
\end{tabular}

\footnotetext{
(a) Vapor concentrations were determined using sample-volume data provided by Westinghouse Hanford Company and are based on averaged data.

(b) Inorganic analyte concentrations are based on dry tank air at standard temperature and pressure (STP).

$\mathrm{N}$ Tentatively identified compound.
} 



\section{Acknowledgments}

The authors gratefully acknowledge the support of other project staff at Pacific Northwest National Laboratory (PNNL) who contributed to the successful completion of this sampling and analysis activity. J. A. Edwards served as the PNNL single-point-of-contact for sample preparation and shipping. J. L. Julya assisted with organic laboratory work. S. O. Slate, K. P. Schielke, L. M. P. Thomas, and G. W. Dennis supported inorganic laboratory work. 



\section{Glossary}

$\begin{array}{ll}\text { \% D } & \text { \% Difference } \\ \text { CAS } & \text { Chemical Abstracts Service } \\ \text { CCV } & \text { continuing calibration verification } \\ \text { COC } & \text { chain-of-custody } \\ \text { C } & \text { concentration by volume } \\ \text { DIW } & \text { deionized water } \\ \text { EPA } & \text { U.S. Environmental Protection Agency } \\ \text { GC/FID } & \text { gas chromatography/flame ionization detector } \\ \text { GC/MS } & \text { gas chromatograph/mass spectrometer } \\ \text { GC/TCD } & \text { gas chromatography/thermal conductivity detection } \\ \text { IC } & \text { ion chromatography } \\ \text { IL } & \text { impact level } \\ \text { IS } & \text { internal standard } \\ \text { ISVS } & \text { in situ vapor sampling system } \\ \text { MDL } & \text { method detection limit } \\ \text { NIST } & \text { National Institute for Standards and Technology } \\ \text { PNL } & \text { previous designation for Pacific Northwest Laboratory } \\ \text { PNNL } & \text { Pacific Northwest National Laboratory } \\ \text { ppbv } & \text { part per billion by volume } \\ \text { PPm } & \text { parts per million } \\ \text { ppmv } & \text { part per million by volume } \\ \text { QA } & \text { quality assurance } \\ \text { RPD } & \text { relative percent difference } \\ \text { RSD } & \text { relative standard deviation } \\ \text { SAP } & \text { sample and analysis plan } \\ \text { SCIC } & \text { suppressed-conductivity ion chromatography } \\ \text { SRM } & \text { standard reference material } \\ \text { STP } & \text { standard temperature and pressure } \\ \text { SUMMA } & \text { stainless steel, passivated interior canister } \\ \text { TEA } & \text { triethanolamine } \\ \text { TIC } & \text { tentatively identified compound } \\ \text { TNMOC } & \text { total non-methane organic compounds } \\ \text { TST } & \text { triple sorbent trap } \\ \text { UHP } & \text { ultra high purity } \\ \text { VAL } & \text { Vapor Analytical Laboratory } \\ \text { WHC } & \text { Westinghouse Hanford Company } \\ & \end{array}$





\section{Contents}

Summary $\ldots \ldots \ldots \ldots \ldots \ldots \ldots \ldots \ldots \ldots \ldots \ldots \ldots \ldots \ldots \ldots \ldots$ iii

Acknowledgments $\ldots \ldots \ldots \ldots \ldots \ldots \ldots \ldots \ldots \ldots \ldots \ldots \ldots \ldots \ldots \ldots \ldots$

Glossary $\ldots \ldots \ldots \ldots \ldots \ldots \ldots \ldots \ldots \ldots \ldots \ldots \ldots \ldots \ldots \ldots \ldots \ldots \ldots \ldots$

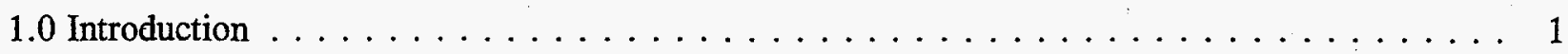

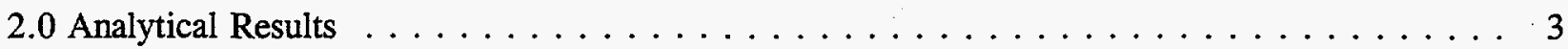

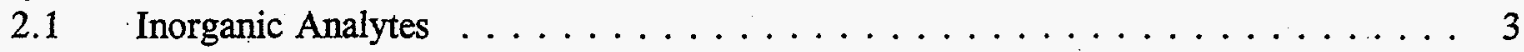

$2.2 \quad$ Permanent Gases $\ldots \ldots \ldots \ldots \ldots \ldots \ldots \ldots \ldots \ldots \ldots \ldots$

2.3 Total Non-Methane Organic Compounds $\ldots \ldots \ldots \ldots \ldots \ldots \ldots \ldots$

$2.4 \quad$ Organic Analytes by SUMMA ${ }^{\mathrm{mn}}$ Method $\ldots \ldots \ldots \ldots \ldots \ldots \ldots \ldots$

2.5 Organic Analytes by Triple Sorbent Trap Method . . . . . . . . . . . . 4

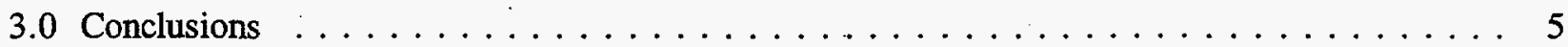

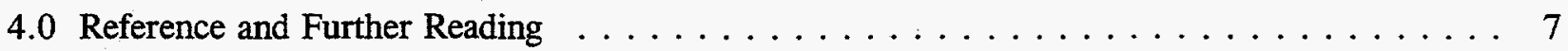

Appendix A: Tank Vapor Characterization: Inorganic Analytes $\ldots \ldots \ldots \ldots \ldots \ldots$ A.1

Appendix B: Tank Vapor Characterization: Permanent Gases . . . . . . . . . . B.1

Appendix C: Tank Vapor Characterization: Total Non-Methane Organic Compounds . . . . . C. C.1

Appendix D: Tank Vapor Characterization: Organic Analytes by SUMMA ${ }^{\mathrm{nu}}$ Method $\ldots \ldots$. D.1

Appendix E: Tank Vapor Characterization: Organic Analytes by Triple Sorbent Trap Method . E.1

Appendix F: Tank Vapor Characterization: Chain of Custody Sample Control Forms . . . . F.1 


\section{Tables}

S.1 Summary Results of Samples to Characterize the Headspace of Tank S-103 on $6 / 12 / 96$

A.1 Analytical Procedures, Quantification Limits, and Notification Levels for Selected Inorganic Analytes $\ldots \ldots \ldots \ldots \ldots \ldots \ldots \ldots \ldots \ldots \ldots \ldots$

A.2 List of PNNL Inorganic Samples, Controls, and Gravimetric Results Obtained from the Headspace of Tank $S-103$ on $6 / 12 / 96 \ldots \ldots \ldots \ldots \ldots \ldots . \ldots \ldots$

A.3 Inorganic Vapor Sample Results Obtained from the Headspace of Tank S-103

B.1 Analytical Procedures and Detection Limits for Permanent Gases $\ldots \ldots \ldots \ldots \ldots$

B.2 Permanent Gas Analysis Results for Samples Collected from the Headspace of Tank S-103 and for Ambient Air and Ambient Air Through the ISVS Collected Near Tank S-103 in SUMMA ${ }^{\mathrm{TM}}$ Canisters on 6/12/96

C.1 TO-12 Results for Samples Collected Through the ISVS from the Headspace of Tank S-103 and from Ambient Air Near Tank S-103 in SUMMA ${ }^{\text {TS }}$ Canisters

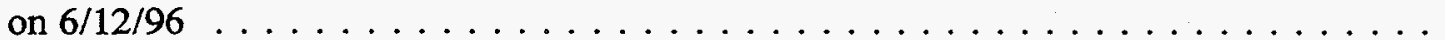

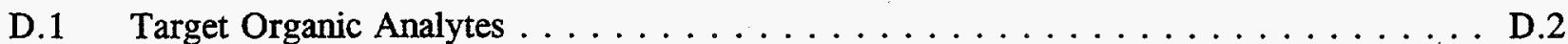

D.2 Positively Identified and Quantitated Target Analytes and Tentatively Identified Compounds and Estimated Concentrations for Samples from the Headspace in Tank S-103 in SUMMA ${ }^{\mathrm{TM}}$ Canisters Collected on 6/12/96 . . . . . . . D.7

D.3 Positively Identified and Quantitated Target Analytes and Tentatively Identified Compounds and Estimated Concentrations of Replicate Analysis of a Single SUMMA $^{\text {TM }}$ Canister Collected from the Headspace of Tank S-103 on $6 / 12 / 96 \ldots \ldots$

D.4 Positively Identified and Quantitated Target Analytes and Tentatively Identified Compounds and Estimated Concentrations in Ambient Air and Ambient Air Through the ISVS Collected Near Tank S-103 in SUMMA ${ }^{\text {ts }}$ Canisters Collected on $6 / 12 / 96 \ldots \ldots \ldots \ldots \ldots \ldots \ldots$

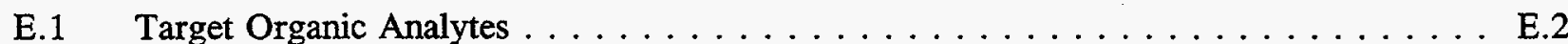

E.2 Positively Identified and Quantitated Target Analytes and Tentatively Identified Compounds and Estimated Concentrations for Triple Sorbent Traps Collected from the Headspace of Tank S-103 on 6/12/96 . 


\section{Tables (Cont)}

E.3 Positively Identified and Quantitated Target Analytes and Tentatively Identified Compounds and Estimated Concentrations of Replicate Analysis of a Single Triple Sorbent Trap Collected from the Headspace of Tank S-103 on 6/12/96

\section{Figures}

D.1 Total Ion Chromatogram for Hanford Waste Tank S-103 SUMMA ${ }^{\mathrm{mM}}$ Canister Sample S6060-A04-080 Collected on $6 / 12 / 96 \ldots \ldots \ldots \ldots \ldots$. . . . . . . . . .

E.1 Total Ion Chromatogram for Hanford Waste Tank S-103 Triple Sorbent Trap Sample S6060-A11-986 Collected on 6/12/96 


\subsection{Introduction}

This report describes the results of vapor samples taken from the headspace of waste storage tank 241-S-103 (Tank S-103) at the Hanford Site in Washington State. Pacific Northwest National Laboratory (PNNL) ${ }^{\text {(a) }}$ contracted with Westinghouse Hanford Company (WHC) to provide sampling devices and analyze samples for inorganic and organic analytes collected from the tank headspace and ambient air near the tank. The analytical work was performed by the PNNL Vapor Analytical Laboratory (VAL) by the Tank Vapor Characterization Project. Work performed was based on a sample and analysis plan (SAP) prepared by WHC. The SAP provided job-specific instructions for samples, analyses, and reporting. The SAP for this sample job was "Vapor Sampling and Analysis Plan" (Homi 1995), and the sample job was designated S6060. Samples were collected by WHC on June 12, 1996 using the In Situ Vapor Sampling System (ISVS).

Sampling devices and controls provided for this job included six sorbent trains for selected inorganic analytes (four sample trains and two field blanks), five SUMMA ${ }^{\mathrm{TM}}$ canisters for permanent gases and volatile organic analytes (three samples and two ambient canisters), and eight triple sorbent traps (TSTs) for semi-volatile organic analytes (four samples, two field blanks, and two trip blanks). The samples and controls were provided to WHC on June 10, 1996. Exposed samples and controls were returned to PNNL on June 18, 1996. Samples and controls were handled, stored, and transported using chain-of-custody $(\mathrm{COC})$ forms to ensure sample quality was maintained.

Samples and controls were handled and stored as per PNNL technical procedure PNL-TVP-07 ${ }^{(b)}$, and, upon return to PNNL, were logged into PNNL Laboratory Record Book 55408. Samples were stored at the VAL under conditions (e.g., ambient, refrigerated) required by technical procedures. Access to the samples was controlled and limited to PNNL staff trained in the application of specific technical procedures to handle samples for the tank vapor characterization project. Analyses were performed in the 300 Area at Hanford; specific analytical methods are described in the text. In summary, sorbent traps for inorganic analytes were either weighed (for water analysis) or weighed and desorbed with the appropriate aqueous solutions for analyzing inorganic analytes by either selective electrode or ion chromatography (IC).

Tank headspace samples were analyzed for

- permanent gases using gas chromatography/thermal conductivity detection (GC/TCD)

- $\quad$ total non-methane organic compounds using cryogenic preconcentration followed by gas chromatography/flame ionization detection (GC/FID)

- $\quad$ volatile organic analytes analyses using cryogenic preconcentration followed by gas chromatograph/mass spectrometer (GC/MS)

(a) Pacific Northwest National Laboratory is operated for the U. S. Department of Energy by Battelle under Contract DE-AC06-76RLO 1830. The previous name of the laboratory was Pacific Northwest Laboratory (PNL), which is used when previously published documents are cited.

(b) PNL-TVP-07, Rev. 2, December 1995, Sample Shipping and Receiving Procedure for PNL Waste Tank Samples, PNL Technical Procedure, Tank Vapor Project, Pacific Northwest Laboratory, Richland, Washington. 
- semi-volatile organic analytes (TST samples) using thermal desorption followed by GC/MS.

This report provides summary and detailed analytical information related to the samples and controls. Section 2.0 provides a summary of analytical results. Section 3.0 provides conclusions. Descriptions of samples, analytical methods, quality assurance (QA) and quality control issues, and detailed sample results are provided for each category of samples and analyses in Appendices A, B, C, D, and E. Appendix F contains the completed COC forms. 


\subsection{Analytical Results}

Samples obtained by WHC from the headspace of S-103 on June 12, 1996 (Sample Job S6060) were analyzed in the PNNL Vapor Analytical Laboratory. Summarized results are described in this section; details of samples, analyses, and data tables are provided in the appendices.

\subsection{Inorganic Analytes}

The vapor concentrations of selected inorganic analytes $\left(\mathrm{NH}_{3}, \mathrm{NO}_{2}\right.$, and $\left.\mathrm{NO}\right)$ and vapor mass concentration (primarily $\mathrm{H}_{2} \mathrm{O}$ ) were determined. The average and one standard deviation of concentration results from inorganic sorbent sample trains used to sample headspace vapors were $150 \pm 4 \mathrm{ppmv}\left(\mathrm{NH}_{3}\right),<0.16 \mathrm{ppmv}\left(\mathrm{NO}_{2}\right),<0.16 \mathrm{ppmv}(\mathrm{NO})$, and $11.2 \pm 0.2 \mathrm{mg} / \mathrm{L}$ (primarily $\mathrm{H}_{2} \mathrm{O}$ ). The vapor concentration results were based on four samples for each compound. All samples $(100 \%)$ were successfully analyzed and used in the averages. Representative field blanks were also analyzed and used to correct data.

Results provided above are estimated to be accurate to within $\pm 10 \%$ (assuming negligible error in the sample volume measurements) and are within the $\pm 30 \%$ specified by the SAP. Measurement precision, as indicated by the relative standard deviation, was $5 \%$ for the compounds found to be present at concentrations greater than the analytical method estimated quantitation limit (EQL), and within the $25 \%$ specified by the SAP. These uncertainties were confirmed by evaluation of spikes and continuing calibration standards $\left(\mathrm{NH}_{3}\right.$ and $\left.\mathrm{NO}_{2}^{-}\right)$and evaluation of the variability of field blanks $\left(\mathrm{H}_{2} \mathrm{O}\right)$. All samples were analyzed within 14 days after being collected. No deviations from standard procedures were noted. Data and additional information on samples, analyses, and results are described in Appendix A. The chain-of-custody form used to control samples, 100092, is included in Appendix F.

\subsection{Permanent Gases}

The complete results of the permanent gas analysis of Tank S-103 can be found in Appendix B. In summary, hydrogen at $79 \mathrm{ppmv}$ and nitrous oxide at $136 \mathrm{ppmv}$ were the only permanent gases observed in the tank headspace samples.

\subsection{Total Non-Methane Organic Compounds}

The complete results of the TO-12 analysis of Tank S-103 can be found in Appendix C. In summary, the average concentration in the three tank headspace was $1.25 \mathrm{mg} / \mathrm{m}^{3}$. This compares to $6.92 \mathrm{mg} / \mathrm{m}^{3}$ for the sum of all target compounds and tentatively identified compounds (TICs) identified in the analysis of the SUMMA ${ }^{\mathrm{TM}}$ canisters.

\subsection{Organic Analytes by SUMMA ${ }^{\mathrm{TM}}$ Method}

The complete results of the SUMMA ${ }^{\mathrm{TI}}$ analysis of Tank S-103 can be found in Appendix D. In summary, 64 target analytes and 30 TICs were detected in the tank headspace samples. Sixty-three 
target analytes and $15 \mathrm{TICs}$ were identified in two or more tank headspace samples. Twelve TICs were not identified and were labelled as unknowns. Methanol at $3.02 \mathrm{mg} / \mathrm{m}^{3}$ and ethanol at 1.18 $\mathrm{mg} / \mathrm{m}^{3}$ accounted for $61 \%$ of the compounds identified in the analysis. The total concentration of the target analytes was $6.57 \mathrm{mg} / \mathrm{m}^{3}$. Methyl cyclohexane $\left(0.06 \mathrm{mg} / \mathrm{m}^{3}\right)$ and pyrazine $\left(0.04 \mathrm{mg} / \mathrm{m}^{3}\right)$, the two highest concentration TICs, accounted for $30 \%$ of the TICs and $1.5 \%$ of the total compounds identified in the analysis. The total concentration of the TICs was $0.35 \mathrm{mg} / \mathrm{m}^{3}$. The total concentration of all the compounds identified was $6.92 \mathrm{mg} / \mathrm{m}^{3}$. This compares to a total concentration of $1.25 \mathrm{mg} / \mathrm{m}^{3}$ identified in the TO- 12 analysis of the three tank headspace samples.

SUMMA $^{\mathrm{TM}}$ canister PNL 082 was analyzed in replicate for target analytes and TICs to determine analytical precision. Twenty-four of 63 target compounds and one of 11 TICs had RPDs of less than $10 \%$.

Sixty-three target compounds and 18 TICS were observed in one or both of the ambient air samples. Many of the compounds were identified at trace levels (below EQL). Several noted exceptions included: methanol, acetone, propanol, 2-butanone, butanenitrile, 1-butanol, cyclohexane, butane, pentanenitrile, 1,1,2-trichloro-1,2,2-trifluoromethane, 4-methyl-2-pentanone, and cyclohexanone. Trace levels of many of the target analytes may be false positives due to the fact that some of the compounds were found in the continuing calibration blank (CCB) above the EQL and are greater than 20 times the concentration found in the sample. These compounds are flagged with a " $\mathrm{B}$ " in the tables.

\subsection{Organic Analytes by Triple Sorbent Trap Method}

The complete results of the sorbent trap analysis of Tank S-103 can be found in Appendix E. In summary, 39 target analytes above the IDL and 28 TICs were detected in the tank headspace samples. Thirty-six of the target analytes and 13 TICs were observed in two or more sorbent traps. Methanol at $1.15 \mathrm{mg} / \mathrm{m}^{3}$ and toluene at $1.16 \mathrm{mg} / \mathrm{m}^{3}$ accounted for $44 \%$ of the target analytes and $28 \%$ of the total concentration identified by the analyses. The total concentration of the target analytes was $5.20 \mathrm{mg} / \mathrm{m}^{3}$ or $64 \%$ of the total concentration identified by the analyses. The predominant TICs observed in these samples were 3-methyl hexane at $0.73 \mathrm{mg} / \mathrm{m}^{3}$ and 2-methyl hexane at $0.42 \mathrm{mg} / \mathrm{m}^{3}$. The total concentration of the TICs was $2.96 \mathrm{mg} / \mathrm{m}^{3}$ or $36 \%$ of the total concentration identified by the analysis. The total concentration of all the compounds identified was $8.16 \mathrm{mg} / \mathrm{m}^{3}$.

Triple sorbent trap sample PNL 987 was analyzed in replicate for target analytes and TICs to determine analytical precision. Twenty-seven of 36 target compounds and 13 of 14 TICs had RPDs of less than $10 \%$.

Review of the TST data found the field blanks badly contaminated with a group of compounds characteristic of the $3 \mathrm{M}$ adhesive tape used on previous ISVS jobs. The special handling associated with preventing radiological contamination of the sample bundle from the riser appears to have severely exacerbated the tape problem which had not in any case been completely eliminated. Because of the tape problem, TST tank results from this sampling activity should be generally considered as suspect. 


\subsection{Conclusions}

The concentrations of inorganic and organic analytes were determined from samples of the headspace of Tank S-103 on April 12, 1996 (Sample Job S6060). The vapor concentrations were based either on whole-volume samples (SUMMA ${ }^{\mathrm{Tx}}$ canisters) or on sorbent traps exposed to sample flow. In the case of the canisters, the concentrations were based on analytical results and the tracking of dilution/concentration of sample volumes obtained directly from the canisters. In the case of the sorbent traps, concentrations were based on analytical results and sample volumes reported by WHC. Known sampling and analytical variances from established quality assurance requirements, where significant, were documented in this report, as required by the SAP (Homi 1995). WHC was immediately notified based on preliminary, uncorrected analytical results, when the ammonia concentration was determined to be above the notification level of $150 \mathrm{ppmv}$. Notification levels and notification procedures are described in the SAP (Homi 1995). 


\section{•}




\subsection{Reference and Further Reading}

\section{Reference}

Homi, C.S. 1995. Vapor Sampling and Analysis Plan. WHC-SD-WM-TP-335, Rev. 2, Westinghouse Hanford Company, Richland, Washington.

\section{Further Reading}

Pacific Northwest Laboratory. Analytical Laboratory Procedure Compendium. Procedure PNL-ALO-271. PNL-MA-599, Pacific Northwest Laboratory, Richland, Washington.

Pacific Northwest Laboratory. Quality Assurance Manual, Part 3: Procedures for Quality Assurance Program. PNL-MA-70, Part 3, Pacific Northwest Laboratory, Richland, Washington.

Pacific Northwest National Laboratory. Quality Assurance Plan for Activities Conducted by the Pacific Northwest National Laboratory Vapor Analytical Laboratory (VAL) and the Pacific Northwest National Laboratory Tank Vapor Characterization Project. ETD-002, Rev. 0, Pacific Northwest National Laboratory, Richland, Washington.

U.S. Department of Energy. Hanford Analytical Services Quality Assurance Plan (HASQAP). DOE/RL-94-55, Rev. 2, U. S. Department of Energy, Richland, Washington.

Westinghouse Hanford Company. Quality Assurance Project Plan for Tank Vapor Characterization. WHC-SD-WM-QAPP-013, Rev. 1, Westinghouse Hanford Company, Richland, Washington. 
Appendix A

Tank Vapor Characterization:

Inorganic Analytes 


\section{Appendix A}

\section{Tank Vapor Characterization: Inorganic Analytes}

Solid sorbent traps, prepared in multi-trap sampling trains, were supplied to Westinghouse Hanford Company (WHC) for sampling the tank headspace using the In Situ Vapor Sampling System (ISVS). Blanks, spiked blanks (when requested), and exposed samples were returned to Pacific Northwest National Laboratory (PNNL) for analysis. Analyses were performed to provide information on the tank headspace concentration of the following analytes: ammonia $\left(\mathrm{NH}_{3}\right)$, nitrogen dioxide $\left(\mathrm{NO}_{2}\right)$, nitric oxide (NO), and water $\left(\mathrm{H}_{2} \mathrm{O}\right)$. Procedures were similar to those developed previously during sample jobs performed with the VSS connected to the headspace of Tank C-103 (Ligotke et al. 1994). During those sample jobs, control samples provided validation that the sorbent tubes effectively trapped $\mathrm{NH}_{3}$ and mass. Samples were prepared, handled, and disassembled as described in Technical Procedure PNL-TVP-09(a). Analytical accuracy was estimated based on procedures used. Sample preparation and analyses were performed following PNNL quality assurance (QA) impact level II requirements.

\section{A.1 Sampling Methodology}

Standard glass tubes containing sorbent materials to trap vapors of selected analytes of $\mathrm{NH}_{3}$, $\mathrm{NO}, \mathrm{NO}_{2}$, and $\mathrm{H}_{2} \mathrm{O}$ (supplied by SKC Inc., Eighty Four, Pennsylvania) were obtained, prepared, and submitted for vapor sampling. The sorbent traps were selected based on their use by the Occupational Safety and Health Administration to perform workplace monitoring and because of available procedures and verification results associated with that particular application. The typical sorbent traps used consisted of a glass tube containing a sorbent material specific to the compound of interest. In general, the tubes contained two sorbent layers, or sections; the first layer was the primary trap, and the second layer provided an indication of breakthrough. In the tubes, sorbent layers are generally held in packed layers separated by glass wool. The sorbent traps, with glasssealed ends, were received from the vendor.

The type and nominal quantity of sorbent material varied by application. Sorbent traps were selected for the tank sample job and included the following products. The $\mathrm{NH}_{3}$ sorbent traps contained carbon beads impregnated with sulfuric acid; nominally, $500 \mathrm{mg}$ were contained in the primary and $250 \mathrm{mg}$ in the breakthrough sections. The $\mathrm{NH}_{3}$ was chemisorbed as ammonium sulfate $\left[\left(\mathrm{NH}_{4}\right)_{2} \mathrm{SO}_{4}\right]$. The $\mathrm{NO}_{2}$ traps contained a zeolite impregnated with triethanolamine (TEA), with $400 \mathrm{mg}$ in the primary and $200 \mathrm{mg}$ in the breakthrough sections. The $\mathrm{NO}_{2}$ was absorbed and disproportionated to equi-molar quantities of nitrite ions $\left(\mathrm{NO}_{2}{ }^{-}\right)$and nitrate ions $\left(\mathrm{NO}_{3}{ }^{-}\right)$. Glass tubes containing $800 \mathrm{mg}$ of an oxidant such as chromate were used to convert $\mathrm{NO}$ to $\mathrm{NO}_{2}$. The converted NO was then collected as nitrite and nitrate in an $\mathrm{NO}_{2}$ trap. The water traps contained $300 \mathrm{mg}$ of silica gel in the primary and $150 \mathrm{mg}$ in the breakthrough sections.

(a) Pacific Northwest Laboratory. 12/95. Sorbent Trap Preparation for Sampling and Analysis: Waste Tank Inorganic Vapor Samples, PNL-TVP-09 (Rev. 2), PNL Technical Procedure, Pacific Northwest Laboratory, Richland, Washington. 
Sorbent trains provided to trap inorganic compounds included all or some of the following: samples, spiked samples, spares, blanks, and spiked blanks. Sorbent trains were prepared from samelot batches, with the oxidizer sections of the $\mathrm{NO}_{\mathrm{x}}$ sorbent trains having been stored previously in a freezer. After sample preparation, sorbent trains were stored at $\leq 10^{\circ} \mathrm{C}$ because of handling recommendations for the oxidizer tubes attached to some samples. After receipt of exposed and radiologically cleared samples from WHC and disassembly of the sorbent trains, samples were provided to the analytical laboratory at ambient temperature.

The sorbent traps were prepared in multi-trap sorbent trains configured so sample flow passed in order through the traps, targeting specific analytes, and then through a desiccant trap. The specific order of traps within the various sorbent trains is described in Section A.4. The ends of the glasstube traps were broken, and the traps were weighed and then connected to each other using uniform lengths of 3/8-in. perfluoroalkoxy-grade Teflon ${ }^{\circledR}$ tubing. The tubing was heated in hot air and forced over the open ends of the traps to form a tight seal. The inlets of the sorbent trains each consist of a short section of tubing that has a 3/8-in. stainless steel Swagelok ${ }^{\circledR}$ nut, sealed using a Swagelok ${ }^{\circledR}$ cap. $^{2}$ The trailing ends of the sorbent trains (the downstream end of the traps containing silica gel) were each sealed with red plastic end caps provided by the manufacturer. The sorbent-tube trains remained sealed other than during the actual sampling periods. During vapor sampling, C-Flex ${ }^{\circledR}$ tubing was provided by WHC to connect the downstream ends of the sorbent trains to the sampling manifold exhaust connections.

A.1.1 Concentration Calculations. The concentrations of target compounds in the tank headspace were determined from sample results, assuming effective sample transport to the sorbent traps. Concentration, in parts per million by volume (ppmv), was determined by dividing the mass of the compound, in $\mu \mathrm{mol}$, by the volume of the dried tank air sampled in moles. The micromolar sample mass was determined by dividing the compound mass, in $\mu \mathrm{g}$, by the molecular weight of the compound, in $\mathrm{g} / \mathrm{mol}$. The molar sample volume was determined, excluding water vapor, by dividing the standard sample volume (at $0^{\circ} \mathrm{C}$ and 760 torr), in $\mathrm{L}$, by $22.4 \mathrm{~L} / \mathrm{mol}$. For example, the concentration by volume $\left(\mathrm{C}_{\mathrm{v}}\right)$ of a 3.00-L sample containing $75.0 \mu \mathrm{g}$ of $\mathrm{NH}_{3}$ equals

$$
\mathrm{C}_{\mathrm{v}}=\frac{75.0 \mu \mathrm{g}}{17.0 \mathrm{~g} / \mathrm{mol}}\left[\frac{3.00 \mathrm{~L}}{22.4 \mathrm{~L} / \mathrm{mol}}\right]^{-1}=32.9 \mathrm{ppmv}
$$

This calculational method produces concentration results that are slightly conservative (greater than actual) because the volume of water vapor in the sample stream is neglected. The volume of water vapor is not included in the measured sampled volume because of its removal in desiccant traps upstream of the mass flowmeter. However, the bias is generally expected to be small. For a tank headspace temperature of $35^{\circ} \mathrm{C}$, the magnitude of the bias would be about 1 to $6 \%$, assuming tank headspace relative humidities of 20 to $100 \%$, respectively. The concentration of mass (determined gravimetrically) was also per dry-gas volume at standard conditions. 


\section{A.2 Analytical Procedures}

The compounds of interest were trapped using solid sorbents and chemisorption (adsorption of water vapor). Analytical results were based on extraction and analysis of selected ions. Analytical procedures used are specified in the text.

A.2.1 Ammonia Analysis. The sorbent material from the $\mathrm{NH}_{3}$-selective sorbent traps was placed into labeled $20-\mathrm{mL}$ glass scintillation vials. Vials containing front-, or primary-, section sorbent material were treated with $10.0 \mathrm{~mL}$ of deionized water (DIW), and vials containing back-upsection sorbent material were treated with $5.0 \mathrm{~mL}$ of DIW. After extraction, the $\mathrm{NH}_{3}$ sorbent traps were analyzed using the selective ion electrode procedure PNL-ALO-226 Rev. $0^{\text {(a) }}$. Briefly, this method includes 1) preparing a $1000-\mu \mathrm{g} / \mathrm{mL}$ (ppm) $\mathrm{NH}_{3}$ stock standard solution from dried reagentgrade $\mathrm{NH}_{4} \mathrm{Cl}$ and DIW, 2) preparing 0.1-, 0.5-, 1.0-, 10-, and 100-ppm $\mathrm{NH}_{3}$ working calibration standards by serial dilution of the freshly made stock standard, 3) generating an initial calibration curve from the measured electromotive force signal versus $\mathrm{NH}_{3}$ concentration data obtained for the set of working standards, 4) performing a calibration-verification check, using a mid-range dilution of a certified National Institute for Standards and Technology (NIST)-traceable $0.1 \mathrm{M} \mathrm{NH}_{4} \mathrm{Cl}$ standard from an independent source, after analyzing every five or six samples, 5) continuing this sequence until all samples of the batch have been measured, including duplicates and spiked samples, and 6) remeasuring the complete set of calibration standards (at the end of the session). Electromotive force (volts) signal measurements obtained for samples are compared to those for standards, either graphically or algebraically (using linear regression) to determine $\mathrm{NH}_{3}$ concentration in the samples.

A.2.2 Nitrite Analysis. The sorbent traps for $\mathrm{NO}_{2}$ and $\mathrm{NO}$ were desorbed in an aqueous TEA and n-butanol solution and analyzed by suppressed-conductivity ion chromatography (SCIC) for nitrite according to PNL-ALO-212, Rev. $1^{(b)}$ modified to obviate interferences by concentrations of non-target analytes. Specifically, the modifications used were 1) eluent $1.44 \mathrm{mM} \mathrm{Na}_{2} \mathrm{CO}_{3}+$ $1.8 \mathrm{mM} \mathrm{NaHCO}$ at $2.0 \mathrm{~mL} / \mathrm{min}, 2$ ) one guard column (AG4A) and two separator columns (AS4A) in series instead of just one separator column, and 3) all standards, samples, and blanks were injected into the IC sample loop through $0.45-\mu \mathrm{m}$ syringe filters.

For the analysis, the sorbent materials were placed into labeled $20-\mathrm{mL}$ glass scintillation vials. To each vial, $3.0 \mathrm{~mL}$ of desorbing solution (15 $\mathrm{g}$ TEA $+1 \mathrm{~mL}$-butanol in $1.0 \mathrm{~L}$ of DIW) was added. Primary sorbent-tube sample materials and back-up (breakthrough) sorbent-trap materials were analyzed separately using identical procedures. Each analytical session was conducted as follows. Working nitrite standards $(0,0.1,0.25$, and $0.5 \mathrm{ppm})$ were prepared by diluting a stock nitrite standard with desorbing solution. An initial calibration curve was prepared from the instrument response (chromatographic peak height) versus nitrite standard concentration data for the set of working standards. A calibration verification check using one of the midrange standards was

(a) Procedure entitled "Ammonia (Nitrogen) in Aqueous Samples," PNL-ALO-226, in the Analytical Chemistry Laboratory $(A C L)$ Procedure Compendium, Vol. 3: Inorganic Instrumental Methods. Pacific Northwest Laboratory, Richland, Washington.

(b) Procedure entitled "Determination of Inorganic Anions by Ion Chromatography," PNL-ALO-212, in the Analytical Chemistry Laboratory (ACL) Procedure Compendium, Vol. 3: Inorganic Instrumental Methods. Pacific Northwest Laboratory, Richland, Washington. 
performed after the analysis of every six samples. If the instrument response indicated that sample nitrite concentration was outside the calibration range ( $>0.5 \mathrm{ppm}$ nitrite), the sample was diluted with desorbing solution and reanalyzed. After all samples of a batch were analyzed, the complete set of calibration standards was remeasured to verify consistent instrument response, and the analytical session was terminated.

Instrument responses (peak height) observed for samples were compared to those for standards to determine the nitrite concentration of the samples. Because $\mathrm{NO}_{2}$ and $\mathrm{NO}$ converted to $\mathrm{NO}_{2}$ were collected on the sorbent as equal quantities of nitrite and nitrate, and the analysis was specific for nitrite, the molar masses of $\mathrm{NO}_{2}$ and $\mathrm{NO}$ were determined by doubling the analytically determined molar mass of nitrite.

A.2.3 Mass (Water) Analysis. Sorbent traps used to make each sample train were weighed using a semi-micro mass balance, after labeling and breaking the glass tube ends, without plastic end caps in accordance with procedure PNL-TVP-09. After receipt of exposed samples, the sorbent traps were again weighed to determine the change in mass. Records of the measurements were documented on sample-preparation data sheets. The mass concentration, generally roughly equal to the concentration of water, was determined by dividing the combined change in mass from all traps in a sorbent train by the actual volume of gas sampled. Field blanks were used to correct results.

\section{A.3 Quality Assurance/Quality Control}

Analytical work was performed according to quality levels identified in the project QA plan and several PNNL documents including PNL-MA-70 (Part 3), PNL-ALO-212, PNL-ALO-226, and Quality Assurance Plan ETD-002. The samples were analyzed following PNNL Impact Level II. A summary of the analysis procedures and limits for the target inorganic compounds is provided in Table A.1. The table also shows generic expected notification ranges and describes related target analytical precision and accuracy levels for each analyte; the information in the table is based on the data quality objective assessment by Osborne et al. (1995). From the table, it can be seen that the EQL required to resolve the analyte at one-tenth of the recommended exposure limit for each of the target analytes is achieved using current procedures and with a vapor-sample volume of $3 \mathrm{~L}$ and a desorption-solution volume of $3 \mathrm{~mL}\left(10 \mathrm{~mL}\right.$ for $\left.\mathrm{NH}_{3}\right)$.

The accuracy of concentration measurements depends on potential errors associated with both sampling and analysis (see Section A.4). Sampling information, including sample volumes, was provided by WHC; sample-volume uncertainty was not provided. The uncertainty of analytical results, which depends on the method used, was estimated to be within allowable tolerances (Osborne et al. 1995; Table A.1). For $\mathrm{NH}_{3}$ analyses, the accuracy of laboratory measurements by selective ion electrode was estimated to be $\pm 5 \%$ relative, independent of concentration at $1 \mu \mathrm{g} / \mathrm{mL}$ or greater levels. The uncertainty includes preparation of standards, purity of the ammonium salt used to prepare standards, potential operator bias, ambient temperature variations, etc. Working standards are traceable to NIST standard reference material (SRM) by using an independent calibration verification standard certified to be NIST traceable. Nitrite analyses (for $\mathrm{NO}_{2}$ and $\mathrm{NO}$ ) are performed using certified but not NIST-traceable SRM; this is because NIST does not make a nitrite SRM. Based on experience in comparing nitrite working standards prepared from several different sources and factors mentioned for $\mathrm{NH}_{3}$ above, the estimated maximum bias for samples derived from sampling for $\mathrm{NO}_{2}$ is $\pm 10 \%$, and for samples derived from sampling for $\mathrm{NO}$ it is $\pm 5 \%$ relative. 
Table A.1. Analytical Procedures, Quantification Limits, and Notification Levels for Selected Inorganic Analytes ${ }^{(a)}$

\begin{tabular}{|c|c|c|c|c|c|}
\hline Analyte & Formula & Procedure & $\begin{array}{c}\mathrm{EQL}^{(b)} \\
(\mu \mathrm{g}) \\
\end{array}$ & $\begin{array}{c}\mathrm{EQL}^{(\mathrm{b})} \\
(\mathrm{ppmv})\end{array}$ & $\begin{array}{c}\text { Notification } \\
\text { Level }^{(c)} \\
\text { (ppmv) } \\
\end{array}$ \\
\hline Ammonia & $\mathrm{NH}_{3}$ & PNL-ALO-226 & 1.0 & 0.71 & $\geq 150$ \\
\hline Nitrogen Dioxide & $\mathrm{NO}_{2}$ & PNL-ALO-212 & 0.3 & 0.16 & $\geq 10$ \\
\hline Nitric oxide & NO & PNL-ALO-212 & 0.3 & 0.16 & $\geq 50$ \\
\hline Mass (water) ${ }^{(d)}$ & $\mathrm{n} / \mathrm{a}$ & PNL-TVP-09 & $0.6 \mathrm{mg}$ & $0.3 \mathrm{mg} / \mathrm{L}$ & $\mathrm{n} / \mathrm{a}$ \\
\hline
\end{tabular}

(a) Analytical precision and accuracy targets for results in the expected ranges equal $\pm 25 \%$ and

(b) The lowest calibration standard is defined as the EQL.

(c) As per Table 7-1 in Osborne et al. (1995). Notification levels require verbal and written reports to WHC on completion of preliminary analyses.

(d) The vapor-mass concentration, thought to be largely water vapor, is determined gravimetrically. $\mathrm{n} / \mathrm{a}=$ not applicable.

The accuracy of measurements of sample mass is typically $\pm 0.1 \mathrm{mg}$, or much less than $1 \%$ of the mass changes of most samples. The analytical accuracy of measurements of the change in mass of sorbent trains, based on the variability in mass change of field-blank sorbent trains, is determined for each sample job and is typically about $\pm 1 \mathrm{mg}$ per five-trap sorbent train.

\section{A.4 Inorganic Sample Results}

Samples were obtained by WHC from the tank headspace of Tank S-103 on June 12, 1996

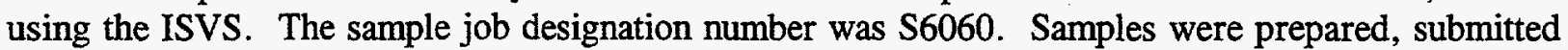
to WHC for the sample job, and then returned to PNNL and analyzed to provide information on the concentrations of $\mathrm{NH}_{3}, \mathrm{NO}_{2}, \mathrm{NO}$, and mass (primarily $\mathrm{H}_{2} \mathrm{O}$ ). Samples were controlled using $\mathrm{COC}$ form 100092 (Appendix F). The inorganic samples and sample volume information were received from WHC on June 18, 1996. Analyses were completed on June 20, 1996 (gravimetric, 8 days elapsed), June 25, 1996 (ammonia, 13 days elapsed), and June 25, 1996 (nitrite, 13 days elapsed).

A list of samples, sampling information, sample volumes, and gravimetric results is shown in Table A.2. The types of sample trains used and the order of sorbent traps within each train are also shown in the table. For example, the sorbent train $\mathrm{NH}_{3} / \mathrm{NO}_{\mathrm{x}} / \mathrm{H}_{2} \mathrm{O}$ contained an $\mathrm{NH}_{3}$ trap at the inlet end, an $\mathrm{NO}_{\mathrm{x}}$ series in the middle (Section A.4.2), and a desiccant trap at the outlet end. Analytical mass and concentration results are shown in Table A.3. Sample volumes were provided by WHC; sample-volume uncertainty was not provided. Tank headspace concentration results (Table A.3) are based on this information, and the listed uncertainties equal plus or minus one standard deviation of the individual results from each set of samples. Percentage relative standard deviation (RSD) may be determined by dividing the standard deviation by the average result and multiplying by 100 . Where analytical results from samples, corrected for blanks, were less than the EQL in Table A.1, the concentration results (Table A.3) are listed as "less-than" the EQL value. Results of control samples, 
such as trip blanks, field blanks, and spiked blanks, are discussed in this section. Spiked blanks, when used, were transported to the field but not opened. Spiked samples, when used, were opened in the field and used to collect tank vapors. Sample results were not corrected for the percentage recoveries of spiked blanks:

A.4.1 Ammonia Results. The concentration of $\mathrm{NH}_{3}$ was $150 \pm 4 \mathrm{ppmv}$, based on all four samples. The blank-corrected $\mathrm{NH}_{3}$ quantities in the sorbent traps ranged from 12.2 to $12.7 \mu \mathrm{mol}$ in front sections; blank-corrected $\mathrm{NH}_{3}$ was not found ( $\leq 0.01 \mu \mathrm{mol}$ ) in back sorbent sections. Blank corrections, $0.37 \mu \mathrm{mol}$ in front and $0.07 \mu \mathrm{mol}$ in back sections, were about $3 \%$ of collected quantities. The analysis of one sample was duplicated and yielded a repeatability of $\pm 3.5 \%$. One blank sorbent trap was spiked with $17 \mu \mathrm{mol}$ of $\mathrm{NH}_{3}$ and yielded a percentage recovery of $104 \%$. One sample leachate was spiked after initial analysis with roughly the quantity of ammonia in the sample and yielded a percentage recovery of $94 \%$. The initial calibration verification (ICV) and continuing calibration verification (CCV) standards, using NIST-traceable material, yielded percentage recoveries of $98 \%$ (ICV) and 96, 100 and 100\% (CCV) during the analytical session. A 5-point calibration was performed over an $\mathrm{NH}_{3}$ range of 0.1 to $1000 \mu \mathrm{g} / \mathrm{mL}$.

A.4.2 Nitrogen Oxides Results. The concentrations of $\mathrm{NO}_{2}$ and $\mathrm{NO}$ were both $<0.16$ ppmv based on all four samples. Blank-corrected $\mathrm{NO}_{2}^{-}$quantities in the sorbent traps were all $<0.013 \mu \mathrm{mol}$. Nitrite blank levels used to correct data were $0.0070 \mu \mathrm{mol}$ in front (four of four blanks analyzed) and $0.0041 \mu \mathrm{mol}$ in back (two of four blanks analyzed) sorbent sections. The analyses of two samples were duplicated and yielded repeatabilities of $\pm 0 \%$ and $\pm 1.0 \%$. Two sample leachates were spiked with $0.25 \mathrm{ppm} \mathrm{NO}_{2}^{-}$and yielded percentage recoveries of 101 and $108 \%$. A 4-point calibration was performed over a concentration range of 0 to $0.5 \mu \mathrm{g} \mathrm{NO}_{2}^{-}$per mL in the desorbing matrix. Although spiked blanks were not tested, blanks spiked with $0.0064,0.047$, 0.11 , and $0.74 \mu \mathrm{mol} \mathrm{NO}_{2}^{-}$during previous sample jobs yielded percentage recoveries of $153 \pm 14$, $103 \pm 4,106 \pm 8$, and $111 \pm 7 \%$, respectively (Clauss et al. 1994; Ligotke et al. 1994).

A.4.3 Gravimetric Results. Gravimetric results yield water vapor concentrations. This is because the total mass concentration of other vapors in the headspaces of Hanford waste tanks, measured in $\mu \mathrm{g} / \mathrm{L}$, are typically two or three orders of magnitude less than the $\mathrm{mg} / \mathrm{L}$ mass concentrations of the water vapor found in even relatively dry tanks. The water vapor mass concentration collected in the 5-trap sorbent trains was $11.2 \pm 0.2 \mathrm{mg} / \mathrm{L}$, based on dry air sample volumes $\left(0^{\circ} \mathrm{C}\right.$ and 760 torr). The result was determined from an average mass gain of $22.3 \mathrm{mg}$ from all four sample trains. The blank correction applied to the results was $-1.35 \mathrm{mg}$ per train, based on a mass gain of $1.35 \pm 0.8 \mathrm{mg}$ per two 5-trap field-blank sorbent trains. A control mass was measured and indicated a measurement accuracy of $\pm 0.1 \mathrm{mg}$. Although no spiked blanks were tested, the percentage recovery of mass from three blank $\mathrm{H}_{2} \mathrm{O}$ traps spiked with $51 \mathrm{mg}$ water was $103 \pm 2 \%$ during a previous sample job (Clauss et al. 1994).

Corrected for a measured tank headspace temperature of $22.6^{\circ} \mathrm{C}$ and pressure of 743.7 torr, the actual water vapor mass concentration from the gravimetric results was $10.0 \pm 0.2 \mathrm{mg} / \mathrm{L}$. Also based on analytical results, the partial pressure of water vapor was $10.2 \pm 0.2$ torr, the relative humidity was $50 \pm 1 \%$, and the dew point was $11.5 \pm 0.2^{\circ} \mathrm{C}$. 
Table A.2 List of PNNL Inorganic Samples, Controls, and Gravimetric Results Obtained from the Headspace of Tank S-103 on 6/12/96

\begin{tabular}{|c|c|c|c|c|c|c|}
\hline \multirow[b]{2}{*}{ Sample Number } & \multirow[b]{2}{*}{ Sorbent Train Type } & \multicolumn{5}{|c|}{ Sample Port and Volume Information ${ }^{(a)}$} \\
\hline & & $\begin{array}{c}\text { Sample } \\
\text { Port } \\
\end{array}$ & $\begin{array}{l}\text { Flow Rate } \\
(\mathrm{mL} / \mathrm{min})\end{array}$ & $\begin{array}{c}\text { Duration } \\
\text { (min) }\end{array}$ & $\begin{array}{c}\text { Volume } \\
\text { (L) }\end{array}$ & $\begin{array}{c}\text { Mass Gain } \\
\text { (g) }\end{array}$ \\
\hline \multicolumn{7}{|l|}{ Samples: } \\
\hline S6060-A07-S91 & $\mathrm{NH} 3 / \mathrm{NOx} / \mathrm{H} 2 \mathrm{O}$ & 1 & 200.0 & 10.0 & 1.86 & 0.0221 \\
\hline S6060-A08-S92 & $\mathrm{NH} 3 / \mathrm{NO} / \mathrm{H} 2 \mathrm{O}$ & 2 & 200.0 & 10.0 & 1.86 & 0.0217 \\
\hline S6060-A09-S93 & $\mathrm{NH} 3 / \mathrm{NOx} / \mathrm{H} 2 \mathrm{O}$ & 3 & 200.0 & 10.0 & 1.86 & 0.0227 \\
\hline S6060-A10-S94 & $\mathrm{NH} 3 / \mathrm{H} 2 \mathrm{O} / \mathrm{H} 2 \mathrm{O}$ & 4 & 200.0 & 10.0 & 1.86 & 0.0225 \\
\hline \multicolumn{7}{|l|}{ Controls: } \\
\hline S6060-A15-S95 & NH3/NOx/H2O Field Blank & $\mathrm{n} / \mathrm{a}^{(\mathrm{b})}$ & $\mathrm{n} / \mathrm{a}$ & $\mathrm{n} / \mathrm{a}$ & $\mathrm{n} / \mathrm{a}$ & 0.0008 \\
\hline S6060-A16-S96 & NH3/NOx/H2O Field Blank & $\mathbf{n} / \mathbf{a}$ & $\mathrm{n} / \mathrm{a}$ & $\mathrm{n} / \mathrm{a}$ & $\mathrm{n} / \mathrm{a}$ & 0.0019 \\
\hline
\end{tabular}

(a) Sampling information and dry-gas sample volumes, corrected to $0^{\circ} \mathrm{C}$ and 760 torr, were provided by WHC. Uncertainty values were not provided with sample-volume results.

(b) $\mathbf{n} / \mathbf{a}=$ not applicable. 
Table A.3 Inorganic Vapor Sample Results Obtained from the Headspace of Tank S-103 on 6/12/96

\begin{tabular}{|c|c|c|c|c|c|}
\hline \multirow[b]{2}{*}{ Sample } & \multicolumn{3}{|c|}{ Analytical Results ( $\mu \mathrm{mol})$} & \multirow{2}{*}{$\begin{array}{c}\text { Sample } \\
\text { Volume } \\
\text { (L) }\end{array}$} & \multirow{2}{*}{$\begin{array}{c}\text { Vapor }^{(a)} \\
\text { Concentration } \\
\text { (ppmv) }\end{array}$} \\
\hline & $\begin{array}{c}\text { Front } \\
\text { Section } \\
\end{array}$ & $\begin{array}{c}\text { Back } \\
\text { Section } \\
\end{array}$ & $\begin{array}{c}\text { Total }^{(\mathrm{b})} \\
\text { Blank-Corrected } \\
\end{array}$ & & \\
\hline $\mathrm{NH}_{3}$ Samples: & . & & 12.5 & $\underline{1.86}$ & $\underline{150 \pm 4}$ \\
\hline S6060-A07-S91 & 12.6 & 0.058 & 12.2 & 1.86 & 147 \\
\hline S6060-A08-S92 & 13.1 & $\mathrm{NA}^{(\mathrm{c})}$ & 12.7 & 1.86 & $153^{\circ}$ \\
\hline S6060-A09-S93 & 13.1 & 0.076 & 12.7 & 1.86 & 153 \\
\hline S6060-A10-S94 & 12.6 & NA & 12.2 & 1.86 & 147 \\
\hline $\mathrm{NO}_{2}$ Samples: & & & $\leq 0.013$ & $\underline{1.86}$ & $\leq 0.16$ \\
\hline S6060-A07-S91 & 0.0101 & NA & $<0.013$ & 1.86 & $<0.16$ \\
\hline S6060-A08-S92 & 0.0101 & 0.0059 & $<0.013$ & 1.86 & $<0.16$ \\
\hline S6060-A09-S93 & 0.0069 & NA & $<0.013$ & 1.86 & $<0.16$ \\
\hline S6060-A10-S94 & 0.0069 & 0.0041 & $<0.013$ & 1.86 & $<0.16$ \\
\hline NO Samples: & & & $\leq 0.013$ & 1.86 & $\leq 0.16$ \\
\hline S6060-A07-S91 & 0.0111 & 0.0055 & $<0.013$ & 1.86 & $<0.16$ \\
\hline S6060-A08-S92 & 0.0113 & NA & $<0.013$ & 1.86 & $<0.16$ \\
\hline S6060-A09-S93 & 0.0074 & 0.0042 & $<0.013$ & 1.86 & $<0.16$ \\
\hline S6060-A10-S94 & 0.0066 & NA & $<0.013$ & 1.86 & $<0.16$ \\
\hline Gravimetric Samples: & & & $20.9 \mathrm{mg}$ & 1.86 & $11.2 \pm 0.2 \mathrm{mg} / \mathrm{L}$ \\
\hline S6060-A07-S91 & $n / a^{(c)}$ & $\mathrm{n} / \mathrm{a}$ & 20.8 & 1.86 & 11.2 \\
\hline S6060-A08-S92 & $\mathrm{n} / \mathbf{a}$ & $\mathrm{n} / \mathrm{a}$ & 20.4 & 1.86 & 10.9 \\
\hline S6060-A09-S93 & $\mathrm{n} / \mathrm{a}$ & $\mathrm{n} / \mathrm{a}$ & 21.4 & 1.86 & 11.5 \\
\hline S6060-A10-S94 & $\mathbf{n} / \mathbf{a}$ & $\mathrm{n} / \mathrm{a}$ & 21.2 & 1.86 & 11.4 \\
\hline
\end{tabular}

(a) Blank-corrected vapor concentrations were calculated using WHC-reported dry-air sample volumes (Table A.2). In the calculation for concentration, the nitrite values (listed) were doubled to account for unanalyzed nitrite. Sample results were not corrected for percentage recovery of spiked samples or spiked blanks. Underlined values represent the average of the set of samples. Concentration uncertainty equals \pm 1 standard deviation (absolute) for each set of samples. Percentage RSD may be determined by dividing standard deviation by the average and multiplying the result by 100 . The use of " $<$ " is defined in Section A.4.

(b) Total blank-corrected analyte masses (nitrite for $\mathrm{NO}_{2}$ and $\mathrm{NO}$ ) were determined, when significant, by subtracting the quantity of analyte found in blanks from that found in samples. The level of analytes found in blanks is described in the subsections of Section A.4.

(c) NA = not analyzed; n/a = not applicable. 


\section{A.5 References}

Clauss, T. W., M. W. Ligotke, B. D. McVeety, K. H. Pool, R. B. Lucke, J. S. Fruchter, and S. C. Goheen. 1994. Vapor Space Characterization of Waste Tank 241-BY-104: Results from Samples Collected on 6/24/94. PNL-10208. Pacific Northwest National Laboratory, Richland, Washington.

Ligotke, M. W., K. H. Pool, and B. D. Lerner. 1994. Vapor Space Characterization of Waste Tank 241-C-103: Inorganic Results from Sample Job 7B (5/12/94 - 5/25/94). PNL-10172, Pacific Northwest National Laboratory, Richland, Washington.

Osborne, J. W., J. L. Huckaby, E. R. Hewitt, C. M. Anderson, D. D. Mahlum, B. A. Pulsipher, and J. Y. Young. 1995. Data Quality Objectives for Generic In-Tank Health and Safety Vapor Resolution. WHC-SD-WM-DQO-002, Rev. 1, Westinghouse Hanford Company, Richland, Washington. 


\title{
Appendix B
}

Tank Vapor Characterization:

\author{
Permanent Gases
}




\section{Appendix B}

\section{Tank Vapor Characterization: Permanent Gases}

\section{B.1 Sampling Methodology}

Before sending SUMMA ${ }^{\mathrm{TM}}$ canisters out to the field for sampling, the canisters are cleaned and verified contaminant-free according to Pacific Northwest National Laboratory (PNNL) Technical Procedure PNL-TVP-02 ${ }^{(a)}$. The cleaning procedure uses an EnTech 3000 cleaning system that controls 1) filling the canisters with purified humid air and 2) evacuating, for several cycles with applied heat, before allowing the canister to evacuate overnight. The canister is filled a final time with purified humid air for analysis. If the canister is verified as clean by TO-12, the canister is evacuated to 5 mtorr, tagged, and stored for use in the field. Before sending the canisters out to the field for sampling, the canister vacuum is measured to determine if any leakage has occurred. If the vacuum has remained constant during storage, the canisters are prehumidified with $100 \mu \mathrm{L}$ of distilled water and labeled with a field-sampling identification. Canisters stored more than 30 but less than 60 days are re-evacuated and rehumidified before use. If stored more than 60 days, the canisters are recleaned and validated before use.

\section{B.2 Analytical Procedure}

The SUMMA ${ }^{\mathrm{m}}$ canister samples were analyzed for permanent gases according to PNNL Technical Procedure PNL-TVP-05 ${ }^{(b)}$ with the exceptions listed in the following text and in the quality assurance/quality control section of this report. This method was developed in-house to analyze permanent gases, defined as hydrogen $\left(\mathrm{H}_{2}\right)$, carbon dioxide $\left(\mathrm{CO}_{2}\right)$, carbon monoxide $(\mathrm{CO})$, methane $\left(\mathrm{CH}_{4}\right)$, and nitrous oxide $\left(\mathrm{N}_{2} \mathrm{O}\right)$, by gas chromatograph/thermal conductivity detection (GC/TCD). Aliquots of sampled air are drawn directly from each canister into a 5-mL gas-tight syringe and injected into a Hewlett-Packard $5890 \mathrm{GC} / \mathrm{TCD}$ fitted with a loop injector valve and a column switching valve. An aliquot of $5 \mathrm{~mL}$ is used so that the $1.0-\mathrm{mL}$ injection loop is completely purged with sample air, ensuring that no dilution of the sample takes place within the injection loop. One set of $\mathrm{GC}$ conditions is used to analyze for $\mathrm{CO}, \mathrm{CO}_{2}, \mathrm{~N}_{2} \mathrm{O}$, and $\mathrm{CH}_{4}$ using Helium $(\mathrm{He})$ as the carrier gas. A second $\mathrm{GC}$ analysis is performed for $\mathrm{H}_{2}$ (using nitrogen as the carrier gas) to enhance the signal sensitivity and lower the detection limit for this analyte. The permanent gases and associated EQLs are listed in Table B.1.

(a) Pacific Northwest Laboratory. 8/94. Cleaning SUMMA Canisters and the Validation of the Cleaning Process, PNL-TVP-02 (Rev. 0), PNL Technical Procedure, Pacific Northwest Laboratory, Richland, Washington.

(b) Pacific Northwest Laboratory. 5/96. Analysis Method for the Determination of Permanent Gases in Hanford Waste Tank Vapor Samples Collected in SUMMA ${ }^{\mathrm{mm}}$ Passivated Stainless Steel Canisters, PNL-TVP-05 (Rev. 2). PNL Technical Procedure, Pacific Northwest Laboratory, Richland, Washington. 
Table B.1. Analytical Procedures and Detection Limits for Permanent Gases

\begin{tabular}{|c|c|c|c|}
\hline Analyte & Formula & Procedure & $\begin{array}{c}\text { Estimated Quantitation } \\
\text { Limit (ppmv) }\end{array}$ \\
\hline Carbon Dioxide & $\mathrm{CO}_{2}$ & PNL-TVP-05 & 17 \\
\hline Carbon Monoxide & $\mathrm{CO}$ & PNL-TVP-05 & 17 \\
\hline Methane & $\mathrm{CH}_{4}$ & PNL-TVP-05 & 25 \\
\hline Hydrogen & $\mathrm{H}_{2}$ & PNL-TVP-05 & 17 \\
\hline Nitrous Oxide & $\mathrm{N}_{2} \mathrm{O}$ & PNL-TVP-05 & 17 \\
\hline
\end{tabular}

\section{B.3 Quality Assurance/Quality Control}

Standards for the permanent gas analysis were blended from commercially prepared and certified standards for each of the analytes reported in Table B.1. The instrument was calibrated for $\mathrm{CH}_{4}$ over a range of 25 to 2100 parts per million by volume (ppmv) and for $\mathrm{CO}, \mathrm{CO}_{2}$, and $\mathrm{N}_{2} \mathrm{O}$ over a range of 17 to $2100 \mathrm{ppmv}$ using standards at five different concentrations and $\mathrm{He}$ as a carrier gas. A similar procedure was followed for $\mathrm{H}_{2}$ with a range of 17 to $2120 \mathrm{ppmv}$, except the carrier gas was changed to $\mathrm{N}_{2}$. An average response factor from the calculation was used for quantification of compound peak area.

Each analyte was quantitated by comparison of sample analyte peak area to the calibration plot generated for the compound. The estimated quantitation limit (EQL) for the method has been established as the low level calibration standard. Before and after each sample analysis set, a gas standard was run to evaluate system performance and to measure system accuracy. The calculated concentration of the individual gases in the standards fell within $\pm 25 \%$ of the expected concentrations. One sample was run in duplicate to provide a measure of method precision. Results of the replicate analysis are presented in Table B.2. An $\mathrm{N}_{2}$ reagent blank, an ambient-air sample collected $\sim 10 \mathrm{~m}$ upwind of Tank S-103 and the ambient air collected through the In Situ Vapor Sampling System (ISVS) were used as method blanks and used to determine the potential for analyte interferences in the samples.

\section{B.4 Permanent Gases Sample Results}

Table B.2 lists results of the permanent gas analysis from samples collected from the headspace of Tank S-103, ambient air collected $\sim 10 \mathrm{~m}$ upwind of the tanik, and ambient air collected through the ISVS. Samples were analyzed on June 25 and July 3, 1996. Hydrogen and nitrous oxide were observed in the tank headspace at an average value of $79 \mathrm{ppmv}$ and $136 \mathrm{ppmv}$, respectively. A replicate analysis was performed on SUMMA ${ }^{\mathrm{ma}}$ PNL 082; however, only the results from the first analysis are included in the average concentration reported for the tank headspace samples.

The original permanent gas analyses were performed on Tank S-103 canisters prior to the $2 \mathrm{X}$ dilution using clean air. The continuing calibration blank for hydrogen for the original analyses (56062501.b) was above the low level standard concentration used in the initial calibration. In 
addition, the carbon dioxide concentration data derived from the original analyses were erratic. A leaking gas tight syringe was the suspected cause. Because of these analytical problems, the diluted canisters were reanalyzed for all fixed gases (hydrogen, carbon dioxide, nitrous oxide, methane, and carbon monoxide). The dilution required reporting detection limits at two times the low level standard concentration (34 ppmv for hydrogen, carbon dioxide, nitrous oxide, and carbon monoxide and 50 ppmv for methane). The QC samples (blanks and continuing calibration checks) for all analyses were within acceptance criteria. 
Table B.2 Permanent Gas Analysis Results for Samples Collected from the Headspace of Tank S-103 and for Ambient Air and Ambient Air Through the ISVS Collected near Tank S-103 in SUMMA (TM) Canisters on $6 / 12 / 96$

\begin{tabular}{|c|c|c|c|c|c|c|c|}
\hline \multirow{3}{*}{$\begin{array}{l}\text { Permanent Gas } \\
\text { Analyte }\end{array}$} & \multirow{2}{*}{$\begin{array}{l}\text { Ambient Air } \\
\text { Upwind } \\
\text { S6060-A01.001 } \\
\text { PNL 001 } \\
\text { (a) }\end{array}$} & \multirow{2}{*}{$\begin{array}{l}\text { Ambient Air } \\
\text { Through Bundle } \\
\text { S6060-A02.010 } \\
\text { PNL } 010^{(\mathrm{a})}\end{array}$} & \multicolumn{4}{|c|}{ Tank Samples } & \multirow{3}{*}{$\begin{array}{c}\text { Average } \\
\text { Concentration } \\
\text { Tank Samples } \\
\text { (ppmv) }\end{array}$} \\
\hline & & & $\begin{array}{c}\text { S6060-A04.080 } \\
\text { PNL 080 }\end{array}$ & $\begin{array}{c}\text { S6060-A05.082 (a) } \\
\text { PNL 082 }\end{array}$ & $\begin{array}{c}\text { S6060-A06.083 } \\
\text { PNL083 } \\
\end{array}$ & $\begin{array}{c}\text { S6060-A05.082 } \\
\text { PNL 082 } \\
\text { (b)(c) }\end{array}$ & \\
\hline & $\begin{array}{c}\text { Concentration } \\
\text { (ppmv) }\end{array}$ & $\begin{array}{c}\text { Concentration } \\
\text { (ppmv) }\end{array}$ & $\begin{array}{c}\text { Concentration } \\
\text { (ppmv) }\end{array}$ & $\begin{array}{c}\text { Concentration } \\
\text { (ppmv) }\end{array}$ & $\begin{array}{c}\text { Concentration } \\
\text { (ppmv) } \\
\end{array}$ & $\begin{array}{c}\text { Concentration } \\
\text { (ppmv) }\end{array}$ & \\
\hline Hydrogen & $<34$ & $<34$ & 81 & $\frac{78}{78}$ & $\frac{79}{79}$ & 78 & $\frac{79}{79}$ \\
\hline Methane & $<50$ & $<50$ & $<50$ & $<50$ & $<50$ & $<50$ & $<50$ \\
\hline Carbon Dioxide & 360 & 360 & $<34$ & $<34$ & $<34$ & $<34$ & $<34$ \\
\hline Carbon Monoxide & $<34$ & $<34$ & $<34$ & $<34$ & $<34$ & $<34$ & $<34$ \\
\hline Nitrous Oxide & $<34$ & $<34$ & 134 & 135 & 139 & 137 & 136 \\
\hline
\end{tabular}

is Footnotes

(a) WHC sample identification number.

(b) PNL canister number.

(c) Replicate analysis for PNL 082; results are not included in the calculation of average concentrations. 


\section{Appendix C}

\section{Tank Vapor Characterization:}

\section{Total Non-Methane Organic Compounds}




\section{Appendix C}

\section{Tank Vapor Characterization: Total Non-Methane Organic Compounds}

\section{C.1 Sampling Methodology}

Before sending SUMMA ${ }^{\mathrm{TM}}$ canisters out to the field for sampling, the canisters are cleaned and verified contaminant-free according to Pacific Northwest National Laboratory (PNNL) Technical Procedure PNL-TVP-02 ${ }^{(a)}$. The cleaning procedure uses an EnTech 3000 cleaning system that controls 1) filling the canisters with purified humid air and 2) evacuating, for several cycles with applied heat, before allowing the canister to evacuate overnight. The canister is filled a final time with purified humid air for analysis. If the canister is verified as clean by TO-12, the canister is evacuated to 5 mtorr, tagged, and stored for use in the field. Before sending the canisters out to the field for sampling, the canister vacuum is measured to determine if any leakage has occurred. If the vacuum has remained constant during storage, the canisters are prehumidified with $100 \mu \mathrm{L}$ of distilled water and labeled with a field-sampling identification. Canisters stored more than 30 but less than 60 days are re-evacuated and rehumidified before use. If stored more than 60 days, the canisters are recleaned and validated before use.

\section{C.2 Analytical Procedure}

The SUMMA ${ }^{\mathrm{TM}}$ canister samples were analyzed according to PNNL Technical Procedure PNL-TVP-08 ${ }^{(b)}$, which is similar to U.S. Environmental Protection Agency (EPA) compendium Method TO-12. The method detection limits in the sub $\mathrm{mg} / \mathrm{m}^{3}$ are required to determine total nonmethane organic compounds (TNMOC) concentration in the tank samples.

The method uses an EnTech 7000 cryoconcentration system interfaced with a Hewlett-Packard 5890 gas chromatograph/flame ionization detector (GC/FID). The EnTech concentrator is used to pull a metered volume of 50 to $100 \mathrm{~mL}$ of sample air from the SUMMA ${ }^{\mathrm{TM}}$ canister mounted on an EnTech 7016CA 16-canister autosampler. The sample is cryogenically concentrated, and constituents are trapped in a stainless steel tube containing glass beads and Tenax. The glass bead/Tenax trap is heated to $180^{\circ} \mathrm{C}$ and purged with ultra high purity (UHP) helium (He). The purged TNMOCs are carried by a UHP He stream to the GC equipped with an FID where gross organic content is detected and measured.

The GC oven is programmed to run at a $150^{\circ} \mathrm{C}$ isothermal temperature. Chromatographic separation is not needed in this method since quantitation is from the entire FID response over the run time. PNL-TVP-02 (Rev. 0), PNL Technical Procedure, Pacific Northwest Laboratory, Richland, Washington.

(b) Pacific Northwest Laboratory. 12/95. Determination of TO-12 Total Nonmethane Organic Compounds in Hanford Waste Tank Headspace Samples Using SUMMA Passivated Canister Sampling and Flame Ionization Detection, PNL-TVP-08 (Rev. 1), PNL Technical Procedure, Pacific Northwest Laboratory, Richland, Washington. 
Twenty-four hours before the analysis, the SUMMA ${ }^{\mathrm{TM}}$ canister samples are pressurized with purified air (supplied by Aadco Instruments, Inc., 1920 Sherwood St., Clearwater, Florida 34625). The starting pressure was first measured using a calibrated diaphragm gauge (Cole Parmer), then pressurized to a level exactly twice the original pressure. For example, if the canister had a starting pressure of 740 torr, it was pressurized to 1480 torr. The sample dilution was taken into account when calculating the analysis results.

\section{C.3 Quality Assurance/Quality Control}

This method requires user calibration (category 2 measuring and test equipment) of the analytical system in accordance with QA plan ETD-002.

The TNMOC is calibrated by using propane as the calibration standard. The instrument calibration mixture for the PNL-TVP-08 analysis consists of National Institute for Standards and Technology (NIST) $99.999 \%$ propane analyzed using an average response factor method for calibration.

A continuing calibration verification (CCV) standard of $100 \mathrm{ppmv}$ propane is analyzed to confirm acceptability of instrument performance. The initial calibration is then used to quantify the samples.

Immediately before running the analysis sequence, a leak-check procedure, which includes evacuating the transfer lines and monitoring the pressure, must be performed on the sample manifold tower. The control limits on this test require that the change in pressure is $<1.5 \mathrm{psi}$, and the absolute pressure after evacuation is $<3$ psi for each manifold position specified in the sequence table. If this criterion is not met, it must be corrected before the samples are analyzed.

Before the tank samples were analyzed, a diagnostic check was performed on the GC/FID instrument by running a system cleanliness procedure and an instrument continuing calibration as described in PNL-TVP-08. First, two blank volumes of Aadco purified air were analyzed to check the cleanliness of the system. This demonstrates through the analysis of a zero-air blank that the level of interference is acceptable in the analytical system. The system should be cleaned to $0.1 \mathrm{mg} / \mathrm{m}^{3}$ of TNMOCs. Second, an instrument continuing calibration is run using $100-\mathrm{mL}$ UHP propane analyzed using the response factor as an external standard method followed by one blank volume of Aadco air.

C.3.1 Quantitation Results of Target Analytes. The $\mathrm{mg} / \mathrm{m}^{3}$ was derived from the fivepoint multilevel calibration curve from the propane standard using the following equation:

$$
\mathrm{mg} / \mathrm{m}^{3}=\frac{(\mathrm{ng} \text { TNMOC) } \mathrm{x} \text { (dilution factor) }}{\mathrm{mL} \text { sampled volume }}
$$


The $\mathrm{ng} / \mathrm{m}^{3}$ concentrations are calculated from $\mathrm{mg} / \mathrm{m}^{3}$ using the equation:

$$
\mathrm{ng} / \mathrm{m}^{3} \text { TNMOC }=\frac{(\mathrm{ng} \text { TNMOC) }}{(\mathrm{mL} \text { sampled })} \times \text { Dilution Factor } \times \frac{(\mathrm{mg})}{\left(1 \times 10^{6} \mathrm{~mL}\right)} \times \frac{\left(1 \times 10^{6} \mathrm{~mL}\right)}{\left(\mathrm{m}^{3}\right)}
$$

\section{C.4 Total Non-Methane Organic Compounds Sample Results}

Table C. 1 lists results of the TO-12 gas analysis from samples collected from the headspace of Tank S-103, ambient air collected $\sim 10 \mathrm{~m}$ upwind of the tank, and ambient air collected through the ISVS. Samples were analyzed on August 12,1996. Concentrations in the ambient air samples ranged from estimates of $0.34 \mathrm{mg} / \mathrm{m}^{3}$ to $0.54 \mathrm{mg} / \mathrm{m}^{3}$. Concentrations in the three tank headspace samples ranged from $1.23 \mathrm{mg} / \mathrm{m}^{3}$ to $1.27 \mathrm{mg} / \mathrm{m}^{3}$ with an average concentration of $1.25 \mathrm{mg} / \mathrm{m}^{3}$. This compares to $6.92 \mathrm{mg} / \mathrm{m}^{3}$ for the sum of all compounds identified in the target and TIC analysis of the SUMMA ${ }^{\text {Ts }}$ canisters. 
Table C.1. TO-12 Results for Samples Collected Through the ISVS from the Headspace of Tank S-103 and from Ambient Air Near Tank S-103 in SUMMA ${ }^{(\mathrm{TM})}$ Canisters on 6/12/96.

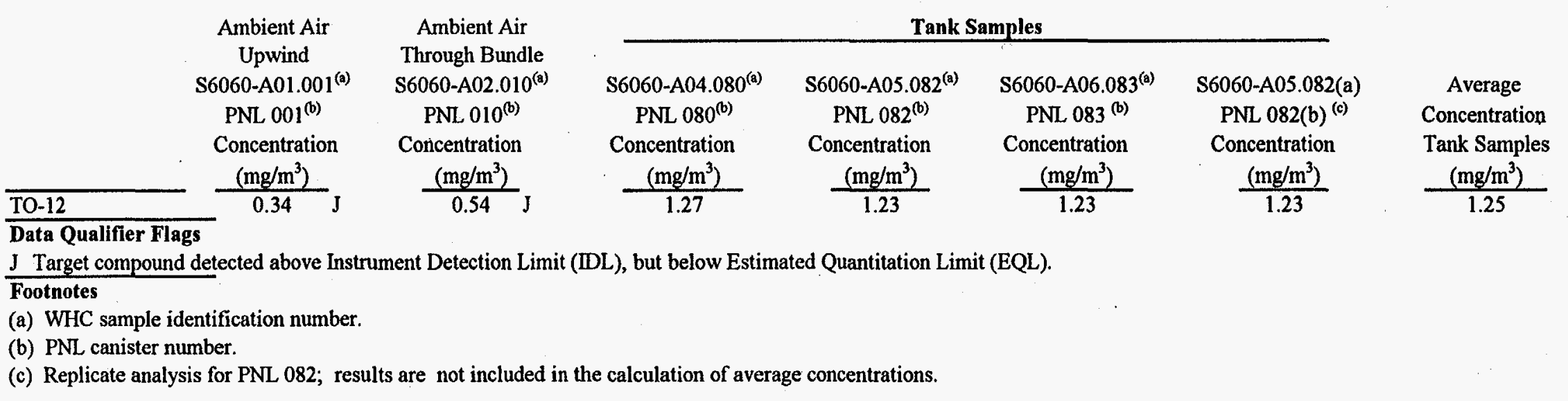




\section{Appendix D}

\section{Tank Vapor Characterization:}

Organic Analytes by SUMMA ${ }^{\mathrm{TM}}$ Method 


\section{Appendix D}

\section{Tank Vapor Characterization: Organic Analytes by SUMMA ${ }^{\mathrm{TM}}$ Method}

\section{D.1 Sampling Methodology}

Before sending SUMMA ${ }^{\mathrm{M}}$ canisters out to the field for sampling, the canisters are cleaned and verified contaminant free according to Pacific Northwest Laboratory (PNNL) Technical Procedure PNL-TVP-02 ${ }^{(a)}$. The cleaning procedure uses an EnTech 3000 cleaning system that controls 1) filling the canisters with purified humid air and 2) evacuating, for several cycles with applied heat, before allowing the canister to evacuate overnight. If the canister is verified as clean, free of TO-14 and unknown contaminants to a level of 5 parts per billion by volume (ppbv), the canister is evacuated to $5 \mathrm{mtorr}$, tagged, and stored for use in the field. Before sending the canisters out to the field for sampling, the canister vacuum is measured to determine if any leakage has occurred. If the vacuum has remained constant during storage, the canisters are prehumidified with $100 \mu \mathrm{L}$ of distilled water and labeled with a field-sampling identification. Cleaned canisters stored more than 30 but less than 60 days are re-evacuated and rehumidified before use. If stored more than 60 days, the canisters are recleaned and validated before use.

\section{D.2 Analytical Procedure}

The SUMMA ${ }^{\mathrm{TW}}$ canister sample was analyzed according to PNNL Technical Procedure PNL-TVP-03 ${ }^{(b)}$, which is a modified version of EPA compendium Method TO-14. The method uses EnTech 7000 cryoconcentration systems interfaced with a 5972 Hewlett-Packard benchtop gas chromatograph/mass spectrometer (GC/MS). The EnTech concentrator is used to pull a metered volume of sample air from the SUMMA ${ }^{\mathrm{mI}}$ canister, cryogenically concentrate the air volume, then transfer the volume to the GC/MS for analysis. A $100-\mathrm{mL}$ volume of sample is measured and analyzed from the tank headspace. The organic components in the sampled air are separated on an analytical column, J\&W Scientific DB-1 phase, $60-\mathrm{m}$ by $0.32-\mathrm{mm}$ internal diameter with $3-\mu \mathrm{m}$ film thickness. The $\mathrm{GC}$ oven is programmed to run a temperature gradient beginning at $40^{\circ} \mathrm{C}$, hold for $5 \mathrm{~min}$, and ramp at $4^{\circ} \mathrm{C}$ per min to a final temperature of $260^{\circ} \mathrm{C}$, with a 5 -min hold. Twenty-four hours before the analysis, the SUMMA ${ }^{\mathrm{TM}}$ canister samples were pressurized with purified air (supplied by Aadco Instruments, Inc., 1920 Sherwood St., Clearwater, Florida 34625). The starting pressure was first measured using a calibrated diaphragm gauge (Cole Parmer), then pressurized to a level exactly twice the original pressure. For example, if the canister had a starting pressure of 740 torr, it was pressurized to 1480 torr. This dilution was an effort to improve the precision of the analysis. The sample dilution was taken into account when calculating the analysis results.

(a) Pacific Northwest Laboratory. 8/94. Cleaning SUMMA Canisters and the Validation of the Cleaning Process, PNL-TVP-02 (Rev. 0), PNL Technical Procedure, Richland, Washington.

(b) Pacific Northwest Laboratory. 8/96. Determination of TO-14 Volatile Organic Compounds in Hanford Tank Headspace Samples Using SUMMA ${ }^{\mathrm{TM}}$ Passivated Canister Sampling and Gas Chromatographic-Mass Spectrometric Analysis, PNL-TVP-03 (Rev, 2), PNL Technical Procedure, Richland, Washington. 
The instrument calibration mixture for the PNL-TVP-03 analysis consists of 66 organic analytes. These 66 compounds that are directly quantified in this analysis make up the target analyte list (these 66 compounds will be referred to as target analytes). A summary of the target analytes is provided in Table D.1. The calibration mixture was prepared by blending a commercially prepared TO-14 calibration mixture with a mixture created using a Kin-Tek ${ }^{\circledR}$ permeation-tube standard

Table D.1 Target Organic Analytes

\begin{tabular}{|c|c|}
\hline Dichlorodifluoromethane & $\mathrm{p} / \mathrm{m}$-Xylene \\
\hline Chloromethane & 1-Pentanenitrile \\
\hline 1,2-Dichloro-1,1,2,2-tetrafluoroethane & Styrene \\
\hline Vinyl Chloride & 1,1,2,2-Tetrachloroethane \\
\hline Bromomethane & o-Xylene \\
\hline Chloroethane & 1,3,5-Trimethylbenzene \\
\hline Trichlorofluoromethane & 1,2,4-Trimethylbenzene \\
\hline 1,1-Dichloroethene & 1,3-Dichlorobenzene \\
\hline Methylene Chloride & 1,4-Dichlorobenzene \\
\hline 1,1,2-Trichloro-1,2,2-trifluoroethane & 1,2-Dichlorobenzene \\
\hline 1,1-Dichloroethane & 1,2,4-Trichlorobenzene \\
\hline cis-1,2-Dichloroethene & Hexachloro-1,3-butadiene \\
\hline Chloroform & 2-Butanone \\
\hline 1,2-Dichloroethane & Acetone \\
\hline $1,1,1$-Trichloroethane & Acetonitrile \\
\hline Benzene & Heptane \\
\hline Carbon Tetrachloride & Tetrahydrofuran \\
\hline 1,2-Dichloropropane & Pyridine \\
\hline Trichloroethene & Butanenitrile \\
\hline cis-1,3-Dichloropropene & Cyclohexane \\
\hline trans-1,3-Dichloropropene & Decane \\
\hline 1,1,2-Trichloroethane & Hexane \\
\hline Toluene & 4-Methyl-2-pentanone \\
\hline 1,2-Dibromoethane & Propanenitrile \\
\hline Tetrachloroethylene & Cyclohexanone \\
\hline Chlorobenzene & Propanol \\
\hline Ethylbenzene & Nonane \\
\hline Undecane & Dodecane \\
\hline Tridecane & Tetradecane \\
\hline Butane & Pentane \\
\hline 1-Butanol & Octane \\
\hline 1-Hexanenitrile & 1-Ethyl-2-methylbenzene \\
\hline Methanol ${ }^{(2)}$ & Ethanol ${ }^{(a)}$ \\
\hline
\end{tabular}

(a) The low level standard is used as the EQL for these compounds 
generation system. The operation of the permeation-tube system follows the method detailed in PNNL Technical Procedure PNL-TVP-06 ${ }^{(a)}$. The standard calibration mix was analyzed using four aliquot sizes ranging from $30 \mathrm{~mL}$ to $200 \mathrm{~mL}$, and a response factor for each compound was calculated. The GC/MS response for these compounds has been previously determined to be linearly related to concentration. Instrument detection limits and EQLs for the target analytes have been determined. Methanol and ethanol are not currently included in the method performance section of the procedure for System 1; however, both analytes were analyzed by this method. The low level standard is used as the EQL for these compounds. Sample results are flagged with a less-than symbol $(<)$ when less than the EQL value.

\section{D.3 Quality Assurance/Quality Control}

Before the tank sample was analyzed, a diagnostic check was performed on the GC/MS instrument by running an instrument "high-sensitivity tune," as described in PNL-TVP-03. Upon satisfactory completion of the instrument diagnostic check, a blank volume of purified nitrogen was analyzed to check the cleanliness of the system. The instrument was then calibrated using a standard gas mixture containing 66 organic compounds. A gas mixture containing bromochloromethane, 1,4-difluorobenzene, chlorobenzene- $\mathrm{d}_{5}$, and bromofluorobenzene was used as an internal standard (IS) for all blank, calibration standard, and sample analyses. Analyte responses from sample components, ISs, and standards were obtained from the extracted ion plot from their selected mass ion. The calibration was generated by calculating the relative response ratios of the IS to calibration standard responses and plotting the ratios against the ratio of the calibration-standard concentration (in ppbv) to the IS concentration. Once it is determined that the relative response is linear with increasing concentration, an average response factor is calculated for each target analyte and used to determine the concentration of target compounds in each sample. Method blanks are analyzed before and after calibration standards and tank headspace samples are analyzed.

D.3.1 Quantitation Results of Target Analytes. The quantitative-analysis results for the target analytes were calculated using the average response factors generated using the IS method described above and in PNL-TVP-03. The conversion from $\mathrm{ppbv}$ to $\mathrm{mg} / \mathrm{m}^{3}$ assumes standard temperature and pressure (STP) conditions of 760 torr and $273 \mathrm{~K}$ and was calculated directly from the following equation:

$$
\mathrm{mg} / \mathrm{m}^{3}=\frac{(\mathrm{ppbv} / 1000) \times \mathrm{g} \mathrm{mol} \mathrm{wt} \mathrm{of} \mathrm{compound}}{22.4 \mathrm{~L} / \mathrm{mol}}
$$

D.3.2 Identification and Quantitation of Tentatively Identified Compounds. The tentatively identified compounds (TICs) are determined by mass-spectral interpretation and comparison of the spectra with the EPA/National Institute for Standards and Technology (NIST) and WILEY electronic mass spectra libraries. Chromatographic peaks with an area count greater than, or equal to, one-tenth of the total area count of the nearest eluting IS are tentatively identified and quantitatively estimated. This is roughly equivalent to $10 \mathrm{ppbv}$, depending on the relative response 
factor of the individual TIC as compared with the nearest elution IS. The quality of the mass-spectral searches was then reviewed by the principal investigators before the identification was assigned to each chromatographic peak.

The concentration of each TIC was estimated using a relative response factor calculated using the total peak area for the nearest eluting IS. The IS peak area was used to calculate a response factor using the IS concentration in $\mathrm{mg} / \mathrm{m}^{3}$ :

$$
\text { Response Factor }=\frac{\text { IS conc. }\left(\mathrm{mg} / \mathrm{m}^{3}\right)}{\text { IS peak area }}
$$

The calculated response factor was then multiplied by the TIC peak area to give an estimated concentration for that compound.

The ppbv concentrations are calculated from $\mathrm{mg} / \mathrm{m}^{3}$ and the molecular weight of the analyte.

$$
\mathrm{TIC} \text { in } \mathrm{ppbv}=\frac{\mathrm{TIC}\left(\mathrm{mg} / \mathrm{m}^{3}\right) \times 22.4 \mathrm{~L} / \mathrm{mol} \times 1000}{\mathrm{TIC} \mathrm{g} \mathrm{mol} \mathrm{wt}}
$$

\section{D.4 Organic Sample Results}

Five SUMMA ${ }^{\mathrm{Tw}}$ canisters were returned to the laboratory on June 18,1996 under WHC COC form 100090 (see Appendix F). Samples were analyzed on July 10, 1996.

The results from the GC/MS analysis of the tank headspace SUMMA ${ }^{\mathrm{TM}}$ samples are presented in Table D.2. The results of replicate analyses on a single SUMMA ${ }^{\mathrm{mM}}$ canister are presented in Table D.3. The results of the GC/MS analysis of the ambient air sample collected upwind of Tank S-103 and through the ISVS near Tank S-103 are presented in Table D.4.

Table D.2 lists the quantitative results for compounds listed as target analytes and TICs. Target compounds not listed in Table D.2 were not detected in any of the tank samples above the compound IDL. Sixty-four target analytes above the IDL and 30 TICs were detected in the tank headspace samples. Sixty-three target analytes and 17 TICs were identified in two or more tank headspace samples. Twelve TICs were not identified and were labeled as unknowns. Methanol at $3.02 \mathrm{mg} / \mathrm{m}^{3}$ and ethanol at $1.18 \mathrm{mg} / \mathrm{m}^{3}$ accounted for $61 \%$ of the compounds identified in the analysis. The total concentration of the target analytes was $6.57 \mathrm{mg} / \mathrm{m}^{3}$. Methyl cyclohexane $\left(0.06 \mathrm{mg} / \mathrm{m}^{3}\right)$ and pyrazine $\left(0.04 \mathrm{mg} / \mathrm{m}^{3}\right)$, the two highest concentration TICs, accounted for $30 \%$ of the TICs and $1.5 \%$ of the total compounds identified in the analysis. The total concentration of the TICs was $0.35 \mathrm{mg} / \mathrm{m}^{3}$. The total concentration of all the compounds identified was $6.92 \mathrm{mg} / \mathrm{m}^{3}$. This compares to a total concentration of $1.25 \mathrm{mg} / \mathrm{m}^{3}$ identified in the TO-12 analysis of the three tank headspace samples.

SUMMA $^{\mathrm{TM}}$ canister PNL 082 was analyzed in replicate for target analytes and TICs to determine analytical precision. Twenty-four of 64 target compounds and one of 11 TICs had RPDs of less than $10 \%$. 
Sixty-three target compounds and 18 TICS were observed in one or both of the ambient air samples. Many of the compounds were identified at trace levels. Several noted exceptions included: methanol, acetone, propanol, 2-butanone, butanenitrile, 1-butanol, cyclohexane, butane, pentanenitrile, 1,1,2-trichloro-1,2,2-trifluoromethane, 4-methyl-2-pentanone, and cyclohexanone. Trace levels of many of the target analytes may be false positives due to the fact that some of the compounds were found in the $\mathrm{CCB}$ above the EQL and are greater than 20 times the concentration found in the sample. These compounds are flagged with a " $\mathrm{B}$ " in the tables.

The following procedural changes and observations were noted during the analysis of Tank S-103:

Methanol and ethanol are not currently included in the method performance section of the procedure for System 1; however, both analytes were analyzed by this method. The low level standard is used as the EQL for these compounds. Sample results are flagged with a less-than symbol $(<)$ when less than the EQL value.

This analytical sequence was run using $100 \mathrm{~mL}$ volumes to quantify target compounds in each tank sample.

Three target compounds (pyridine at $79.3 \%$, tridecane at $38.7 \%$, and tetradecane at $51.5 \%$ ) surpassed the $30 \%$ relative standard deviation (\%RSD) acceptance criteria for the initial calibration. Pyridine was found in all the tank samples in concentrations between the IDL and the EQL. Pyridine was also found in the continuing calibration blank in concentrations between the IDL and the EQL; therefore, one can assume that this substance presents in the tank samples due to crossover contamination of the device. Tridecane and tetradecane were not found in the tank sample at concentrations above the IDL.

Seven target compounds (pyridine, butanenitrile, 1,2,4-trichlorobenzene, dodecane, hexachloro-1,3-butadiene, tridecane, and tetradecane) were outside the $25 \%$ difference ( $\% \mathrm{D}$ ) acceptance criteria for the continuing calibration verification (CCV) sample. However, the CCV passed the procedural criterion requiring $\pm 25 \% \mathrm{D}$ passage for $85 \%$ of all target compounds. Tetradecane and tridecane were not found in tank samples in concentrations above the IDL. Butanenitrile was found in tank samples S6060-A02.010, S6060-A04.080, and S6060-A04.082 in concentrations between the EQL and the upper quantitation limit (UQL). These concentrations may be under estimated. Also, butanenitrile was found in the other tank samples at concentrations between the IDL and the EQL. The compounds 1,2,4-trichlorobenzene and hexachloro-1,3-butadiene were found in all the samples in concentrations between the IDL and the EQL. Dodecane was found in samples S6060-A01.001, S6060-A02.010, S6060-A04.080, and S6060-A05.082 REP in concentrations between the IDL and the EQL. Dodecane was also found in the other tank samples at concentrations below the IDL. Pyridine was found in all of the tank samples.

Twenty-six target compounds were found din the CCB above the EQL, but the concentrations of all of them were less than $4 \mathrm{ppbv}$ and slightly exceeded the EQL. The compound 1,2,4-trichlorobenzene was detected in the initial calibration blank above the EQL. This compound was also found in the CCB above the EQL, but was not found in the tank samples above the EQL. 
The internal standard quantification area percent recoveries for all of the tank samples were within the acceptance criterion (50\% to $200 \%$ ) allowed by procedure PNL-TVP-03, except the second internal standard for tank sample S6060-A04.082 (44.98\%). 
Table D.2. Positively Identified and Quantitated Target Analytes and Tentatively Identifed Compounds and Estimated Concentrations for Samples from the Headspace in Tank S-103 in SUMMA canisters collected on 6/12/96

\begin{tabular}{|c|c|c|c|c|c|c|c|c|c|c|c|c|c|c|c|c|}
\hline \multirow[b]{2}{*}{ Target Analytes $^{(\text {a) }}$} & \multirow[b]{2}{*}{ CAS } & \multirow[b]{2}{*}{ MW } & \multirow{2}{*}{$\begin{array}{c}\text { Ret } \\
\text { Time } \\
\end{array}$} & \multicolumn{3}{|c|}{ S6060-A04.080 ${ }^{\text {(c) }}$ ISVS } & \multicolumn{3}{|c|}{ S6060-A05.082 ${ }^{(\mathrm{c})(\mathrm{d})}$ ISVS } & \multicolumn{3}{|c|}{ S6060-A06.083 ${ }^{(\mathrm{c})}$ ISVS } & \multicolumn{2}{|c|}{$\begin{array}{l}\text { Mean and } \\
\text { Standard Deviation }\end{array}$} & \multirow[b]{2}{*}{ (ppbv) } & \multirow[b]{2}{*}{ St. Dev. } \\
\hline & & & & $\left(\mathrm{mg} / \mathrm{m}^{3}\right)$ & (ppbv) & Flag & $\left(\mathrm{mg} / \mathrm{m}^{3}\right)$ & (ppbv) & Flag & $\left(\mathrm{mg} / \mathrm{m}^{3}\right)$ & (ppbv) & Flag & $\left(\mathrm{mg} / \mathrm{m}^{3}\right)$ & St. Dev. & & \\
\hline Dichlorodiffuoromethane & $75-71-8$ & 121 & 4.6 & 0.030 & 5.5 & $\mathrm{~B}$ & 0.031 & 5.7 & $\overline{\mathrm{B}}$ & 0.031 & 5.8 & $\bar{B}$ & 0.030 & 0.001 & 5.6 & 0.17 \\
\hline Chloromethane & $74-87-3$ & 50 & 4.9 & 0.014 & 6.2 & $\mathbf{J}$ & 0.017 & 7.7 & $\mathbf{J}$ & 0.015 & 6.7 & $\mathbf{J}$ & 0.015 & 0.002 & 6.8 & 0.75 \\
\hline 12dichloro1122-tetrafluoroethane & $76-14-2$ & 171 & 5.2 & 0.027 & 3.5 & $\mathbf{J}$ & 0.034 & 4.4 & $\mathrm{~J}$ & 0.028 & 3.6 & $\mathbf{J}$ & 0.029 & 0.004 & 3.9 & 0.48 \\
\hline Methanol & $67-56-1$ & 32 & 5.2 & 2.446 & 1710 & $\mathrm{Y}$ & 3.835 & 2681 & $\mathbf{Y}$ & 2.783 & 1946 & $\mathrm{Y}$ & 3.021 & 0.724 & 2112 & 506 \\
\hline Vinyl Chloride & $75-01-4$ & 63 & 5.4 & 0.014 & 5.2 & $\mathbf{J}$ & 0.019 & 6.8 & & 0.014 & 5.1 & $\mathbf{J}$ & 0.016 & 0.003 & 5.7 & 0.98 \\
\hline Butane & $106-97-8$ & 58 & 5.9 & 0.042 & 16 & & 0.049 & 19 & & 0.044 & 17 & & 0.045 & 0.004 & 17 & 1.4 \\
\hline Bromomethane & 74-83-9 & 95. & 6.3 & 0.019 & 4.4 & $\mathbf{J}$ & 0.021 & 4.9 & $\mathbf{J}$ & 0.020 & 4.8 & $\mathbf{J}$ & 0.020 & 0.001 & 4.7 & 0.25 \\
\hline Chloroethane & $75-00-3$ & 65 & 6.7 & 0.016 & 5.6 & $\mathbf{J}$ & 0.019 & 6.7 & $\mathbf{J}$ & 0.023 & 8.1 & $\mathbf{J}$ & 0.020 & 0.004 & 6.8 & 1.3 \\
\hline Ethanol & $64-17-5$ & 46 & 6.8 & 0.907 & 442 & $\mathrm{Y}$ & 1.272 & 619 & $\mathrm{Y}$ & 1.357 & 660 & $\mathrm{Y}$ & 1.178 & 0.239 & 574 & 116 \\
\hline Acetonitrile & $75-05-8$ & 41 & 7.3 & 0.047 & 26 & & 0.044 & 24 & & 0.047 & 25 & & 0.046 & 0.002 & 25 & 1.1 \\
\hline Acetone & $67-64-1$ & 58 & 7.8 & 0.283 & 109 & & 0.298 & 115 & & 0.307 & 118 & & 0.296 & 0.012 & 114 & 4.5 \\
\hline Trichlorofluoromethane & $75-69-4$ & 137 & 8.3 & 0.081 & 13 & & 0.096 & 16 & & 0.090 & 15 & & 0.089 & 0.007 & 14 & 1.2 \\
\hline Pentane & $109-66-0$ & 72 & 8.9 & 0.022 & 6.7 & $\mathbf{J}$ & 0.029 & 9.0 & $\mathbf{J}$ & 0.030 & 9.4 & $\mathbf{J}$ & 0.027 & 0.005 & 8.4 & 1.4 \\
\hline 1,1-Dichloroethene & $75-35-4$ & 97 & 9.5 & 0.013 & 3.1 & $\mathbf{J}$ & 0.016 & 3.7 & $\mathrm{~J}$ & 0.016 & 3.6 & $\mathrm{~J}$ & 0.015 & 0.001 & 3.5 & 0.32 \\
\hline Methylene Chloride & $75-09-2$ & 85 & 9.7 & 0.032 & 8.4 & B & 0.034 & 9.0 & B & 0.034 & 9.0 & B & 0.033 & 0.001 & 8.8 & 0.30 \\
\hline 112trichloro122trifluoroethane & $76-13-1$ & 187 & 10.2 & 0.047 & 5.6 & & 0.052 & 6.2 & & 0.047 & 5.6 & & 0.049 & 0.003 & 5.8 & 0.33 \\
\hline Propanol & $71-23-8$ & 60 & 10.9 & 0.079 & 29 & B & 0.078 & 29 & B & 0.079 & 29 & $\mathbf{B}$ & 0.079 & 0.001 & 29 & 0.33 \\
\hline Propanenitrile & $107-12-0$ & 55 & 10.9 & 0.036 & 15 & $\mathbf{J}$ & 0.026 & 11 & $\mathrm{~J}$ & 0.033 & 13 & $J$ & 0.032 & 0.005 & 13 & 2.1 \\
\hline 1,1-Dichloroethane & $75-34-3$ & 99 & 11.8 & 0.023 & 5.2 & B & 0.026 & 5.9 & $\mathbf{B}$ & 0.027 & 6.0 & B & 0.025 & 0.002 & 5.7 & 0.44 \\
\hline 2-Butanone & $78-93-3$ & 72 & 12.5 & 0.078 & 24 & B & 0.066 & 21 & $\mathbf{B}$ & 0.074 & 23 & $\mathbf{B}$ & 0.073 & 0.006 & 23 & 1.8 \\
\hline cis-1,2-Dichloroethene & $156-59-2$ & 97 & 13.4 & 0.018 & 4.2 & $\mathbf{J}$ & 0.021 & 4.8 & $\mathbf{J}$ & 0.020 & 4.5 & $\mathrm{~J}$ & 0.019 & 0.001 & 4.5 & 0.30 \\
\hline Hexane & $110-54-3$ & 86 & 13.7 & 0.036 & 9.3 & B & 0.037 & 9.6 & B & 0.034 & 8.8 & $\mathbf{B}$ & 0.036 & 0.002 & 9.2 & 0.39 \\
\hline Chloroform & $67-66-3$ & 119 & 13.9 & 0.026 & 4.8 & $\mathbf{J}$ & 0.028 & 5.2 & & 0.029 & 5.4 & & 0.027 & 0.002 & 5.2 & 0.29 \\
\hline Tetrahydrofuran & $109-99-9$ & 72 & 14.7 & 0.033 & 10 & B & 0.033 & 10 & $\mathbf{B}$ & 0.033 & 10 & $\mathbf{B}$ & 0.033 & 0.000 & 10 & 0.0058 \\
\hline 1,2-Dichloroethane & $107-06-2$ & 99 & 15.3 & 0.019 & 4.2 & $\mathbf{J}$ & 0.021 & 4.8 & $\mathrm{~J}$ & 0.020 & 4.5 & $\mathbf{J}$ & 0.020 & 0.001 & 4.5 & 0.30 \\
\hline Butanenitrile & $109-74-0$ & 69 & 15.8 & 0.043 & 14 & & 0.035 & 11 & & 0.030 & 9.7 & $\mathbf{J}$ & 0.036 & 0.007 & 12 & 2.1 \\
\hline 1,1,1-Trichloroethane & $71-55-6$ & 133 & 15.8 & 0.033 & 5.5 & B & 0.035 & 5.9 & B & 0.034 & 5.7 & $\mathbf{B}$ & 0.034 & 0.001 & 5.7 & 0.23 \\
\hline 1-Butanol & $71-36-3$ & 74 & 16.3 & 0.205 & 62 & B & 0.238 & 72 & $\mathbf{B}$ & 0.211 & 64 & B & 0.218 & 0.018 & 66 & 5.4 \\
\hline Benzene & $71-43-2$ & 78 & 16.7 & 0.022 & 6.2 & $\mathrm{~B}$ & 0.024 & 6.9 & B & 0.023 & 6.5 & B & 0.023 & 0.001 & 6.5 & 0.35 \\
\hline Carbon Tetrachloride & $56-23-5$ & 154 & 17.0 & 0.029 & 4.3 & $\mathbf{J}, \mathbf{B}$ & 0.031 & 4.5 & $\mathrm{~J}, \mathrm{~B}$ & 0.028 & 4.1 & $\mathbf{J}, \mathbf{B}$ & $0: 029$ & 0.001 & 4.3 & 0.17 \\
\hline Cyclohexane & $110-82-7$ & 84 & 17.3 & 0.118 & 31 & & 0.121 & 32 & & 0.124 & 33 & & 0.121 & 0.003 & 32 & 0.82 \\
\hline 1,2-Dichloropropane & $78-87-5$ & 113 & 18.3 & 0.026 & 5.1 & $\mathbf{J}$ & 0.028 & 5.5 & $J$ & 0.033 & 6.5 & & 0.029 & 0.004 & 5.7 & 0.74 \\
\hline Trichloroethene & $79-01-6$ & 131 & 18.8 & 0.029 & 4.9 & $\mathrm{~B}$ & 0.027 & 4.6 & B & 0.028 & 4.8 & B & 0.028 & 0.001 & 4.8 & 0.13 \\
\hline Heptane & $142-82-5$ & 100 & 19.3 & 0.032 & 7.1 & B & 0.029 & 6.4 & B & 0.030 & 6.8 & B & 0.030 & 0.002 & 6.8 & 0.37 \\
\hline 4-Methyl-2-Pentanone & $108-10-1$ & 100 & 20.5 & 0.056 & 12 & B & 0.048 & 11 & $\mathbf{B}$ & 0.047 & 10 & B & 0.050 & 0.005 & 11 & 1.1 \\
\hline cis-1,3-Dichloropropene & $10061-01-5$ & 111 & 20.5 & 0.022 & 4.4 & $\mathbf{J}$ & 0.018 & 3.6 & $\mathrm{~J}$ & 0.020 & 4.1 & $\mathbf{J}$ & 0.020 & 0.002 & 4.0 & 0.44 \\
\hline Pyridine & $110-86-1$ & 79 & 20.6 & 0.071 & 20 & $\mathbf{J}$ & 0.054 & 15 & J & 0.051 & 14 & $\mathbf{J}$ & 0.058 & 0.011 & 17 & 3.1 \\
\hline trans-1,3-Dichloropropene & $10061-02-6$ & 111 & 21.5 & 0.028 & 5.7 & & 0.020 & 4.0 & & 0.020 & 4.0 & & 0.023 & 0.005 & 4.6 & 1.0 \\
\hline
\end{tabular}


Table D.2. Positively Identified and Quantitated Target Analytes and Tentatively Identifed Compounds and Estimated Concentrations for Samples from the Headspace in Tank S-103 in SUMMA canisters collected on 6/12/96

\begin{tabular}{|c|c|c|c|c|c|c|c|c|c|c|c|c|c|c|c|c|}
\hline \multirow[b]{2}{*}{ Target Analytes $^{(a)}$} & \multirow[b]{2}{*}{ CAS } & \multirow[b]{2}{*}{ MW } & \multirow{2}{*}{$\begin{array}{l}\text { Ret } \\
\text { Time }\end{array}$} & \multicolumn{3}{|c|}{ S6060-A04.080 ${ }^{(\mathrm{c})}$ ISVS } & \multicolumn{3}{|c|}{ S6060-A05.082 $2^{(\mathrm{c})(\mathrm{d})}$ ISVS } & \multicolumn{3}{|c|}{ S6060-A06.083 ${ }^{(c)}$ ISVS } & \multicolumn{2}{|c|}{$\begin{array}{l}\text { Mean and } \\
\text { Standard Deviation }\end{array}$} & \multirow[b]{2}{*}{ (ppbv) } & \multirow[b]{2}{*}{ St. Dev. } \\
\hline & & & & $\left(\mathrm{mg} / \mathrm{m}^{3}\right)$ & (ppbv) & Flag & $\left(\mathrm{mg} / \mathrm{m}^{3}\right)$ & (ppbv) & Flag & $\left(\mathrm{mg} / \mathrm{m}^{3}\right)$ & (ppbv) & Flag & $\left(\mathrm{mg} / \mathrm{m}^{3}\right)$ & St. Dev. & & \\
\hline Pentanenitrile & $110-59-8$ & 83 & 21.6 & 0.049 & 13 & $\bar{B}$ & 0.034 & 9.0 & $\mathbf{J , B}$ & 0.039 & 10 & $\mathrm{~J}, \mathrm{~B}$ & 0.041 & 0.008 & 11 & 2.2 \\
\hline 1,1,2-Trichloroethane & $79-00-5$ & 133 & 22.0 & 0.038 & 6.3 & B & 0.029 & 4.9 & B & 0.030 & 5.0 & $\mathbf{B}$ & 0.032 & 0.005 & 5.4 & 0.80 \\
\hline Toluene & $108-88-3$ & 92 & 22.6 & 0.029 & 6.9 & & 0.038 & 9.2 & & 0.040 & 9.7 & & 0.035 & 0.006 & 8.6 & 1.5 \\
\hline 1,2-Dibromoethane & $106-93-4$ & 188 & 24.2 & 0.024 & 2.9 & $\mathbf{J}$ & 0.026 & 3.1 & $\mathbf{J}$ & 0.027 & 3.2 & $\mathbf{J}$ & 0.026 & 0.002 & 3.1 & 0.20 \\
\hline Octane & $111-65-9$ & 114 & 24.7 & 0.014 & 2.8 & $\mathbf{J}$ & 0.018 & 3.4 & $\mathbf{J}$ & 0.016 & 3.2 & $\mathrm{~J}$ & 0.016 & 0.002 & 3.1 & 0.31 \\
\hline Tetrachloroethylene & $127-18-4$ & 166 & 25.2 & 0.037 & 5.0 & $\mathbf{J}$ & 0.048 & 6.4 & & 0.050 & 6.7 & & 0.045 & 0.007 & 6.1 & 0.92 \\
\hline Chlorobenzene & $108-90-7$ & 113 & 26.8 & 0.016 & 3.2 & $\mathbf{J}$ & 0.017 & 3.3 & $\mathbf{J}$ & 0.017 & 3.3 & $\mathbf{J}$ & 0.016 & 0.000 & 3.3 & 0.078 \\
\hline Hexanenitrile & $628-73-9$ & 97 & 27.1 & 0.030 & 6.9 & $\mathbf{J}$ & 0.032 & 7.3 & $\mathbf{J}$ & 0.029 & 6.7 & $\mathbf{J}$ & 0.030 & 0.001 & 7.0 & 0.30 \\
\hline Ethylbenzene & $100-41-4$ & 106 & 27.7 & 0.016 & 3.4 & $\mathfrak{J}$ & 0.018 & 3.8 & $\mathrm{~J}$ & 0.017 & 3.6 & $\mathrm{~J}$ & 0.017 & 0.001 & 3.6 & 0.18 \\
\hline $\mathrm{p} / \mathrm{m}$-Xylene & $106-42-3$ & 106 & 27.7 & 0.082 & 17 & $\mathbf{J}$ & 0.086 & 18 & $\mathbf{J}$ & 0.085 & 18 & $\mathrm{~J}$ & 0.084 & 0.002 & 18 & 0.47 \\
\hline Cyclohexanone & $108-94-1$ & 98 & 28.5 & 0.019 & 4.4 & $\mathbf{J}$ & 0.025 & 5.7 & $\mathbf{J}$ & 0.022 & 5.1 & $\mathrm{~J}$ & 0.022 & 0.003 & 5.0 & 0.67 \\
\hline Styrene & $100-42-5$ & 104 & 29.0 & 0.013 & 2.9 & $\mathbf{J}$ & 0.012 & 2.5 & $\mathbf{J}$ & 0.012 & 2.6 & $\mathrm{~J}$ & 0.012 & 0.001 & 2.7 & 0.19 \\
\hline 1,1,2,2-Tetrachloroethane & $79-34-5$ & 168 & 29.3 & 0.027 & 3.6 & $\mathbf{J}$ & 0.025 & 3.4 & $\mathbf{J}$ & 0.027 & 3.6 & $\mathrm{~J}$ & 0.027 & 0.001 & 3.5 & 0.13 \\
\hline o-Xylene & $95-47-6$ & 106 & 29.3 & 0.017 & 3.5 & $\mathbf{J}$ & 0.015 & 3.2 & $\mathbf{J}$ & 0.016 & 3.4 & $\mathrm{~J}$ & 0.016 & 0.001 & 3.4 & 0.16 \\
\hline Nonane & $111-84-2$ & 128 & 29.8 & 0.015 & 2.6 & $\mathbf{J}, \mathbf{B}$ & 0.012 & 2.2 & $\mathbf{J} ; \mathbf{B}$ & 0.015 & 2.6 & $\mathrm{~J}, \mathrm{~B}$ & 0.014 & 0.001 & 2.5 & 0.26 \\
\hline 1-Ethyl-2-Methyl-Benzene & $611-14-3$ & 120 & 33.0 & 0.018 & 3.3 & $\mathbf{J}, \mathbf{B}$ & 0.015 & 2.8 & $\mathbf{J}, \mathbf{B}$ & 0.016 & 3.0 & $\mathrm{~J}, \mathbf{B}$ & 0.016 & 0.001 & 3.0 & 0.26 \\
\hline 1,3,5-Trimethylbenzene & $108-67-8$ & 120 & 33.0 & 0.015 & 2.8 & $\mathbf{J}$ & 0.013 & 2.5 & $\mathbf{J}$ & 0.015 & 2.8 & $\mathrm{~J}$ & 0.014 & 0.001 & 2.7 & 0.19 \\
\hline 1,2,4-Trimethylbenzene & $95-63-6$ & 120 & 34.2 & 0.016 & 2.9 & $\mathbf{J}$ & 0.013 & 2.4 & $\mathbf{J}$ & 0.015 & 2.8 & $\mathbf{J}$ & 0.014 & 0.002 & 2.7 & 0.30 \\
\hline Decane & $124-18-5$ & 142 & 34.5 & 0.029 & 4.6 & $\mathbf{J}, \mathbf{B}$ & 0.028 & 4.3 & $\mathbf{J}, \mathbf{B}$ & 0.030 & 4.7 & $\mathrm{~J}, \mathrm{~B}$ & 0.029 & 0.001 & 4.5 & 0.17 \\
\hline 1,3-Dichlorobenzene & $541-73-1$ & 147 & 34.7 & 0.016 & 2.4 & $\mathrm{~J}, \mathrm{~B}$ & 0.014 & 2.1 & J,B & 0.015 & 2.3 & $\mathrm{~J}, \mathrm{~B}$ & 0.015 & 0.001 & 2.3 & 0.17 \\
\hline 1,4-Dichlorobenzene & $106-46-7$ & 147 & 34.7 & 0.016 & 2.4 & $\mathrm{~J}, \mathrm{~B}$ & 0.014 & 2.1 & J,B & 0.015 & 2.3 & $\mathbf{J}, \mathbf{B}$ & 0.015 & 0.001 & 2.2 & 0.17 \\
\hline 1,2-Dichlorobenzene & $95-50-1$ & 147 & 36.1 & 0.016 & 2.5 & $\mathbf{J}, \mathbf{B}$ & 0.014 & 2.2 & $\mathbf{J}, \mathbf{B}$ & 0.015 & 2.3 & $\mathrm{~J}, \mathbf{B}$ & 0.015 & 0.001 & 2.3 & 0.15 \\
\hline Undecane & $1120-21-4$ & 156 & 38.8 & 0.013 & 1.9 & $\mathbf{J}$ & 0.013 & 1.8 & $\mathbf{J}$ & 0.015 & 2.2 & $\mathbf{J}$ & 0.014 & 0.001 & 1.9 & 0.21 \\
\hline 1,2,4-Trichlorobenzene & $120-82-1$ & 181 & 42.3 & 0.009 & 1.1 & $\mathbf{J}, \mathbf{B}$ & 0.010 & 1.2 & J,B & 0.010 & 1.3 & $\mathrm{~J}, \mathrm{~B}$ & 0.010 & 0.001 & 1.2 & 0.085 \\
\hline Dodecane & $112-40-3$ & 170 & 42.8 & 0.013 & 1.7 & $\mathbf{J}$ & 0.010 & 1.3 & $\mathrm{U}$ & 0.010 & 1.3 & $\mathbf{U}$ & $\mathrm{e}$ & $\mathbf{e}$ & $\mathrm{e}$ & $\mathbf{e}$ \\
\hline Hexachloro-1,3-butadiene & $87-68-3$ & 261 & 44.1 & 0.023 & 1.9 & $\mathrm{~J}, \mathrm{~B}$ & 0.021 & 1.8 & $\mathrm{~J}, \mathrm{~B}$ & 0.020 & 1.7 & $\mathrm{~J}, \mathrm{~B}$ & 0.021 & 0.001 & 1.8 & 0.10 \\
\hline \multicolumn{17}{|l|}{ Tentatively } \\
\hline \multicolumn{17}{|l|}{ Identified Compounds $^{(\mathrm{b})}$} \\
\hline Cyclopropane & $75-19-4$ & 42 & 4.4 & nd & nd & & nd & nd & & 0.016 & 8.4 & $\mathrm{~N}$ & e & $\mathbf{e}$ & c & e \\
\hline Propene & $115-07-1$ & 42 & 4.4 & 0.018 & 9.7 & $\mathrm{~N}$ & 0.015 & 8.0 & $\mathrm{~N}$ & 0.044 & 22 & $\mathbf{N}$ & 0.026 & 0.016 & 13 & 7.8 \\
\hline Propane & $74-98-6$ & 44 & 4.4 & nd & nd & & 0.044 & 22 & $\mathbf{N}$ & nd & nd & & $\mathbf{e}$ & $\mathbf{e}$ & $\mathrm{e}$ & $\mathrm{e}$ \\
\hline Unknown Alkane & & & 4.5 & 0.040 & f & & nd & nd & & nd & nd & & e & e & e & e \\
\hline Unknown & & & 4.9 & 0.009 & $\mathbf{f}$ & & 0.023 & $\mathrm{f}$ & & nd & nd & & 0.016 & e & e & e \\
\hline Cyclopropane & $75-19-4$ & 42 & 5.0 & 0.028 & 15 & $\mathrm{~N}$ & 0.048 & 26 & $\mathrm{~N}$ & nd & nd & & 0.038 & $\mathbf{e}$ & 20 & e \\
\hline Unknown & & & 6.2 & 0.010 & f & & 0.010 & $\mathrm{f}$ & & 0.024 & $\mathrm{f}$ & & 0.015 & 0.008 & $\mathbf{e}$ & e \\
\hline Unknown & & & 9.1 & 0.004 & $\mathbf{f}$ & & nd & nd & & 0.008 & $\mathrm{f}$ & & 0.006 & e & e & e \\
\hline 2-Propanol, 2-methyl- & $75-65-0$ & 74 & 9.4 & nd & nd & & nd & nd & & 0.016 & 4.7 & $\mathrm{~N}$ & $\mathrm{e}$ & e & e & e \\
\hline
\end{tabular}


Table D.2. Positively Identified and Quantitated Target Analytes and Tentatively Identifed Compounds and Estimated Concentrations for Samples from the Headspace in Tank S-103 in SUMMA canisters collected on 6/12/96

Tentatively

Identified Compounds ${ }^{(b)}$

Unknown Alcohol

1-Propene, 3-chloro-

Silanol, trimethyl-

Butanal

2-Butanol, $(.+/-$.$) .$

2-Butanol

Unknown

N-Nitrosodimethylamine

1,3-Diazine

Pyrazine

Unknown

Cyclohexane, methyl-

2-Hexanone

Hexanal

Cyclotrisiloxane, hexamethyl-

$\bullet \quad$ Unknown

6 Unknown

Unknown Alkane

Unknown Alkane

Unknown Alkane

Data Quality Flags

B Target compound detected in associated laboratory blank and sample

J Target compound detected above the IDL but below the EQL.

$N$ Denotes tentatively identified compound

U Target compound not detected at or above the IDL.

Y Initial calibration and CCV was performed; however, the analyte was not part of the current operating procedure.

\section{Footnotes}

(a) Detected target analytes.

(b) Semi-quantitative estimate calculated using concentration of closest eluting IS.

(c) WHC sample identification number.

(d) Replicates of this sample are found in Table D.3.

(e) Mean and/or standard deviation are not meaningful for this analyte.

(f) No molecular weight available for calculation.

nd Not detected
Mean and

Standard Deviation

$\left(\mathrm{mg} / \mathrm{m}^{3}\right) \quad$ St. Dev. (ppbv) St. Dev.

$\begin{array}{cccc}\mathrm{e} & \mathrm{e} & \mathrm{e} & \mathrm{e} \\ 0.013 & 0.003 & 3.7 & 1.0\end{array}$

$\begin{array}{llllllll}\text { e } & \text { e } & \text { e } & \text { e }\end{array}$

0.042 e 13 e

$\begin{array}{llll}\mathrm{e} & \mathrm{e} & \mathrm{e} & \mathrm{e}\end{array}$

e $\quad$ e $\quad$ e $\quad$ e

$\begin{array}{lllll}0.017 & 0.005 & \mathrm{e} & \mathrm{e}\end{array}$

$\begin{array}{llll}0.008 & 0.002 & 2.5 & 0.52\end{array}$

e e e e

$\begin{array}{lccc}0.043 & \mathrm{e} & 12 & \mathrm{e}\end{array}$

$\begin{array}{llll}0.013 & 0.002 & \mathrm{e} & \mathrm{e}\end{array}$

$\begin{array}{cccc}0.062 & 0.017 & 14 & 3.8 \\ 0.004 & 0.000 & 0.80 & 0.026\end{array}$

$\begin{array}{llll}0.023 & 0.002 & 5.1 & 0.50\end{array}$

$\begin{array}{llllllllllll}100 & 23.6 & 0.026 & 5.7 & \mathrm{~N} & 0.004 & 0.82 & \mathrm{~N} & 0.004 & 0.81 & \mathrm{~N} \\ & & 0.021 & 4.8 & \mathrm{~N} & 0.022 & 5.0 & \mathrm{~N}\end{array}$

$\begin{array}{ccccccc}25.5 & \text { nd } & \text { nd } & \text { nd } & \text { nd } & 0.084 & 8.4 \\ 28.9 & 0.002 & f & \text { nd } & \text { nd } & \text { nd } & \text { nd }\end{array}$

$33.8 \quad 0.002 \quad f$

nd nd

$\begin{array}{lll}37.5 & 0.003 & \mathrm{f}\end{array}$

46.2 nd nd

0.007

0.008

0.005

0.012

f

$\begin{array}{cccc}\mathrm{e} & \mathrm{e} & \mathrm{e} & \mathrm{e} \\ \mathrm{e} & \mathrm{e} & \mathrm{e} & \mathrm{e} \\ \mathrm{e} & \mathrm{e} & \mathrm{e} & \mathrm{e} \\ 0.015 & 0.007 & \mathrm{e} & \mathrm{e} \\ 0.006 & 0.003 & \mathrm{e} & \mathrm{e} \\ 0.009 & \mathrm{e} & \mathrm{e} & \mathrm{e}\end{array}$

0.009

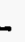


Table D.3. Positively Identified and Quantitated Target Analytes ${ }^{(a)}$ and Tentatively Identifed Compounds and Estimated Concentrations ${ }^{(b)}$ of Replicate Analysis of a single SUMMA ${ }^{\mathrm{TM}}$ Cannister Collected from the Headspace of Tank S-103 on 6/12/96

\begin{tabular}{|c|c|c|c|c|c|c|c|c|c|c|}
\hline \multirow[b]{2}{*}{ Target Analytes ${ }^{(a)}$} & \multirow[b]{2}{*}{ CAS } & \multirow[b]{2}{*}{ MW } & \multirow{2}{*}{$\begin{array}{l}\text { Ret } \\
\text { Time }\end{array}$} & \multicolumn{6}{|c|}{ S6060-A05.082 $2^{(\mathrm{c})}$ ISVS } & $\begin{array}{c}\text { Relative Percent } \\
\text { Difference }^{(d)}\end{array}$ \\
\hline & & & & $\left(\mathrm{mg} / \mathrm{m}^{3}\right)$ & (ppbv) & Flag & $\left(\mathrm{mg} / \mathrm{m}^{3}\right)$ & (ppbv) & Flag & $\%$ \\
\hline Dichlorodifluoromethane & $75-71-8$ & 121 & 4.6 & 0.031 & 5.7 & $\bar{B}$ & 0.028 & 5.2 & $\mathbf{B}$ & 8 \\
\hline Chloromethane & $74-87-3$ & 50 & 4.9 & 0.017 & 7.7 & $\mathbf{J}$ & 0.015 & 6.7 & $\mathrm{~J}$ & 14 \\
\hline 12dichloro 1 122-tetrafluoroethane & $76-14-2$ & 171 & 5.2 & 0.034 & 4.4 & $J$ & 0.032 & 4.2 & $\mathbf{J}$ & 4 \\
\hline Methanol & $67-56-1$ & 32 & 5.2 & 3.835 & 2681 & & 2.852 & 1994 & & 29 \\
\hline Vinyl Chloride & $75-01-4$ & 63 & 5.4 & 0.019 & 6.8 & & 0.016 & 5.8 & & 16 \\
\hline Butane & $106-97-8$ & 58 & 5.9 & 0.049 & 19 & & 0.047 & 18 & & 5 \\
\hline Bromomethane & $74-83-9$ & 95 & 6.3 & 0.021 & 4.9 & J & 0.021 & 4.9 & $J$ & 0 \\
\hline Chloroethane & $75-00-3$ & 65 & 6.7 & 0.019 & 6.7 & $\mathbf{J}$ & 0.027 & 9.3 & $\mathrm{~J}$ & 32 \\
\hline Ethanol & $64-17-5$ & 46 & 6.8 & 1.272 & 619 & & 1.188 & 579 & & 7 \\
\hline Acetonitrile & $75-05-8$ & 41 & 7.3 & 0.044 & 24 & & 0.036 & 20 & $\mathrm{~J}$ & 19 \\
\hline Acetone & $67-64-1$ & 58 & 7.8 & 0.298 & 115 & & 0.226 & 87 & & 27 \\
\hline Trichlorofluoromethane & $75-69-4$ & 137 & 8.3 & 0.096 & 16 & & 0.086 & 14 & & 11 \\
\hline Pentane & $109-66-0$ & 72 & 8.9 & 0.029 & 9.0 & $J$ & 0.029 & 9.0 & $\mathrm{~J}$ & 0 \\
\hline 1,1-Dichloroethene & $75-35-4$ & 97 & 9.5 & 0.016 & 3.7 & $\mathbf{J}$ & 0.015 & 3.3 & $\mathrm{~J}$ & 9 \\
\hline Methylene Chloride & $75-09-2$ & 85 & 9.7 & 0.034 & 9.0 & B & 0.031 & 8.2 & B & 9 \\
\hline 112trichlorol22trifluoroethane & $76-13-1$ & 187 & 10.2 & 0.052 & 6.2 & & 0.043 & 5.2 & & 18 \\
\hline Propanol & $71-23-8$ & 60 & 10.9 & 0.078 & 29 & B & 0.062 & 23 & B & 22 \\
\hline Propanenitrile & $107-12-0$ & 55 & 10.9 & 0.026 & 11 & J & 0.024 & 9.7 & $\mathrm{~J}$ & 9 \\
\hline 1,1-Dichloroethane & $75-34-3$ & 99 & 11.8 & 0.026 & 5.9 & $\mathrm{~B}$ & 0.021 & 4.8 & B & 22 \\
\hline 2-Butanone & $78-93-3$ & 72 & 12.5 & 0.066 & 21 & B & 0.052 & 16 & B & 25 \\
\hline cis-1,2-Dichloroethene & $156-59-2$ & 97 & 13.4 & 0.021 & 4.8 & $\mathrm{~J}$ & 0.017 & 4.0 & $\mathrm{~J}$ & 18 \\
\hline Hexane & $110-54-3$ & 86 & 13.7 & 0.037 & 9.6 & B & 0.032 & 8.4 & $\mathbf{B}$ & 13 \\
\hline Chloroform & $67-66-3$ & 119 & 13.9 & 0.028 & 5.2 & & 0.025 & 4.7 & $\mathrm{~J}$ & 11 \\
\hline Tetrahydrofuran & $109-99-9$ & 72 & 14.7 & 0.033 & 10 & $\mathrm{~B}$ & 0.024 & 7.5 & B & 30 \\
\hline 1,2-Dichloroethane & $107-06-2$ & 99 & 15.3 & 0.021 & 4.8 & $\mathbf{J}$ & 0.017 & 3.8 & $\mathrm{~J}$ & 24 \\
\hline Butanenitrile & $109-74-0$ & 69 & 15.8 & 0.035 & 11 & & 0.023 & 7.4 & $J$ & 43 \\
\hline 1,1,1-Trichloroethane & $71-55-6$ & 133 & 15.8 & 0.035 & 5.9 & B & 0.025 & 4.2 & $\mathrm{~J}, \mathrm{~B}$ & 35 \\
\hline 1-Butanol & $71-36-3$ & 74 & 16.3 & 0.238 & 72 & B & 0.127 & 38 & B & 61 \\
\hline Benzene & $71-43-2$ & 78 & 16.7 & 0.024 & 6.9 & B & 0.019 & 5.6 & B & 21 \\
\hline Carbon Tetrachloride & $56-23-5$ & 154 & 17.0 & 0.031 & 4.5 & $\mathbf{J}, \mathbf{B}$ & 0.024 & 3.5 & $\mathrm{~J}, \mathbf{B}$ & 24 \\
\hline Cyclohexane & $110-82-7$ & 84 & 17.3 & 0.121 & 32 & & 0.110 & 29 & & 10 \\
\hline 1,2-Dichloropropane & $78-87-5$ & 113 & 18.3 & 0.028 & 5.5 & $\mathbf{J}$ & 0.024 & 4.8 & $\mathrm{~J}$ & 13 \\
\hline Trichloroethene & $79-01-6$ & 131 & 18.8 & 0.027 & 4.6 & $\mathrm{~B}$ & 0.025 & 4.3 & B & 6 \\
\hline Heptane & $142-82-5$ & 100 & 19.3 & 0.029 & 6.4 & B & 0.029 & 6.5 & B & 2 \\
\hline 4-Methyl-2-Pentanone & $108-10-1$ & 100 & 20.5 & 0.048 & 11 & B & 0.025 & 5.6 & $\mathbf{J}, \mathbf{B}$ & 63 \\
\hline cis-1,3-Dichloropropene & $10061-01-5$ & 111 & 20.5 & 0.018 & 3.6 & $\mathbf{J}$ & 0.017 & 3.4 & $\mathrm{~J}$ & 4 \\
\hline Pyridine & $110-86-1$ & 79 & 20.6 & 0.054 & 15 &. $\mathbf{J}$ & 0.032 & 8.9 & $\mathbf{J}$ & 52 \\
\hline trans-1,3-Dichloropropene & $10061-02-6$ & 111 & 21.5 & 0.020 & 4.0 & & 0.013 & 2.7 & $\mathbf{J}$ & 39 \\
\hline Pentanenitrile & $110-59-8$ & 83 & 21.6 & 0.034 & 9.0 & $\mathbf{J}, \mathbf{B}$ & 0.021 & 5.6 & $\mathbf{J , B}$ & 48 \\
\hline 1,1,2-Trichloroethane & $79-00-5$ & 133 & 22.0 & 0.029 & 4.9 & B & 0.023 & 3.9 & $\mathbf{J}, \mathbf{B}$ & 23 \\
\hline Toluene & $108-88-3$ & 92 & 22.6 & 0.038 & 9.2 & & 0.047 & 11 & & 21 \\
\hline 1,2-Dibromoethane & $106-93-4$ & 188 & 24.2 & 0.026 & 3.1 & $\mathbf{J}$ & 0.025 & 2.9 & $\mathbf{J}$ & 6 \\
\hline Octane & $111-65-9$ & 114 & 24.7 & 0.018 & 3.4 & $\mathrm{~J}$ & 0.018 & 3.5 & $\mathrm{~J}$ & 3 \\
\hline Tetrachloroethylene & $127-18-4$ & 166 & 25.2 & 0.048 & 6.4 & & 0.057 & 7.7 & & 18 \\
\hline Chlorobenzene & $108-90-7$ & 113 & 26.8 & 0.017 & 3.3 & $\mathrm{~J}$ & 0.015 & 3.1 & $\mathbf{J}$ & 8 \\
\hline Hexanenitrile & $628-73-9$ & 97 & 27.1 & 0.032 & 7.3 & $\mathrm{~J}$ & 0.022 & 5.0 & J & 37 \\
\hline Ethylbenzene & $100-41-4$ & 106 & 27.7 & 0.018 & 3.8 & $\mathbf{J}$ & 0.015 & 3.1 & $\mathbf{J}$ & 19 \\
\hline p/m-Xylene & $106-42-3$ & 106 & 27.7 & 0.086 & 18 & $\mathrm{~J}$ & 0.070 & 15 & $\mathbf{J}$ & 21 \\
\hline Cyclohexanone & $108-94-1$ & 98 & 28.5 & 0.025 & 5.7 & $\mathrm{~J}$ & 0.013 & 3.0 & $\mathbf{J}$ & 63 \\
\hline Styrene & $100-42-5$ & 104 & 29.0 & 0.012 & 2.5 & $\mathbf{J}$ & 0.012 & 2.7 & $\mathbf{J}$ & 6 \\
\hline 1,1,2,2-Tetrachloroethane & $79-34-5$ & 168 & 29.3 & 0.025 & 3.4 & $\mathrm{~J}$ & 0.024 & 3.2 & $\mathbf{J}$ & 6 \\
\hline o-Xylene & $95-47-6$ & 106 & 29.3 & 0.015 & 3.2 & $\mathrm{~J}$ & 0.017 & 3.5 & $\mathbf{J}$ & 10 \\
\hline Nonane & $111-84-2$ & 128 & 29.8 & 0.012 & 2.2 & $\mathrm{~J}, \mathrm{~B}$ & 0.016 & 2.8 & J,B & 24 \\
\hline 1-Ethyl-2-Methyl-Benzene & $611-14-3$ & 120 & 33.0 & 0.015 & 2.8 & $\mathrm{~J}, \mathrm{~B}$ & 0.013 & 2.5 & $\mathrm{~J}, \mathrm{~B}$ & 12 \\
\hline
\end{tabular}


Table D.3. Positively Identified and Quantitated Target Analytes ${ }^{(a)}$ and Tentatively Identifed Compounds and Estimated Concentrations ${ }^{(b)}$ of Replicate Analysis of a single SUMMA ${ }^{\mathrm{TM}}$ Cannister Collected from the Headspace of Tank S-103 on 6/12/96

\begin{tabular}{|c|c|c|c|c|c|c|c|c|c|c|}
\hline \multirow[b]{2}{*}{ Target Analytes $^{(a)}$} & \multirow[b]{2}{*}{ CAS } & \multirow[b]{2}{*}{ MW } & \multirow{2}{*}{$\begin{array}{c}\text { Ret } \\
\text { Time }\end{array}$} & \multicolumn{6}{|c|}{ S6060-A05.082 $2^{(\mathrm{c})}$ ISVS } & \multirow{2}{*}{$\begin{array}{c}\begin{array}{c}\text { Relative Percen } \\
\text { Difference }^{(\mathrm{d})}\end{array} \\
\%\end{array}$} \\
\hline & & & & $\left(\mathrm{mg} / \mathrm{m}^{3}\right)$ & (ppbv) & Flag & $\left(\mathrm{mg} / \mathrm{m}^{3}\right)$ & (ppbv) & Flag & \\
\hline 1,3,5-Trimethylbenzene & $108-67-8$ & 120 & 33.0 & 0.013 & 2.5 & $\mathrm{~J}, \mathrm{~B}$ & 0.013 & 2.5 & $\mathrm{~J}, \mathrm{~B}$ & 0 \\
\hline 1,2,4-Trimethylbenzene & $95-63-6$ & 120 & 34.2 & 0.013 & 2.4 & $\mathbf{J}$ & 0.013 & 2.5 & $\mathrm{~J}$ & 5 \\
\hline Decane & $124-18-5$ & 142 & 34.5 & 0.028 & 4.3 & $\mathrm{~J}, \mathrm{~B}$ & 0.028 & 4.4 & $\mathrm{~J}, \mathrm{~B}$ & 0 \\
\hline 1,3-Dichlorobenzene & $541-73-1$ & 147 & 34.7 & 0.014 & 2.1 & $\mathrm{~J}, \mathrm{~B}$ & 0.013 & 2.0 & $\mathrm{~J}, \mathrm{~B}$ & 4 \\
\hline 1,4-Dichlorobenzene & $106-46-7$ & 147 & 34.7 & 0.014 & 2.1 & $\mathrm{~J}, \mathrm{~B}$ & 0.014 & 2.1 & $\mathrm{~J}, \mathrm{~B}$ & 1 \\
\hline 1,2-Dichlorobenzene & $95-50-1$ & 147 & 36.1 & 0.014 & 2.2 & $\mathrm{~J}, \mathbf{B}$ & 0.014 & 2.2 & $J, B$ & 1 \\
\hline Undecane & $1120-21-4$ & 156 & 38.8 & 0.013 & 1.8 & $\mathrm{~J}$ & 0.011 & 1.6 & $J$ & 10 \\
\hline 1,2,4-Trichlorobenzene & $120-82-1$ & 181 & .42 .3 & 0.010 & 1.2 & $\mathrm{~J}, \mathbf{B}$ & 0.008 & 1.0 & $\mathbf{J , B}$ & 18 \\
\hline Dodecane & $112-40-3$ & 170 & 42.8 & 0.010 & 1.3 & $\mathrm{U}$ & 0.013 & 1.7 & $\mathbf{J}$ & \\
\hline Hexachloro-1,3-butadiene & $87-68-3$ & 261 & 44.1 & 0.021 & 1.8 & J,B & 0.019 & 1.7 & $\mathrm{~J}, \mathrm{~B}$ & 6 \\
\hline
\end{tabular}

Tentatively

Identified Compounds ${ }^{(\text {b) }}$

\begin{tabular}{|c|c|c|c|c|c|c|c|c|c|c|}
\hline Cyclopropane & $75-19-4$ & 42 & 4.4 & nd & nd & & 0.015 & 7.9 & $\mathrm{~N}$ & \\
\hline Propene & $115-07-1$ & 42 & 4.4 & 0.015 & 8.0 & $N$ & 0.043 & 22 & $\mathrm{~N}$ & 97 \\
\hline Propane & $74-98-6$ & 44 & 4.4 & 0.044 & 22 & $\mathrm{~N}$ & nd & nd & & \\
\hline Unknown & & & 4.7 & nd & nd & & 0.005 & e & & \\
\hline Unknown & & & 4.9 & 0.023 & e & & nd & nd & & \\
\hline Cyclopropane & $75-19-4$ & 42 & 5.0 & 0.048 & 26 & $\mathbf{N}$ & nd & nd & & \\
\hline Unknown & & & 6.2 & 0.010 & e & & 0.015 & e & & 36 \\
\hline Unknown & & & 9.1 & nd & nd & & 0.002 & e & & \\
\hline 1-Propene, 3-chloro- & $107-05-1$ & 76 & 9.9 & 0.012 & 3.7 & $\mathrm{~N}$ & 0.022 & 6.4 & $\mathbf{N}$ & 55 \\
\hline Butanal & $123-72-8$ & 72 & 12.3 & 0.042 & 13 & $\mathrm{~N}$ & 0.029 & 9.1 & $\mathrm{~N}$ & 36 \\
\hline 2-Butanol, $(.+/-)-$. & $15892-23-6$ & 74 & 13.0 & nd & nd & & 0.014 & 4.2 & $\mathrm{~N}$ & \\
\hline 2-Pentanone & $107-87-9$ & 86 & 16.0 & nd & nd & & 0.003 & 0.89 & $\mathrm{~N}$ & \\
\hline Unknown & & & 16.9 & 0.019 & e & & nd & nd & & \\
\hline Propane, 1,2-dichloro- & $78-87-5$ & 112 & 18.3 & nd & nd & & 0.019 & 3.8 & $\mathrm{~N}$ & \\
\hline N-Nitrosodimethylamine & $62-75-9$ & 74 & 19.6 & 0.007 & 2.2 & $\mathbf{N}$ & 0.002 & 0.48 & $\mathrm{~N}$ & 126 \\
\hline Pyrazine & $290-37-9$ & 80 & 19.8 & 0.046 & 13 & $\mathrm{~N}$ & 0.023 & 6.5 & $\mathrm{~N}$ & 66 \\
\hline Unknown & & & 20.3 & 0.015 & e & & 0.007 & $\mathrm{e}$ & & 73 \\
\hline Cyclohexane, methyl- & $108-87-2$ & 98 & 20.8 & 0.047 & 11 & $\mathbf{N}$ & 0.074 & 17 & $\mathbf{N}$ & 44 \\
\hline 2-Hexanone & $591-78-6$ & 100 & 23.0 & 0.004 & 0.82 & $\mathbf{N}$ & nd & nd & & \\
\hline Hexanal & $66-25-1$ & 100 & 23.6 & 0.021 & 4.8 & $\mathbf{N}$ & nd & nd & & \\
\hline Unknown Alkane & & & 37.2 & 0.021 & e & & 0.013 & e & & 51 \\
\hline Unknown Alkane & & & 37.5 & 0.007 & e & & 0.007 & e & & 1 \\
\hline Unknown Alkane & & & 46.2 & 0.012 & e & & 0.015 & $\mathrm{e}$ & & 18 \\
\hline
\end{tabular}

Data Quality Flags

B Target compound detected in associated laboratory blank and sample

$\mathrm{J}$ Target compound detected above the $\mathrm{IDL}$ but below the EQL.

$\mathrm{N}$ Denotes tentatively identified compound

$\mathrm{U}$ Target compound not detected at or above the IDL.

$\mathrm{Y}$ Initial calibration and $\mathrm{CCV}$ was performed; however, the analyte was not part of the current operating procedure.

Footnotes
(a) TO-14 plus 26 additional target analytes.
(b) Semi-quantitative estimate calculated using concentration of closest eluting IS.
(c) WHC sample identification number.
(d) Relative percent differences (RPDs) based on $\mathrm{mg} / \mathrm{m} 3$ values.
(e) No molecular weight available for calculation
nd Not detected 
Table D.4. Positively Identified and Quantitated Target Analytes ${ }^{(a)}$ and Tentatively Identifed Compounds and Estimated Concentrations $^{(b)}$ in Ambient Air and Ambient Air Through the ISVS Collected Near Tank S-103 in SUMMA ${ }^{\mathrm{TM}}$ Canisters Collected on 6/12/96

$\mathrm{S} 6060-\mathrm{A} 01.001^{(\mathrm{c})}$

Ret

Target Analytes ${ }^{(a)}$

Dichlorodifluoromethane

Chloromethane

12dichloro1122-tetrafluoroethane

Methanol

Vinyl Chloride

Butane

Bromomethane

Chloroethane

Acetonitrile

Acetone

Trichlorofluoromethane

Pentane

1,1-Dichloroethene

Methylene Chloride

112trichloro122trifluoroethane

Propanol

Propanenitrile

1,1-Dichloroethane

2-Butanone

cis-1,2-Dichloroethene

Hexane

Chloroform

Tetrahydrofuran

1,2-Dichloroethane

Butanenitrile

1,1,1-Trichloroethane

1-Butanol

Benzene

Carbon Tetrachloride

Cyclohexane

1,2-Dichloropropane

Trichloroethene

Heptane

4-Methyl-2-Pentanone

cis-1,3-Dichloropropene

Pyridine

trans-1,3-Dichloropropene

Pentanenitrile

1,1,2-Trichloroethane

Toluene

1,2-Dibromoethane

Octane

Tetrachloroethylene

Chlorobenzene

Hexanenitrile

Ethylbenzene

p/m-Xylene

Cyclohexanone

Styrene

1,1,2,2-Tetrachloroethane

ISVS Upwind Ambient

S6060-A02.010 (c)

ISVS Amb Thru Bundle

\begin{tabular}{|c|c|c|c|c|c|c|c|c|}
\hline CAS & MW & Time & $\left(\mathrm{mg} / \mathrm{m}^{3}\right)$ & (ppbv) & Flag & $\left(\mathrm{mg} / \mathrm{m}^{3}\right)$ & (ppbv) & Flag \\
\hline $75-71-8$ & 121 & 4.6 & 0.016 & 3.0 & $\mathrm{~J}, \mathrm{~B}$ & 0.037 & 6.9 & B \\
\hline $74-87-3$ & 50 & 4.9 & 0.006 & 2.8 & $\mathrm{~J}$ & 0.015 . & 6.5 & $\mathbf{J}$ \\
\hline $76-14-2$ & 171 & 5.2 & 0.013 & $1: 7$ & $\mathrm{U}$ & 0.038 & 5.0 & J \\
\hline $67-56-1$ & 32 & 5.2 & $<0.110$ & $<77$ & $\mathrm{Y}$ & 0.127 & 89 & $\mathrm{Y}$ \\
\hline $75-01-4$ & 63 & 5.4 & 0.007 & 2.4 & $J$ & 0.016 & 5.8 & \\
\hline $106-97-8$ & 58 & 5.9 & 0.010 & 3.9 & $J$ & 0.027 & 11 & \\
\hline $74-83-9$ & 95 & 6.3 & 0.008 & $1: 9$ & $J$ & 0.024 & 5.7 & $\mathbf{J}$ \\
\hline $75-00-3$ & 65 & 6.7 & 0.005 & 1.9 & $\mathrm{U}$ & 0.019 & 6.6 & $\mathbf{J}$ \\
\hline $75-05-8$ & 41 & 7.3 & 0.008 & 4.2 & $J$ & 0.012 & $6: 8$ & $\mathbf{J}$ \\
\hline $67-64-1$ & 58 & 7.8 & 0.036 & 14 & & 0.076 & 29 & \\
\hline $75-69-4$ & 137 & 8.3 & 0.010 & 1.6 & $\mathrm{~J}$ & 0.030 & 5.0 & $J$ \\
\hline $109-66-0$ & 72 & 8.9 & 0.006 & 2.0 & $\mathrm{~J}$ & 0.027 & 8.3 & J \\
\hline $75-35-4$ & 97 & 9.5 & 0.006 & 1.3 & $\mathrm{~J}$ & 0.018 & 4.2 & J \\
\hline $75-09-2$ & 85 & 9.7 & 0.021 & 5.6 & B & 0.035 & 9.3 & B \\
\hline $76-13-1$ & 187 & 10.2 & 0.012 & 1.4 & $J$ & 0.090 & 11 & \\
\hline $71-23-8$ & 60 & 10.9 & 0.023 & 8.4 & $\mathrm{~J}, \mathrm{~B}$ & 0.042 & 16 & B \\
\hline $107-12-0$ & 55 & 10.9 & 0.016 & 6.7 & $\mathbf{J}$ & 0.023 & 9.3 & $\mathbf{J}$ \\
\hline $75-34-3$ & 99 & 11.8 & 0.011 & 2.5 & $\mathrm{~J}, \mathrm{~B}$ & 0.025 & 5.8 & B \\
\hline $78-93-3$ & 72 & 12.5 & 0.020 & 6.4 & J,B & 0.033 & 10 & B \\
\hline $156-59-2$ & 97 & 13.4 & 0.010 & 2.3 & $J$ & 0.016 & 3.8 & $\mathbf{J}$ \\
\hline $110-54-3$ & 86 & 13.7 & 0.015 & 3.9 & $\mathrm{~J}, \mathrm{~B}$ & 0.033 & 8.4 & B \\
\hline $67-66-3$ & 119 & 13.9 & 0.015 & 2.9 & $\mathbf{J}$ & 0.027 & 5.0 & \\
\hline $109-99-9$ & 72 & 14.7 & 0.012 & 3.7 & $\mathrm{~J}, \mathrm{~B}$ & 0.020 & 6.3 & B \\
\hline $107-06-2$ & 99 & 15.3 & 0.012 & 2.6 & $\mathbf{J}$ & 0.017 & 3.8 & $\mathrm{~J}$ \\
\hline $109-74-0$ & 69 & 15.8 & 0.015 & 4.9 & $\mathbf{J}$ & 0.044 & 14 & \\
\hline $71-55-6$ & 133 & 15.8 & 0.016 & 2.7 & $\mathrm{~J}, \mathrm{~B}$ & 0.039 & 6.6 & $\mathrm{~B}$ \\
\hline $71-36-3$ & 74 & 16.3 & 0.035 & 11 & B & 0.079 & 24 & B \\
\hline $71-43-2$ & 78 & 16.7 & 0.009 & 2.7 & $\mathrm{~J}, \mathrm{~B}$ & 0.019 & 5.5 & B \\
\hline $56-23-5$ & 154 & 17.0 & 0.016 & 2.3 & $\mathrm{~J}, \mathrm{~B}$ & 0.035 & 5.1 & B \\
\hline $110-82-7$ & 84 & 17.3 & 0.093 & 25 & & 0.115 & 30 & \\
\hline $78-87-5$ & 113 & 18.3 & 0.019 & 3.8 & $\mathrm{~J}$ & 0.003 & 0.59 & $\mathrm{U}$ \\
\hline $79-01-6$ & 131 & 18.8 & 0.018 . & 3.0 & $\mathrm{~J}, \mathrm{~B}$ & 0.027 & 4.5 & B \\
\hline $142-82-5$ & 100 & 19.3 & 0.017 & 3.8 & $\mathrm{~J}, \mathrm{~B}$ & 0.023 & 5.1 & B \\
\hline $108-10-1$ & 100 & 20.5 & 0.030 & 6.8 & $\mathrm{~J}, \mathrm{~B}$ & 0.073 & 16 & B \\
\hline $10061-01-5$ & 111 & 20.5 & 0.016 & 3.1 & $\mathbf{J}$ & 0.017 & 3.4 & $\mathbf{J}$ \\
\hline $110-86-1$ & 79 & 20.6 & 0.042 & 12 & $\mathbf{J}$ & 0.130 & 37 & $\mathbf{J}$ \\
\hline $10061-02-6$ & 111 & 21.5 & 0.015 & 3.0 & $\mathbf{J}$ & 0.023 & 4.7 & \\
\hline $110-59-8$ & 83 & 21.6 & 0.022 & 5.9 & $\mathrm{~J}, \mathrm{~B}$ & 0.053 & 14 & B \\
\hline $79-00-5$ & 133 & 22.0 & 0.022 & 3.7 & $\mathrm{~J}$ & 0.030 & 5.0 & \\
\hline $108-88-3$ & 92 & 22.6 & 0.014 & 3.5 & $\mathrm{~J}, \mathrm{~B}$ & 0.016 & 3.9 & $\mathrm{~J}, \mathrm{~B}$ \\
\hline $106-93-4$ & 188 & 24.2 & 0.021 & 2.5 & $\mathrm{~J}$ & 0.028 & 3.3 & $\mathbf{J}$ \\
\hline $111-65-9$ & 114 & 24.7 & 0.014 & 2.8 & $\mathrm{~J}$ & 0.016 & 3.1 & $\mathbf{J}$ \\
\hline $127-18-4$ & 166 & 25.2 & 0.020 & 2.7 & $J$ & 0.021 & 2.9 & $\mathrm{~J}$ \\
\hline $108-90-7$ & 113 & 26.8 & 0.013 & 2.6 & $\mathbf{J}$ & 0.017 & 3.3 & $\mathbf{J}$ \\
\hline $628-73-9$ & 97 & 27.1 & 0.024 & 5.5 & $\mathbf{J}$ & 0.051 & 12 & $\mathbf{J}$ \\
\hline $100-41-4$ & 106 & 27.7 & 0.011 & 2.4 & $\mathbf{J}$ & 0.017 & 3.6 & $\mathbf{J}$ \\
\hline $106-42-3$ & 106 & 27.7 & 0.055 & 12 & $\mathrm{~J}$ & 0.093 & 20 & $\mathbf{J}$ \\
\hline $108-94-1$ & 98 & 28.5 & 0.016 & 3.7 & $\mathbf{J}$ & 0.064 & 15 & \\
\hline $100-42-5$ & 104 & 29.0 & 0.011 & 2.3 & $\mathbf{J}$ & 0.012 & 2.6 & $\mathbf{J}$ \\
\hline $79-34-5$ & 168 & 29.3 & 0.021 & 2.8 & $\mathbf{J}$ & 0.029 & 3.9 & $\mathbf{J}$ \\
\hline
\end{tabular}


Table D.4. Positively Identified and Quantitated Target Analytes ${ }^{(a)}$ and Tentatively Identifed Compounds and Estimated Concentrations $^{(b)}$ in Ambient Air and Ambient Air Through the ISVS Collected Near Tank S-103 in SUMMA ${ }^{\text {TM }}$ Canisters Collected on 6/12/96

\begin{tabular}{|c|c|c|c|c|c|c|c|c|c|}
\hline \multirow[b]{2}{*}{ Target Analytes $^{(2)}$} & \multirow[b]{2}{*}{ CAS } & \multirow[b]{2}{*}{ MW } & \multirow{2}{*}{$\begin{array}{l}\text { Ret } \\
\text { Time }\end{array}$} & \multicolumn{3}{|c|}{ S6060-A01.001 ${ }^{(\mathrm{c})}$} & \multicolumn{3}{|c|}{$\mathrm{S} 6060-\mathrm{A} 02.010^{(\mathrm{c})}$} \\
\hline & & & & $\left(\mathrm{mg} / \mathrm{m}^{3}\right)$ & (ppbv) & Flag & $\left(\mathrm{mg} / \mathrm{m}^{3}\right)$ & (ppbv) & Flag \\
\hline o-Xylene & $95-47-6$ & 106 & 29.3 & 0.012 & 2.5 & $\bar{J}$ & 0.014 & 2.9 & $\mathrm{~J}$ \\
\hline Nonane & $111-84-2$ & 128 & 29.8 & 0.012 & 2.1 & $\mathrm{~J}, \mathrm{~B}$ & 0.014 & 2.5 & $\mathrm{~J}, \mathrm{~B}$ \\
\hline 1-Ethyl-2-Methyl-Benzene & $611-14-3$ & 120 & 33.0 & 0.012 & 2.3 & $\mathrm{~J}, \mathrm{~B}$ & 0.017 & 3.2 & $\mathbf{J}, \mathbf{B}$ \\
\hline 1,3,5-Trimethylbenzene & $108-67-8$ & 120 & $33: 0$ & 0.012 & 2.2 & $\mathrm{~J}, \mathrm{~B}$ & 0.016 & 2.9 . & $\mathbf{J}, \mathbf{B}$ \\
\hline 1,2,4-Trimethylbenzene & $95-63-6$ & 120 & 34.2 & 0.012 & 2.2 & J & 0.016 & 3.1 & $\mathbf{J}$ \\
\hline Decane & $124-18-5$ & 142 & 34.5 & 0.021 & 3.4 & $\mathfrak{f , B}$ & 0.028 & 4.4 & $\mathbf{J}, \mathbf{B}$ \\
\hline 1,3-Dichlorobenzene & $541-73-1$ & 147 & 34.7 & 0.013 & 2.0 & $\mathrm{~J}, \mathrm{~B}$ & 0.017 & 2.6 & $\mathrm{~J}, \mathrm{~B}$ \\
\hline 1,4-Dichlorobenzene & $106-46-7$ & 147 & 34.7 & 0.014 & 2.1 & $\mathrm{~J}, \mathrm{~B}$ & 0.016 & 2.4 & $\mathrm{~J}, \mathrm{~B}$ \\
\hline 1,2-Dichlorobenzene & $95-50-1$ & 147 & 36.1 & 0.015 & 2.2 & $\mathrm{~J}, \mathrm{~B}$ & 0.019 & 2.8 & B \\
\hline Undecane & $1120-21-4$ & 156 & 38.8 & 0.008 & 1.2 & $\mathrm{~J}$ & 0.015 & 2.1 & $\mathbf{J}$ \\
\hline 1,2,4-Trichlorobenzene & $120-82-1$ & 181 & 42.3 & 0.008 & 1.0 & গ,B & 0.014 & 1.7 & $\mathrm{~J}, \mathrm{~B}$ \\
\hline Dodecane & $112-40-3$ & 170 & 42.8 & 0.011 & 1.4 & $\mathbf{J}$ & 0.013 & 1.7 & $\mathbf{J}$ \\
\hline Hexachloro-1,3-butadiene & $87-68-3$ & 261 & 44.1 & 0.021 & 1.8 & $\mathrm{~J}, \mathrm{~B}$ & 0.026 & 2.2 & $\mathrm{~J}, \mathrm{~B}$ \\
\hline \multicolumn{10}{|l|}{ Tentatively } \\
\hline \multicolumn{10}{|l|}{ Identified Compounds $^{(b)}$} \\
\hline Cyclopropane & $75-19-4$ & 42 & 4.4 & 0.010 & 5.1 & $\mathbf{N}$ & nd & nd & \\
\hline Propene & $115-07-1$ & 42 & 4.4 & nd & nd & & 0.016 & 8.4 & $\mathrm{~N}$ \\
\hline Unknown & & & 4.4 & 0.009 & d & & nd & nd & \\
\hline Acetaldehyde & $75-07-0$ & 44 & 5.2 & 0.022 & 11 & $\mathrm{~N}$ & nd & nd & \\
\hline 1-Propene, 3-chloro- & $107-05-1$ & 76 & 9.9 & nd & nd & & 0.015 & 4.5 & $\mathrm{~N}$ \\
\hline Unknown & & & 10.4 & 0.017 & d & & nd & nd & \\
\hline Silanol, trimethyl- & $1066-40-6$ & 90 & 11.6 & nd & nd & & 0.068 & 17 & $\mathrm{~N}$ \\
\hline Butanal & $123-72-8$ & 72 & 12.3 & 0.007 & 2.2 & $\mathbf{N}$ & 0.008 & 2.4 & $\mathrm{~N}$ \\
\hline 2-Hexanone & $591-78-6$ & 100 & 23.0 & 0.003 & 0.55 & $\mathrm{~N}$ & nd & nd & \\
\hline Unknown & & & 23.0 & nd & nd & & 0.005 & d & \\
\hline Hexanal & $66-25-1$ & 100 & 23.6 & 0.015 & 3.3 & $\mathrm{~N}$ & 0.082 & 18 & $\mathrm{~N}$ \\
\hline Cyclotrisiloxane, hexamethyl- & $541-05-9$ & 222 & 25.5 & 0.012 & 1.2 & $\mathrm{~N}$ & 0.013 & 1.3 & $\mathrm{~N}$ \\
\hline Heptanal & $111-71-7$ & 114 & 28.9 & nd & nd & & 0.004 & 0.77 & $\mathrm{~N}$ \\
\hline Unknown & & & 33.8 & nd & nd & & 0.004 & d & \\
\hline Unknown Alkane & & & 37.2 & nd & nd & & 0.023 & d & \\
\hline Unknown Alkane & & & 37.5 & nd & nd & & 0.006 & d & \\
\hline Unknown & & & 42.8 & nd & nd & & 0.022 & d & \\
\hline Unknown Alkane & & & 46.2 & nd & nd & & 0.027 & $\mathrm{~d}$ & \\
\hline
\end{tabular}

\section{Data Quality Flags}

B Target compound detected in associated laboratory blank and sample

J Target compound detected above the IDL but below the EQL.

$\mathrm{N}$ Denotes tentatively identified compound

U Target compound not detected at or above the IDL.

$\mathrm{Y}$ Initial calibration and CCV was performed; however, the analyte was not part of the current operating procedure.

Footnotes
(a) TO-14 plus 26 additional target analytes.
(b) Semi-quantitative estimate calculated using concentration of closest eluting IS.
(c) WHC sample identification number.
(d) No molecular weight available for calculation.
nd Not detected 


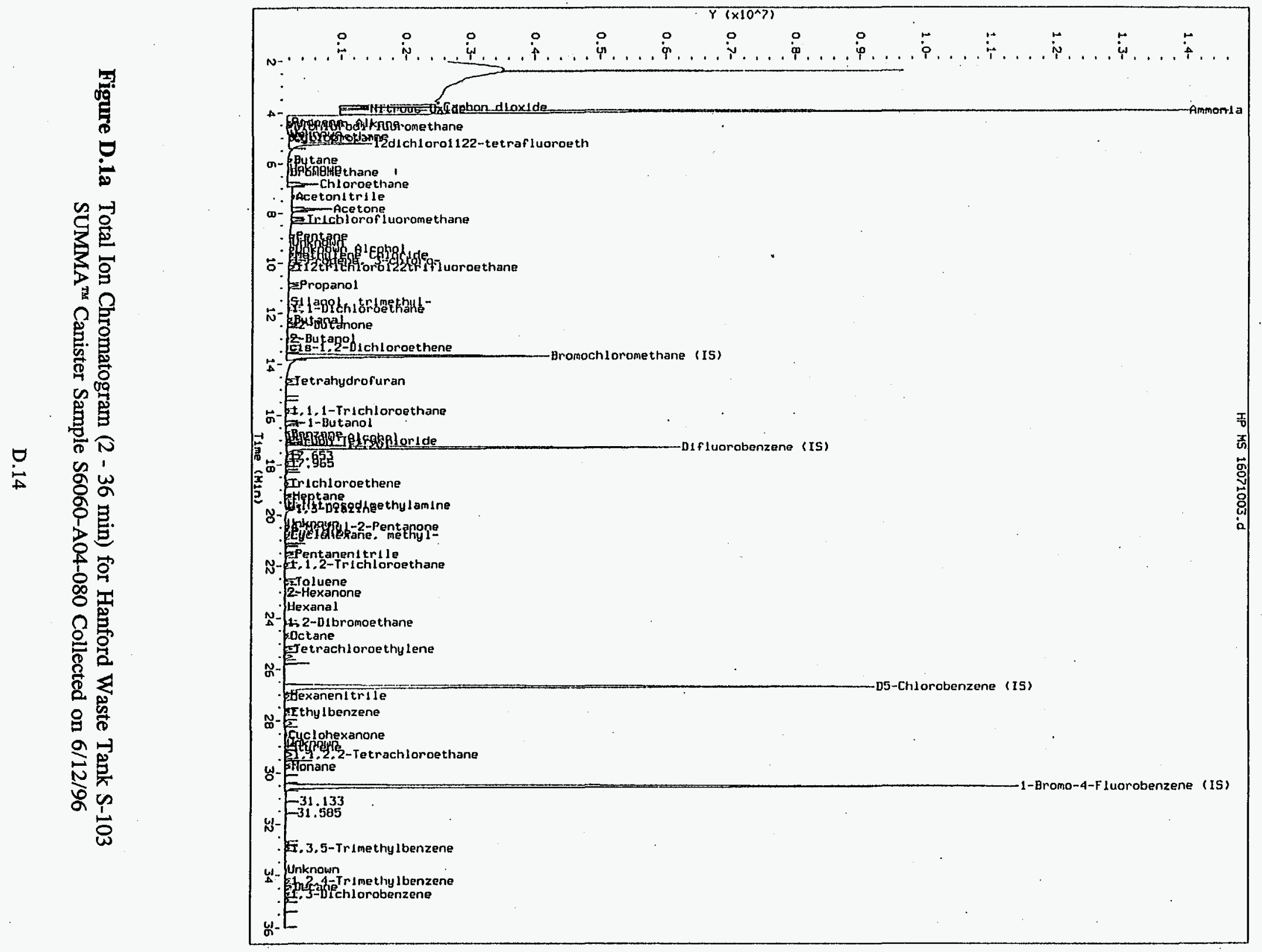




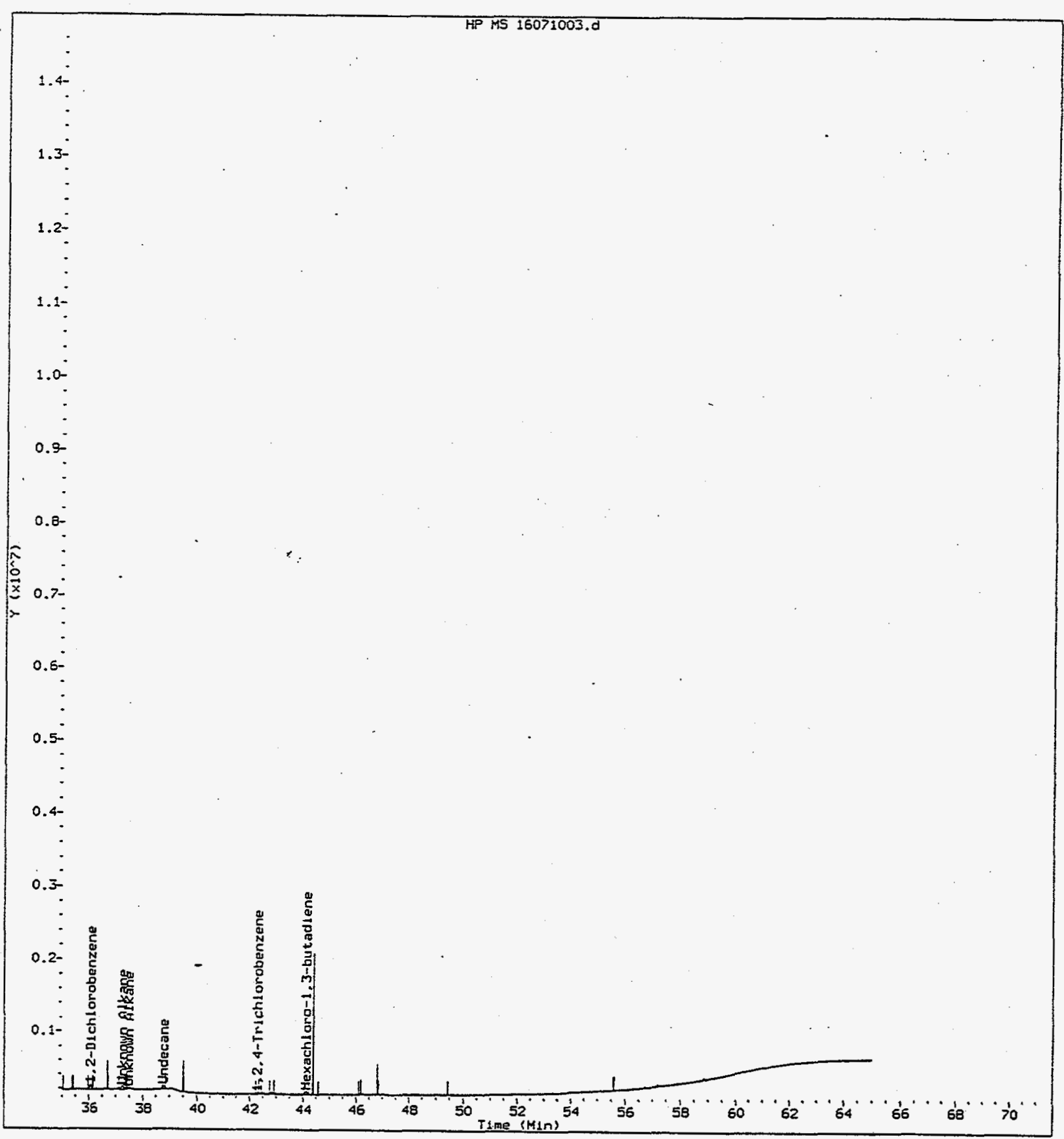

Figure D.1b Total Ion Chromatogram (36 - $70 \mathrm{~min}$ ) for Hanford Waste Tank S-103 SUMMA $^{\mathrm{mi}}$ Canister Sample S6060-A04-080 Collected on 6/12/96

D. 15 


\title{
Appendix E
}

Tank Vapor Characterization:

\author{
Organic Analytes \\ by Triple Sorbent Trap Method
}




\section{Appendix E}

\section{Tank Vapor Characterization: Organic Analytes' by Triple Sorbent Trap Method}

\section{E.1 Sampling Methodology}

Samples are collected on Supelco 300 graphite based triple sorbent traps (TST). Before field deployment, each trap is heated to $380^{\circ} \mathrm{C}$ under inert gas flow for a minimum of $60 \mathrm{~min}$. Tubes are prepared in batches with each tank sampling job constituting one batch. One tube is selected from each batch and run immediately to verify cleanliness. All remaining tubes in the batch receive equal amounts of 3 surrogate compounds (hexafluorobenzene, toluene-d8, and bromobenzene-d5). One per batch tube is run immediately to verify successful addition of surrogate spikes to that batch. Tubes are then placed in individually labeled plastic shipping tubes (Supelco $\mathrm{TD}^{3}$ ), which are sealed with gasketed end caps, thus providing a rugged, headspace-free shipping and storage medium. As a precautionary measure, sample tubes are kept in refrigerated storage before and after sampling.

\section{E.2 Analytical Procedure}

The Supelco 300 tubes were analyzed according to Pacific Northwest National Laboratory (PNNL) Technical Procedure PNL-TVP-10 (a), with the exceptions noted in Section E.4. The method employs Supelco Carbotrap ${ }^{\mathrm{TM}} 300$ traps for sample collection and preconcentration. The traps are ground-glass tubes $(11.5 \mathrm{~cm}$ long X $6 \mathrm{~mm} \mathrm{OD,} 4 \mathrm{~mm}$ ID) containing a series of sorbents arranged in order of increasing retentivity. Each trap contains $300 \mathrm{mg}$ of Carbotrap ${ }^{\mathrm{TM}} \mathrm{C}, 200 \mathrm{mg}$ of Carbotrap $^{\mathrm{TM}} \mathrm{B}$, and $125 \mathrm{mg}$ of Carbosieve $\mathrm{e}^{\mathrm{TM}} \mathrm{S}-\mathrm{III}$. The first 2 sorbents are deactivated graphite with limited sorption power for less volatile compounds. The final trapping stage, the Carbosieve ${ }^{\mathrm{TM}} \mathrm{S}-\mathrm{III}$, is a graphetized molecular sieve used to retain the most volatile components, including some permanent gases such as Freon-12. Following sample collection and addition of internal standard (IS), the traps are transferred to a Dynatherm ACEM 900 thermal desorber unit for analysis. The trap on the ACEM 900 is then desorbed by ballistic heating to $350^{\circ} \mathrm{C}$ with the sample then transferred to a smaller focusing trap. A 10:1 split is used during the transfer with $10 \%$ of the sample analyzed and the rest retained for reanalysis. The split sample collected on a second identical Carbotrap ${ }^{\mathrm{mM}} 300$ trap is used for repeat analysis on at least one sample per batch. Since the IS also follows the same path, quantitation may be performed directly on the repeat run without changing the calibration. Following desorption from the Carbotrap ${ }^{\mathrm{mM}} 300$ trap, the analyte is transferred to a long, thin focusing trap filled with the same type of trapping materials as the Carbotrap ${ }^{\mathrm{TM}} 300$ traps and in approximately the same ratios. The purpose of the focusing trap is to provide an interface to a capillary gas chromatography (GC) column, which may be thermally desorbed at a helium (He) flow rate compatible with the column and mass spectrometry (MS) interface $(1.2 \mathrm{~mL} / \mathrm{min})$. The focusing trap is

(a) Pacific Northwest Laboratory. 2/96. Determination of Volatile Organic Compounds in Hanford Waste Tank Headspace Samples Using Triple Sorbent Trap Sampling and Gas Chromatograph-Mass Spectrometer Analysis, PNL-TVP-10 (Rev. 2), PNL Technical Procedure, Richland, Washington. 
ballistically heated to thermally desorb components onto a capillary GC column. The column is subsequently temperature programmed to separate the method analytes, which are then detected by MS.

The instrument calibration mixture for the TST analysis consists of 65 compounds. These 65 compounds that are directly quantified in this analysis make up the target analyte list (these 65 compounds will be referred to as target analytes). A summary of the target analytes is provided in Table E.1. The calibration mixture is prepared in common with the mixture used for the SUMMA ${ }^{\mathrm{mm}}$ analysis (see Section D.2). The standard calibration mix was analyzed using 4 aliquot sizes ranging from $100 \mathrm{~mL}$ to $1200 \mathrm{~mL}$, and a response factor for each compound was calculated. Volumes of

Table E.1 Target Organic Analytes

\begin{tabular}{|c|c|}
\hline Dichlorodifluoromethane & $\mathrm{p} / \mathrm{m}$-Xylene \\
\hline Chloromethane & Styrene \\
\hline 1,2-Dichloro-1,1,2,2-tetrafluoroethane & 1,1,2,2-Tetrachloroethane \\
\hline Vinyl Chloride & o-Xylene \\
\hline Chloroethane & 1,3,5-Trimethylbenzene \\
\hline Trichlorofluoromethane & 1,2,4-Trimethylbenzene \\
\hline 1,1-Dichloroethene & 1,3-Dichlorobenzene \\
\hline Methylene Chloride & 1,4-Dichlorobenzene \\
\hline 1,1,2-Trichloro-1,2,2-trifluoroethane & 1,2-Dichlorobenzene \\
\hline 1,1-Dichloroethane & 1,2,4-Trichlorobenzene \\
\hline cis-1,2-Dichloroethene & Hexachloro-1,3-butadiene \\
\hline Chloroform & 2-Butanone \\
\hline 1,2-Dichloroethane & Chlorobenzene \\
\hline 1,1,1-Trichloroethane & Acetonitrile \\
\hline Benzene & Heptane \\
\hline Carbon Tetrachloride & Tetrahydrofuran \\
\hline 1,2-Dichloropropane & Pyridine \\
\hline Trichloroethene & Butanenitrile \\
\hline cis-1;3-Dichloropropene & Cyclohexane \\
\hline trans-1,3-Dichloropropene & Decane \\
\hline 1,1,2-Trichloroethane & Hexane \\
\hline Toluene & 4-Methyl-2-pentanone \\
\hline 1,2-Dibromoethane & Propanenitrile \\
\hline Tetrachloroethylene & Cyclohexanone \\
\hline Ethylbenzene & Propanol \\
\hline Butane & Acetone \\
\hline Pentane & Undecane \\
\hline Dodecane & Tridecane \\
\hline 1-Butanol & Pentanenitrile \\
\hline Octane & Hexanenitrile \\
\hline Tetradecane & Nonane \\
\hline 1-Ethyl-2-methylbenzene & Methanol $^{(a)}$ \\
\hline Ethanot ${ }^{(a)}$ & \\
\hline
\end{tabular}

(a) The low level standard is used as the EQL for these compounds. Note: Compounds shown in italics have an exceptionally high volatility. They are routinely included in the standard and are quantified, but have a restricted linear dynamic range because of the potential for trap breakthrough. 
standard added to the traps are measured by pressure difference on a SUMMA ${ }^{\mathrm{TM}}$ canister of known volume. The GC/MS response for these compounds has been previously determined to be linearly related to concentration. Instrument detection limits and EQLs for the target analytes have been developed.

\section{E.3 Quality Assurance/Quality Control}

Before the tank sample was analyzed, a diagnostic check was performed on the GC/MS instrument by running a full auto tune, as described in PNL-TVP-10. Upon satisfactory completion of the instrument diagnostic check, a blank tube was analyzed to check the cleanliness of the system. The instrument was then calibrated using a $300-\mathrm{mL}$ volume of standard gas mixture containing 65 compounds shown in Table E.1. A gas mixture containing difluorobenzene, chlorobenzene- $\mathrm{d}_{5}$, and 1,4 bromofluorobenzene was used as an IS for all calibration standard and sample analyses. Analyte responses from sample components, ISs, and standards were obtained from the extracted ion plot from their selected mass ion. A continuing calibration was generated by calculating the relative response ratios of the IS to calibration standard responses and plotting the ratios against the ratio of the calibration-standard concentration (in ppbv) to the IS concentration. Once it is determined that the relative response is linear with increasing concentration, an average response factor is calculated for each target analyte and used to determine the concentration of target compounds in each sample.

E.3.1 Quantitation Results of Target Analytes. The quantitative-analysis results for the target analytes were calculated directly from the calibration curve generated using the IS method described above and in PNL-TVP-10. The conversion from $\mathrm{ppbv}$ to $\mathrm{mg} / \mathrm{m}^{3}$ assumes standard temperature and pressure (STP) conditions of 760 torr and $273 \mathrm{~K}$ and was calculated directly from the following equation:

$$
\mathrm{mg} / \mathrm{m}^{3}=\frac{(\mathrm{ppbv} / 1000) \times \mathrm{g} \mathrm{mol} \mathrm{wt} \mathrm{of} \mathrm{compound}}{22.4 \mathrm{~L} / \mathrm{mol}}
$$

E.3.2 Identification and Quantitation of Tentatively Identified Compounds. The tentatively identified compounds (TICs) are determined by mass-spectral interpretation and comparison of the spectra with the U.S. Environmental Protection Agency (EPA)/National Institute for Standards and Technology (NIST) and WILEY Libraries, which are a part of the Hewlett-Packard $5971 / 5972$ instrument operating system. Chromatographic peaks with an area count greater than, or equal to, one-tenth of the total area count of the nearest eluting IS are tentatively identified and quantitatively estimated. The quality of the mass-spectral searches was then reviewed by the principal investigators before the identification was assigned to each chromatographic peak.

The concentration of each TIC was estimated using a relative response factor calculated using the total peak area for the nearest eluting IS. The IS peak area was used to calculate a response factor using the IS concentration in $\mathrm{mg} / \mathrm{m}^{3}$ :

$$
\text { Response Factor }=\frac{\text { IS conc. }\left(\mathrm{mg} / \mathrm{m}^{3}\right)}{\text { IS peak area }}
$$


The calculated response factor was then multiplied by the TIC peak area to give an estimated concentration for that compound.

The ppbv concentrations are calculated from $\mathrm{mg} / \mathrm{m}^{3}$ and the molecular weight of the analyte.

$$
\mathrm{TIC} \text { in } \mathrm{ppbv}=\frac{\mathrm{TIC}\left(\mathrm{mg} / \mathrm{m}^{3}\right) \times 22.4 \mathrm{~L} / \mathrm{mol} \times 1000}{\text { TIC } \mathrm{g} \mathrm{mol} \mathrm{wt}}
$$

\section{E.4 Organic Sample Results}

Eight triple sorbent traps consisting of four samples, two field blanks and two trip blanks were returned to the laboratory on June 18, 1996 under WHC COC form 100091. Samples were analyzed on June 28 and July 1, 1996.

The results from the GC/MS analysis of the tank headspace TST samples are presented in Table E.2. The results of replicate analyses on a single TST are presented in Table E.3.

Table E.2 lists the quantitative results for compounds listed as target analytes and TICs. Target compounds not listed in Table D.2 were not detected in any of the tank samples above the compound IDL. A total of 39 target analytes above the IDL and 28 TICs were detected in the tank headspace samples. Thirty-six of the target analytes and 13 TICs were observed in two or more sorbent traps. Methanol at $1.15 \mathrm{mg} / \mathrm{m}^{3}$ and toluene at $1.16 \mathrm{mg} / \mathrm{m}^{3}$ accounted for $44 \%$ of the target analytes and $28 \%$ of the total concentration identified by the analyses. The total concentration of the target analytes was $5.20 \mathrm{mg} / \mathrm{m}^{3}$ or $64 \%$ of the total concentration identified by the analyses. The predominant TICs observed in these samples were 3-methyl hexane at $0.73 \mathrm{mg} / \mathrm{m}^{3}$ and 2-methyl hexane at $0.42 \mathrm{mg} / \mathrm{m}^{3}$. The total concentration of the TICs was $2.96 \mathrm{mg} / \mathrm{m}^{3}$ or $36 \%$ of the total concentration identified by the analysis. The total concentration of all the compounds identified was $8.16 \mathrm{mg} / \mathrm{m}^{3}$.

Triple sorbent trap sample PNL 987 was analyzed in replicate for target analytes and TICs to determine analytical precision. Twenty-seven of 36 target compounds and 13 of 14 TICs had RPDs of less than $10 \%$.

The following procedural changes and observations were noted during the analysis of Tank S-103:

Methanol and ethanol are not currently included in procedure PNL-TVP-10; however, both compounds were analyzed per this method. The low level standard is used as the EQL for these compounds. Sample results are flagged with a less-than symbol $(<)$ when less than the EQL value.

Tributyl phosphate is included in the target list based on a calibration performed on January 5 and 9, 1996. The TBP was introduced onto a series of double sorbent traps as a methanolic solution standard rather than a vapor standard. This served to determine the retention time and verify the mass spectral characteristics of the compound. However, verification of the calibration acceptability was not performed because the compound is not present in the CCV. 
At present, it is not possible to prepare a gas standard from this material. The calibration information on TBP demonstrated that detectability at $0.8 \mathrm{ppbv}$ (based on $200 \mathrm{~mL}$ sample) was possible. Tributyl phosphate was not detected in the tank samples.

Very narrow air spikes (mass 32) occasionally are present in chromatograms from this period. This problem has been traced to high frequency air bursts from the surface of MS vacuum system o-rings. Attempts at permanently eliminating this problems have been unsuccessful to date, and the matter has been referred to Hewlett Packard for further investigation. It has no known impact on data quality but the spikes do appear as features on the total ion chromatogram.

At the completion of sampling, a large amount of contamination came out of the riser, requiring special handling techniques. The field blanks were badly contaminated with a group of compounds characteristic of the $3 \mathrm{M}$ adhesive tape used on previous ISVS jobs. The special handling associated with the riser contamination appears to have severely exacerbated the tape problem, which had not in any case been completely eliminated. The field blank contained numerous target compounds at levels in excess of the EQL including acetone, 2-butanone, hexane, 1-butanol, cyclohexane, heptane, 4-methyl-2-pentanone, toluene, ethylbenzene, and $\mathrm{p} / \mathrm{m}$ xylene. A number of compounds were detected in at least one of the blanks at trace levels (below EQL). Numerous TICs typical of adhesive tape emanations were also observed, including methyl cyclohexane, which provides a characteristic signature for the $3 \mathrm{M}$ tape. Two other compounds that showed up in both field blanks as well as the tank samples were isopropanol and 1-fluoro-1,1-dichloroethane. The origin of these compounds is unclear. They may be associated in some way with the decontamination operation. In addition, Field blanks, trip blanks, and samples contained minor amounts of 1-chloro, 1,1-difluoroethane. This compound has appeared persistently in most samples sent to the field in the past, including blanks. It is believed to be a fugitive refrigerant. This material is never present in tubes archived for a similar amount of time in the 326 Vapor Lab or 329 Building temporary storage. The origin of the material is unclear, but since it has shown up in trip blanks as well as field blanks, the most likely candidate is one of the refrigerators used for interim storage such as the $222 \mathrm{~S} \mathrm{lab}$. Because of the tape problem, TST tank results from this sampling activity should be generally considered as suspect.

The tank samples contained numerous target compounds at levels in excess of the EQL. Compounds that were not observed in the field blanks at levels in excess of the EQL included methanol, ethanol, acetonitrile, trichlorofluoromethane, benzene, 1,1,2 trichloroethane, styrene, and decane. A number of compounds were detected in at least one of the samples at trace levels (below EQL). Many of the target compounds observed (acetone, 2-butanone, hexane, 1-butanol, cyclohexane, heptane, 4-methyl-2-pentanone, toluene, ethylbenzene, $\mathrm{p} / \mathrm{m}$ xylene, and o-xylene) and numerous TICs including methylcyclohexane are generally ascribable to contamination during sampling and subsequent handling associated with the use of $3 \mathrm{M}$ adhesive tape as described previously.

Sample volumes for all ISVS tank samples have been corrected to STP from the $21^{\circ} \mathrm{C}$ calibration used on the sampling cart flowmeters. The correction was included in the reported data to provide seamless compatibility with past VSS data that were collected using a $0^{\circ} \mathrm{C}$ calibration. 
The TST samples were analyzed in two batches. The analytical sequence runs (batches) were as follows:

Batch 6/28/96 (file identifier 46062801.d) - S6060-A17.991, S6060-A18.992, S6060-A19.993, S6060-A20.994;

Batch 7/1/96 (file identifier 46070101.d) - S6060-A11.986, S6060-A12.987, S6060-A12.987REP, S6060-A13.988.

The following discussion provides details regarding QC criterion failures for each batch.

Batch 6/28/96:

Samples included in this batch consisted of the two field blanks and two trip blanks. The first $\mathrm{CCV}$ run was within nominal limits as specified in the procedure for all target compounds, with the exception of ethanol (22.5\%) and tridecane (37.5\%). The computer shut down just before elution of the tetradecane peak and data were not available for that compound. A second CCV was run to verify the response to tetradecane. The second CCV was generally less satisfactory, and for the purpose of calculation, the first CCV was used. This is considered to be the best approach because the second $\mathrm{CCV}$ did not produce a good quality tetradecane response as is almost always the case for daily calibration samples, and the field and trip blanks did not show the presence of significant quantities of tetradecane. Due to the absence of tetradecane CCV data, tetradecane was quantified using the average relative response factor value from the initial calibration. The continuing calibration blank (CCB) contained trace amounts (below EQL) of methylene chloride and tetradecane. The CCB was otherwise clean.

\section{Batch 7/1/96:}

Samples included in this batch consisted of the three tanks samples and one repeat analysis of a tank sample. The first CCV run was outside nominal limits as specified in the procedure for all target compounds, and a second CCV was run. The second CCV was within nominal limits for all compounds with the exception of 1-butanol $(31.1 \%)$, trichloroethene $(27.6 \%)$, cis-1,3-dichloropropene (25.5\%), 1,2-dibromoethane (30.8\%), cyclohexanone $(41.7 \%)$, and $1,1,2,2$ tetrachloroethane $(44.9 \%)$. The CCB contained trace amounts (below EQL) of methylene chloride, toluene, and tetradecane. The CCB was otherwise clean. 
Table E.2. Positively Identified and Quantitated Target Analytes ${ }^{(a)}$ and Tentatively Identifed Compounds and Estimated Concentrations ${ }^{(b)}$ for Triple Sorbent Traps Collected from the Headspace of Tank S-103 on 6/12/96

\begin{tabular}{|c|c|c|c|c|c|c|c|c|c|c|c|c|c|c|c|c|}
\hline \multirow[b]{2}{*}{ Target Analytes ${ }^{(a)}$} & \multirow[b]{2}{*}{ CAS } & \multirow[b]{2}{*}{$\mathrm{MW}$} & \multirow{2}{*}{$\begin{array}{c}\text { Ret } \\
\text { Time }\end{array}$} & \multicolumn{3}{|c|}{ S6060-A11.986 $6^{(\mathrm{c})}$ ISVS } & \multicolumn{3}{|c|}{ S6060-A12.987 $7^{(\mathrm{c})(\mathrm{d})}$ ISVS } & \multicolumn{3}{|c|}{ S6060-A13.988 ${ }^{(\mathrm{c})}$ ISVS } & \multicolumn{2}{|c|}{$\begin{array}{l}\text { Mean and } \\
\text { Standard Deviation }\end{array}$} & \multirow[b]{2}{*}{ (ppbv) } & \multirow[b]{2}{*}{ St. Dev. } \\
\hline & & & & $\left(\mathrm{mg} / \mathrm{m}^{3}\right)$ & (ppbv) & Flag & $\left(\mathrm{mg} / \mathrm{m}^{3}\right)$ & (ppbv) & Flag & $\left(\mathrm{mg} / \mathrm{m}^{3}\right)$ & (ppbv) & Flag & $\left(\mathrm{mg} / \mathrm{m}^{3}\right)$ & St. Dev. & & \\
\hline Methanol & $67-56-1$ & 32 & 10.1 & 1.430 & 1000 & $\mathrm{Y}$ & 0.888 & 621 & $\mathrm{Y}$ & 1.143 & 799 & $\bar{Y}$ & 1.154 & 0.271 & 807 & 190 \\
\hline Butane & $106-97-8$ & 58 & 10.8 & 0.022 & 8.6 & $\mathbf{J}$ & 0.018 & 6.9 & $\mathbf{J}$ & 0.018 & 6.9 & $\mathbf{J}$ & 0.019 & 0.002 & 7.4 & 0.97 \\
\hline Ethanol & $64-17-5$ & 46 & 12.6 & 0.293 & 143 & $\mathrm{Y}$ & $<0.275$ & $<133$ & $\mathbf{Y}$ & 0.353 & 171 & $\mathrm{Y}$ & 0.323 & e & 157 & $\mathrm{e}$ \\
\hline Acetonitrile & $75-05-8$ & 41 & 13.1 & 0.048 & 26 & & 0.033 & 18 & $\mathbf{J}$ & 0.044 & 24 & & 0.042 & 0.007 & 23 & 4.0 \\
\hline Acetone & $67-64-1$ & 58 & 13.7 & 0.319 & 123 & & 0.270 & 104 & & 0.283 & 109 & & 0.291 & 0.025 & 112 & 9.6 \\
\hline Trichlorofluoromethane & $75-69-4$ & 137 & 14.2 & 0.055 & 9.0 & & 0.057 & 9.2 & & 0.060 & 9.7 & & 0.057 & 0.002 & 9.3 & 0.37 \\
\hline Pentane & $109-66-0$ & 72 & 15.0 & 0.006 & 2.0 & $\mathbf{J}$ & 0.007 & 2.2 & $\mathbf{J}$ & 0.005 & 1.5 & $\mathbf{J}$ & 0.006 & 0.001 & 1.9 & 0.36 \\
\hline 1,1-Dichloroethene & $75-35-4$ & 97 & 15.6 & 0.007 & 1.7 & $J$ & 0.002 & 0.49 & $\mathrm{U}$ & 0.002 & 0.52 & $\mathrm{U}$ & e & e & $\mathrm{e}$ & $\mathrm{e}$ \\
\hline Methylene Chloride & $75-09-2$ & 85 & 15.8 & 0.087 & 23 & $\mathrm{~J}$ & 0.052 & 14 & $\mathrm{~J}$ & 0.070 & 19 & $\mathbf{J}$ & 0.070 & 0.018 & 18 & 4.6 \\
\hline 112trichloro 122 trifluoroethane & $76-13-1$ & 187 & 16.3 & 0.006 & 0.69 & $\mathbf{J}$ & 0.014 & 1.7 & $\mathrm{~J}$ & 0.007 & 0.81 & $\mathbf{J}$ & 0.009 & 0.004 & 1.1 & 0.53 \\
\hline Propanol & $71-23-8$ & 60 & 17.1 & 0.055 & 21 & $\mathrm{~J}$ & 0.044 & 16 & $\mathbf{J}$ & 0.047 & 17 & $\mathbf{J}$ & 0.049 & 0.006 & 18 & 2.2 \\
\hline 2-Butanone & $78-93-3$ & 72 & 18.6 & 0.054 & 17 & & 0.052 & $\cdot 16$ & & 0.050 & 16 & & 0.052 & 0.002 & 16 & 0.62 \\
\hline Hexane & $110-54-3$ & 86 & 19.9 & 0.073 & 19 & & 0.071 & 19 & & 0.072 & 19 & & 0.072 & 0.001 & 19 & 0.24 \\
\hline Tetrahydrofuran & 109-99-9 & 72 & 20.8 & 0.008 & 2.6 & $\mathrm{~J}$ & 0.011 & 3.4 & $\mathrm{~J}$ & 0.008 & 2.5 & $\mathbf{J}$ & 0.009 & $0.002^{\circ}$ & 2.8 & 0.48 \\
\hline 1,1,1-Trichloroethane & $71-55-6$ & 133 & 22.0 & 0.014 & 2.3 & $\mathrm{~J}$ & 0.016 & 2.7 & $\mathrm{~J}$ & 0.025 & 4.2 & $\mathbf{J}$ & 0.018 & 0.006 & 3.1 & 1.0 \\
\hline 1-Butanol & $71-36-3$ & 74 & 22.3 & 0.305 & 92 & & 0.290 & 88 & & 0.245 & 74 & & 0.280 & 0.031 & 85 & 9.3 \\
\hline Cyclohexane & $110-82-7$ & 84 & 23.4 & 0.115 & 31 & & 0.112 & 30 & & 0.108 & 29 & & 0.112 & 0.004 & 30 & 0.96 \\
\hline Trichloroethene & $79-01-6$ & 131 & 24.8 & 0.004 & 0.73 & $\mathbf{J}$ & 0.004 & 0.64 & $\mathrm{U}$ & 0.004 & 0.68 & $\mathrm{U}$ & e & e & $\mathrm{e}$ & $\mathrm{e}$ \\
\hline Heptane & $142-82-5$ & 100 & 25.2 & 0.740 & 165 & & 0.655 & 146 & & 0.660 & 148 & & $0.685^{\circ}$ & 0.047 & 153 & 11 \\
\hline 4-Methyl-2-Pentanone & $108-10-1$ & 100 & 26.4 & 0.034 & 7.7 & & 0.030 & 6.7 & & 0.013 & 2.9 & $\mathbf{J}$ & 0.026 & 0.011 & 5.7 & 2.5 \\
\hline Pyridine & $110-86-1$ & 79 & 26.6 & 0.069 & 19 & $\mathrm{~J}$ & 0.053 & 15 & $\mathrm{~J}$ & 0.053 & 15 & $\mathbf{J}$ & 0.058 & 0.009 & 17 & 2.5 \\
\hline Pentanenitrile & $110-59-8$ & 83 & 27.4 & 0.002 & 0.60 & J & 0.002 & 0.57 & $\mathrm{~J}$ & 0.002 & 0.53 & $\mathbf{J}$ & 0.002 & 0.000 & 0.57 & 0.035 \\
\hline 1,1,2-Trichloroethane & $79-00-5$ & 133 & 27.9 & 0.033 & 5.5 & & 0.002 & 0.27 & $\mathrm{U}$ & 0.002 & 0.29 & $\mathrm{U}$ & e & e & e & e \\
\hline Toluene & $108-88-3$ & 92 & 28.5 & 1.175 & 286 & & 1.078 & - 262 & & 1.225 & 298 & & 1.159 & 0.075 & 282 & 18 \\
\hline Tetrachloroethylene & $127-18-4$ & 166 & 31.1 & 0.025 & 3.4 & J & 0.027 & 3.6 & & 0.020 & 2.6 & J & 0.024 & 0.004 & 3.2 & 0.53 \\
\hline Hexanenitrile & $628-73-9$ & 97 & 32.8 & 0.007 & 1.7 & J & 0.005 & 1.0 & $\mathrm{~J}$ & 0.651 & 150 & & 0.221 & 0.372 & 51 & 86 \\
\hline Ethylbenzene & $100-41-4$ & 106 & 33.5 & 0.049 & 10 & & 0.043 & 9.1 & & 0.036 & 7.5 & & 0.043 & 0.007 & 9.0 & 1.4 \\
\hline $\mathrm{p} / \mathrm{m}$-Xylene & $106-42-3$ & 106 & 33.9 & 0.172 & 36 & & 0.154 & 33 & & 0.136 & 29 & & 0.154 & 0.018 & 32 & 3.7 \\
\hline
\end{tabular}


Table E.2. Positively Identified and Quantitated Target Analytes ${ }^{(a)}$ and Tentatively Identifed Compounds and Estimated Concentrations ${ }^{(b)}$ for Triple Sorbent Traps Collected from the Headspace of Tank S-103 on 6/12/96

\begin{tabular}{|c|c|c|c|c|c|c|c|c|c|c|c|c|c|c|c|c|}
\hline \multirow[b]{2}{*}{ Target Analytes ${ }^{(\mathfrak{a})}$} & \multirow[b]{2}{*}{ CAS } & \multirow[b]{2}{*}{ MW } & \multirow{2}{*}{$\begin{array}{l}\text { Ret } \\
\text { Time }\end{array}$} & \multicolumn{3}{|c|}{ S6060-A11.986 ${ }^{(\mathrm{c})}$ ISVS } & \multicolumn{3}{|c|}{ S6060-A12.987 ${ }^{(c)(d)}$ ISVS } & \multicolumn{3}{|c|}{ S6060-A13.988 ${ }^{(\mathrm{c})}$ ISVS } & \multicolumn{2}{|c|}{$\begin{array}{l}\text { Mean and } \\
\text { Standard Deviation }\end{array}$} & \multirow[b]{2}{*}{ (ppbv) } & \multirow[b]{2}{*}{ St. Dev. } \\
\hline & & & & $\left(\mathrm{mg} / \mathrm{m}^{3}\right)$ & (ppbv) & Flag & $\left(\mathrm{mg} / \mathrm{m}^{3}\right)$ & (ppbv) & Flag & $\left(\mathrm{mg} / \mathrm{m}^{3}\right)$ & (ppbv) & Flag & $\left(\mathrm{mg} / \mathrm{m}^{3}\right)$ & St. Dev. & & \\
\hline Styrene & $100-42-5$ & 104 & 34.8 & 0.035 & 7.6 & & 0.031 & 6.7 & & 0.036 & 7.7 & & 0.034 & 0.002 & 7.3 & 0.54 \\
\hline o-Xylene & $95-47-6$ & 106 & 35.1 & 0.052 & 11 & & 0.047 & 9.9 & & 0.033 & 7.0 & & 0.044 & 0.010 & 9.3 & 2.1 \\
\hline Nonane & $111-84-2$ & 128 & 35.5 & 0.010 & 1.8 & $\mathrm{~J}$ & 0.009 & 1.5 & $\mathbf{J}$ & 0.007 & 1.2 & $\mathrm{~J}$ & 0.009 & 0.002 & 1.5 & 0.27 \\
\hline 1-Ethyl-2-methyl benzene & $611-14-3$ & 120 & 38.5 & 0.008 & 1.5 & $\mathbf{J}$ & 0.007 & 1.3 & $\mathbf{J}$ & 0.007 & 1.3 & $\mathrm{~J}$ & 0.007 & 0.001 & 1.4 & 0.11 \\
\hline 1,3,5-Trimethylbenzene & $108-67-8$ & 120 & 38.7 & 0.007 & 1.2 & $\mathrm{~J}$ & 0.007 & 1.3 & $\mathbf{J}$ & 0.007 & 1.4 & $\mathrm{~J}$ & 0.007 & 0.000 & 1.3 & 0.080 \\
\hline 1,2,4-Trimethylbenzene & $95-63-6$ & 120 & 40.0 & 0.026 & 4.9 & & 0.023 & 4.2 & $\mathbf{J}$ & 0.024 & 4.4 & $\mathbf{J}$ & 0.024 & 0.002 & 4.5 & 0.34 \\
\hline Decane & $124-18-5$ & 142 & 40.2 & 0.043 & 6.8 & & 0.029 & 4.6 & $\mathbf{J}$ & 0.027 & 4.2 & $\mathrm{~J}$ & 0.033 & 0.009 & 5.2 & 1.4 \\
\hline Undecane & $1120-21-4$ & 156 & 44.5 & 0.020 & 2.9 & $\mathrm{~J}$ & 0.015 & 2.2 & $\mathbf{J}$ & 0.011 & 1.6 & $J$ & 0.016 & 0.005 & 2.2 & 0.68 \\
\hline Tridecane & $629-50-5$ & 184 & 52.3 & 0.087 & 11 & $\mathbf{J}$ & 0.076 & 9.2 & $\mathbf{J}$ & 0.060 & 7.3 & $\mathrm{U}$ & 0.082 & e & 9.9 & e \\
\hline Tetradecane & $629-59-4$ & 198 & 55.8 & 0.041 & 4.6 & $\mathrm{~J}$ & 0.030 & 3.4 & J & 0.050 & 5.7 & $\mathrm{~J}$ & 0.040 & 0.010 & 4.5 & 1.1 \\
\hline
\end{tabular}

Tentatively

$\infty$ Identified Compounds ${ }^{(\mathbf{b})}$

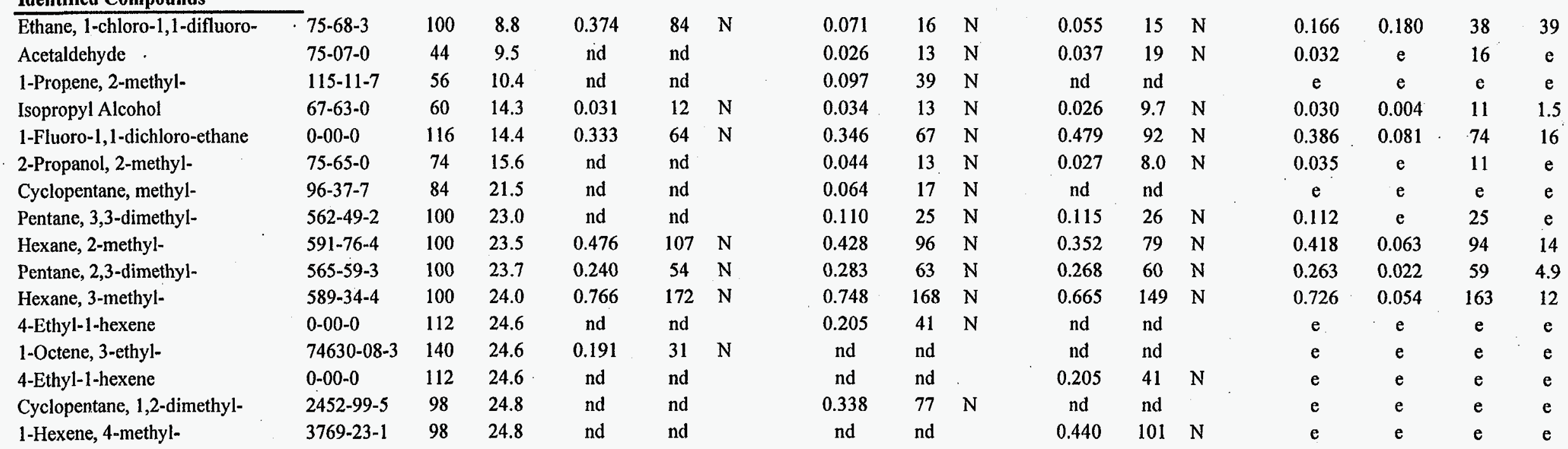


Table E.2. Positively Identified and Quantitated Target Analytes ${ }^{(a)}$ and Tentatively Identifed Compounds and Estimated Concentrations ${ }^{(b)}$ for Triple Sorbent Traps Collected from the Headspace of Tank S-103 on 6/12/96

\begin{tabular}{|c|c|c|c|c|c|c|c|c|c|c|c|c|}
\hline \multirow{2}{*}{$\begin{array}{l}\text { Tentatively } \\
\text { Identified Compounds }{ }^{(b)}\end{array}$} & \multirow[b]{2}{*}{ CAS } & \multirow[b]{2}{*}{ MW } & \multirow{2}{*}{$\begin{array}{l}\text { Ret } \\
\text { Time }\end{array}$} & \multicolumn{3}{|c|}{ S6060-A11.986 ${ }^{(\mathrm{c})}$ ISVS } & \multicolumn{3}{|c|}{ S6060-A12.987 $7^{(\mathrm{c})(\mathrm{d})}$ ISVS } & \multicolumn{3}{|c|}{ S6060-A13.988 ${ }^{(\mathrm{c})}$ ISVS } \\
\hline & & & & $\left(\mathrm{mg} / \mathrm{m}^{3}\right)$ & (ppbv) & Flag & $\left(\mathrm{mg} / \mathrm{m}^{3}\right)$ & (ppbv) & Flag & $\left(\mathrm{mg} / \mathrm{m}^{3}\right)$ & (ppbv) & Flag \\
\hline Cyclohexane, methyl- & $108-87-2$ & 98 & 26.8 & 1.221 & 279 & $\mathrm{~N}$ & nd & nd & & nd & nd & \\
\hline Hexane, 2,4-dimethyl- & $589-43-5$ & 114 & 27.1 & 0.154 & 30 & $\mathrm{~N}$ & 0.169 & 33 & $\mathrm{~N}$ & 0.176 & 35 & $N$ \\
\hline Cyclopentane, 1,2,4-trimethyl- & $2815-58-9$ & 112 & 27.7 & 0.169 & 34 & $\mathrm{~N}$ & 0.188 & 38 & $\mathrm{~N}$ & 0.194 & 39 & $\mathrm{~N}$ \\
\hline Heptane, 2-methyl- & $592-27-8$ & 114 & 28.8 & 0.140 & 27 & $\mathrm{~N}$ & 0.130 & 26 & $\mathrm{~N}$ & 0.124 & 24 & $\mathrm{~N}$ \\
\hline Cyclotrisiloxane, hexamethyl- & $541-05-9$ & 222 & 31.2 & 0.283 & 29 & $\mathrm{~N}$ & nd & nd & & nd & nd & \\
\hline Hexane, 2,3,5-trimethyl- & $1069-53-0$ & 128 & 31.6 & 0.115 & 20 & $\mathrm{~N}$ & nd & nd & & nd & nd & \\
\hline Heptane, 2,4-dimethyl- & $2213-23-2$ & 128 & 31.8 & 0.418 & 73 & $\mathrm{~N}$ & 0.371 & 65 & $\mathrm{~N}$ & 0.140 & 24 & $\mathrm{~N}$ \\
\hline Cyclotetrasiloxane, octamethyl- & $556-67-2$ & 296 & 39.5 & 0.812 & 61 & $\mathrm{~N}$ & nd & nd & & nd & nd & \\
\hline Unknown C12 Alkane & & 170 & 43.0 & 0.625 & 82 & $\mathbf{N}$ & 0.524 & 69 & & 0.152 & 19 & \\
\hline Unknown C12 Alkane & & 170 & 43.2 & 0.304 & 40 & $\mathrm{~N}$ & 0.288 & 38 & & 0.129 & 17 & \\
\hline
\end{tabular}

Mean and

Standard Deviation

\begin{tabular}{cccc}
$\left(\mathrm{mg} / \mathrm{m}^{3}\right)$ & St. Dev. & (ppbv) & St. Dev. \\
\hline $\mathrm{e}$ & $\mathrm{e}$ & $\mathrm{e}$ & $\mathrm{e}$
\end{tabular}

$\begin{array}{cccc}\mathrm{e} & \mathrm{e} & \mathrm{e} & \mathrm{e} \\ 0.167 & 0.011 & 33 & 2.2 \\ 0.184 & 0.013 & 37 & 2.5 \\ 0.131 & 0.008 & 26 & 1.5 \\ \mathrm{e} & \mathrm{e} & \mathrm{e} & \mathrm{e} \\ \mathrm{e} & \mathrm{e} & \mathrm{e} & \mathrm{e} \\ 0.309 & 0.149 & 54 & 26 \\ \mathrm{e} & \mathrm{e} & \mathrm{e} & \mathrm{e} \\ 0.434 & 0.249 & 57 & 34 \\ 0.240 & 0.097 & 32 & 13\end{array}$

Data Quality Flags

J Target compound detected above the IDL but below the EQL.

6 N Denotes tentatively identified compound

U Target compound not detected at or above the IDL.

$\mathrm{Y}$ Initial calibration and CCV was performed; however, the analyte was not part of the current operating procedure.

\section{Footnotes}

(a) Detected target analytes.

(b) Semi-quantitative estimate calculated using concentration of closest eluting IS.

(e) WHC sample identification number.

(d) Replicates of this sample are found in Table D.3.

(e) Mean and/or standard deviation are not meaningful for this analyte.

(f) No molecular weight available for calculation.

nd Not detected 
Table E.3. Positively Identified and Quantitated Target Analytes ${ }^{(a)}$ and Tentatively Identifed Compounds and Estimated Concentrations ${ }^{(b)}$ of Replicate Analysis of a Single Triple Sorbent Trap Collected from the Headspace of Tank S-103 on 6/12/96

\begin{tabular}{|c|c|c|c|c|c|c|c|c|c|c|}
\hline \multirow[b]{2}{*}{ Target Analytes ${ }^{(a)}$} & \multirow[b]{2}{*}{ CAS } & \multirow[b]{2}{*}{ MW } & \multirow{2}{*}{$\begin{array}{l}\text { Ret } \\
\text { Time }\end{array}$} & \multicolumn{6}{|c|}{ S6060-A12.987 $7^{(\mathrm{c})}$ ISVS } & \multirow{2}{*}{$\begin{array}{c}\begin{array}{c}\text { Relative Percent } \\
\text { Difference }\end{array} \\
\%\end{array}$} \\
\hline & & & & $\left(\mathrm{mg} / \mathrm{m}^{3}\right)$ & $\overline{\text { (ppbv) }}$ & Flag & $\left(\mathrm{mg} / \mathrm{m}^{3}\right)$ & $\overline{\text { (ppbv) }}$ & Flag & \\
\hline Methanol & $67-56-1$ & 32 & 10.1 & 0.888 & 621 & $\bar{Y}$ & 0.916 & 640 & $\mathrm{Y}$ & 3 \\
\hline Butane & $106-97-8$ & 58 & 10.8 & 0.018 & 6.9 & $J$ & 0.019 & 7.1 & $\mathrm{~J}$ & 4 \\
\hline Ethanol & $64-17-5$ & 46 & 12.6 & $<0.275$ & $<133$ & $\mathrm{Y}$ & $<0.275$ & $<133$ & $Y$ & \\
\hline Acetonitrile & $75-05-8$ & 41 & 13.1 & 0.033 & 18 & $\mathrm{~J}$ & 0.036 & 20 & & 8 \\
\hline Acetone & $67-64-1$ & 58 & 13.7 & 0.270 & 104 & & 0.256 & 99 & & 5 \\
\hline Trichlorofluoromethane & $75-69-4$ & 137 & 14.2 & 0.057 & 9.2 & & 0.056 & 9.1 & & 1 \\
\hline Pentane & $109-66-0$ & 72 & 15.0 & 0.007 & 2.2 & J & 0.007 & 2.1 & J & 4 \\
\hline Methylene Chloride & $75-09-2$ & 85 & 15.8 & 0.052 & 14 & $\mathbf{J}$ & 0.060 & 16 & $\mathbf{J}$ & 14 \\
\hline 112 trichloro122trifluoroethane & $76-13-1$ & 187 & 16.3 & 0.014 & 1.7 & $\mathbf{J}$ & 0.012 & 1.5 & J & 12 \\
\hline Propanol & $71-23-8$ & 60 & 17.1 & 0.044 & 16 & J & 0.041 & 15 & $\mathbf{J}$ & 8 \\
\hline 2-Butanone & $78-93-3$ & 72 & 18.6 & 0.052 & 16 & & 0.047 & 15 & & 10 \\
\hline Hexane & $110-54-3$ & 86 & 19.9 & 0.071 & 19 & & 0.071 & 19 & & 0 \\
\hline Tetrahydrofuran & 109-99-9 & 72 & 20.8 & 0.011 & 3.4 & $\mathrm{~J}$ & 0.009 & 2.8 & $\mathrm{~J}$ & 17 \\
\hline Benzene & $71-43-2$ & 78 & 22.8 & 0.013 & 3.6 & $\mathrm{~J}$ & 0.013 & 3.8 & $\mathrm{~J}$ & 5 \\
\hline 1,1,1-Trichloroethane & $71-55-6$ & 133 & 22.0 & 0.016 & 2.7 & $\mathbf{J}$ & 0.016 & 2.7 & $\mathrm{~J}$ & 1 \\
\hline 1-Butanol & $71-36-3$ & 74 & 22.3 & 0.290 & 88 & & 0.276 & $83^{\circ}$ & & 5 \\
\hline Cyclohexane & $110-82-7$ & 84 & 23.4 & 0.112 & 30 & & 0.109 & 29 & & 3 \\
\hline Heptane & $142-82-5$ & 100 & 25.2 & 0.655 & 146 & & 0.654 & 146 & & 0 \\
\hline 4-Methyl-2-Pentanone & $108-10-1$ & 100 & 26.4 & 0.030 & 6.7 & & 0.020 & 4.5 & $\mathrm{~J}$ & 40 \\
\hline Pyridine & $110-86-1$ & 79 & 26.6 & 0.053 & 15 & $\mathbf{J}$ & 0.053 & 15 & $\mathrm{~J}$ & 1 \\
\hline Pentanenitrile & $110-59-8$ & 83 & 27.4 & 0.002 & 0.57 & $\mathbf{J}$ & 0.037 & 9.9 & & 178 \\
\hline Toluene & $108-88-3$ & 92 & 28.5 & 1.078 & 262 & & 1.081 & 263 & & 0 \\
\hline Tetrachloroethylene & $127-18-4$ & 166 & 31.1 & 0.027 & 3.6 & & 0.026 & 3.5 & & 3 \\
\hline Hexanenitrile & $628-73-9$ & 97 & 32.8 & 0.005 & 1.0 & $\mathbf{J}$ & 0.005 & 1.1 & J & 6 \\
\hline Ethylbenzene & $100-41-4$ & 106 & 33.5 & 0.043 & 9.1 & & 0.042 & $8: 8$ & & 4 \\
\hline $\mathrm{p} / \mathrm{m}$-Xylene & $106-42-3$ & 106 & 33.9 & 0.154 & 33 & & 0.154 & 33 & & 0 \\
\hline Styrene & $100-42-5$ & 104 & 34.8 & 0.031 & 6.7 & & 0.031 & 6.6 & & 1 \\
\hline o-Xylene & $95-47-6$ & 106 & 35.1 & 0.047 & 9.9 & & 0.046 & 9.8 & & 1 \\
\hline Nonane & $111-84-2$ & 128 & 35.5 & 0.009 & 1.5 & $\mathrm{~J}$ & 0.008 & 1.5 & $\mathrm{~J}$ & 6 \\
\hline 1-Ethyl-2-methyl benzene & $611-14-3$ & 120 & 38.5 & 0.007 & 1.3 & J & 0.006 & 1.2 & $\mathrm{~J}$ & 9 \\
\hline 1,3,5-Trimethylbenzene & $108-67-8$ & 120 & 38.7 & 0.007 & 1.3 & 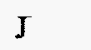 & 0.007 & 1.2 & $\mathrm{~J}$ & 4 \\
\hline 1,2,4-Trimethylbenzene & $95-63-6$ & 120 & 40.0 & 0.023 & 4.2 & J & 0.022 & 4.2 & $\mathrm{~J}$ & 1 \\
\hline Decane & $124-18-5$ & 142 & 40.2 & 0.029 & 4.6 & $\mathrm{~J}$ & 0.028 & 4.5 & $\mathrm{~J}$ & 3 \\
\hline Undecane & $1120-21-4$ & 156 & 44.5 & 0.015 & 2.2 & $\mathrm{~J}$ & 0.013 & 1.9 & $\mathrm{~J}$ & 15 \\
\hline Tridecane & $629-50-5$ & 184 & 52.3 & 0.076 & 9.2 & $\mathrm{~J}$ & 0.066 & 8.0 & $\mathrm{~J}$ & 14 \\
\hline Tetradecane & $629-59-4$ & 198 & 55.8 & 0.030 & 3.4 & $\mathrm{~J}$ & 0.031 & 3.5 & $\mathrm{~J}$ & 3 \\
\hline
\end{tabular}

\section{Tentatively}

Identified Compounds ${ }^{(b)}$

\begin{tabular}{|c|c|c|c|c|c|c|c|c|c|c|}
\hline Ethane, 1-chloro-1,1-difluoro- & $75-68-3$ & 100 & 8.8 & 0.071 & 16 & $\mathrm{~N}$ & 0.061 & 17 & $\mathrm{~N}$ & 14 \\
\hline Acetaldehyde & $75-07-0$ & 44 & 9.5 & 0.026 & 13 & $\mathrm{~N}$ & 0.025 & 13 & $\mathrm{~N}$ & 2 \\
\hline 1-Propene, 2-methyl- & $115-11-7$ & 56 & 10.4 & 0.097 & 39 & N & nd & nd & & \\
\hline Isopropyl Alcohol & $67-63-0$ & 60 & 14.3 & 0.034 & 13 & $\mathrm{~N}$ & 0.034 & 13 & $\mathrm{~N}$ & 1 \\
\hline 1-Fluoro-1,1-dichloro-ethane & $0-00-0$ & 116 & 14.4 & 0.346 & 67 & $\mathrm{~N}$ & 0.340 & 66 & $\mathrm{~N}$ & 2 \\
\hline 2-Propanol, 2-methyl- & $75-65-0$ & 74 & 15.6 & 0.044 & 13 & $\mathrm{~N}$ & 0.043 & 13 & $\mathrm{~N}$ & 3 \\
\hline Pentane, 3-methyl- & $96-14-0$ & 86 & 19.1 & nd & nd & & 0.062 & 16 & $\mathrm{~N}$ & \\
\hline Cyclopentane, methyl- & $96-37-7$ & 84 & 21.5 & 0.064 & 17 & $\mathrm{~N}$ & nd & nd & & \\
\hline Pentane, 3,3-dimethyl- & $562-49-2$ & 100 & 23.0 & 0.110 & 25 & $\mathrm{~N}$ & 0.107 & 24 & $\mathrm{~N}$ & 3 \\
\hline Hexane, 2-methyl- & $591-76-4$ & 100 & 23.5 & 0.428 & 96 & $\mathbf{N}$ & 0.433 & 97 & $\mathrm{~N}$ & 1 \\
\hline Pentane, 2,3-dimethyl- & $565-59-3$ & 100 & 23.7 & 0.283 & 63 & $\mathrm{~N}$ & 0.279 & 62 & $\mathbf{N}$ & 1 \\
\hline Hexane, 3-methyl- & $589-34-4$ & 100 & 24.0 & 0.748 & 168 & $\mathrm{~N}$ & 0.733 & 164 & $\mathrm{~N}$ & 2 \\
\hline 4-Ethyl-1-hexene & $0-00-0$ & 112 & 24.6 & 0.205 & 41 & $\mathrm{~N}$ & nd & nd & & \\
\hline
\end{tabular}


Table E.3. Positively Identified and Quantitated Target Analytes ${ }^{(\mathrm{a})}$ and Tentatively Identifed Compounds and Estimated Concentrations ${ }^{(\mathrm{b})}$ of Replicate Analysis of a Single Triple Sorbent Trap Collected from the Headspace of Tank S-103 on 6/12/96

Tentatively

Identified Compounds ${ }^{(b)}$

Hexane, 2,3-dimethyl-

Cyclopentane, 1,2-dimethyl-, cis-

Cyclopentane, 1,2-dimethyl-

Cyclohexane, methyl-

Hexane, 2,4-dimethyl-

Cyclopentane, ethyl-

Cyclopentane, 1,2,4-trimethyl-

Heptane, 2-methyl-

Heptane, 2,4-dimethyl-

Unknown C12 Alkane

Unknown C12 Alkane

\section{Data Quality Flags}

J Target compound detected above the IDL but below the EQL.

$N$ Denotes tentatively identified compound

$\mathrm{U}$ Target compound not detected at or above the IDL.

Y Initial calibration and CCV was performed; however, the analyte was not part of the current operating procedure.

\section{Footnotes}
(a) Detected target analytes.
(b) Semi-quantitative estimate calculated using concentration of closest eluting IS.
(c) WHC sample identification number.
(d) Relative percent differences (RPDs) based on $\mathrm{mg} / \mathrm{m} 3$ values.

\author{
nd Not detected
}

Relative Percent Difference $^{(d)}$

$\%$

0

0

$\begin{array}{llllll}0.169 & 33 & \mathrm{~N} & 0.169 & 33 & \mathrm{~N}\end{array}$

$\begin{array}{llll}\text { nd nd } & 0.105 & 24 & \mathrm{~N}\end{array}$

$0.188 \quad 38 \quad \mathrm{~N}$ nd nd

0.130 . $26 \quad \mathrm{~N} \quad 0.129 \quad 25 \mathrm{~N}$

$\begin{array}{lllllll}0.371 & 65 & \mathrm{~N} & 0.369 & 64 & \mathrm{~N}\end{array}$

$\begin{array}{llllll}0.524 & 69 & \mathrm{~N} & 0.508 & 67 & \mathrm{~N}\end{array}$

$\begin{array}{llllll}0.288 & 38 & \mathrm{~N} & 0.243 & 32 & \mathrm{~N}\end{array}$

1

3

17 


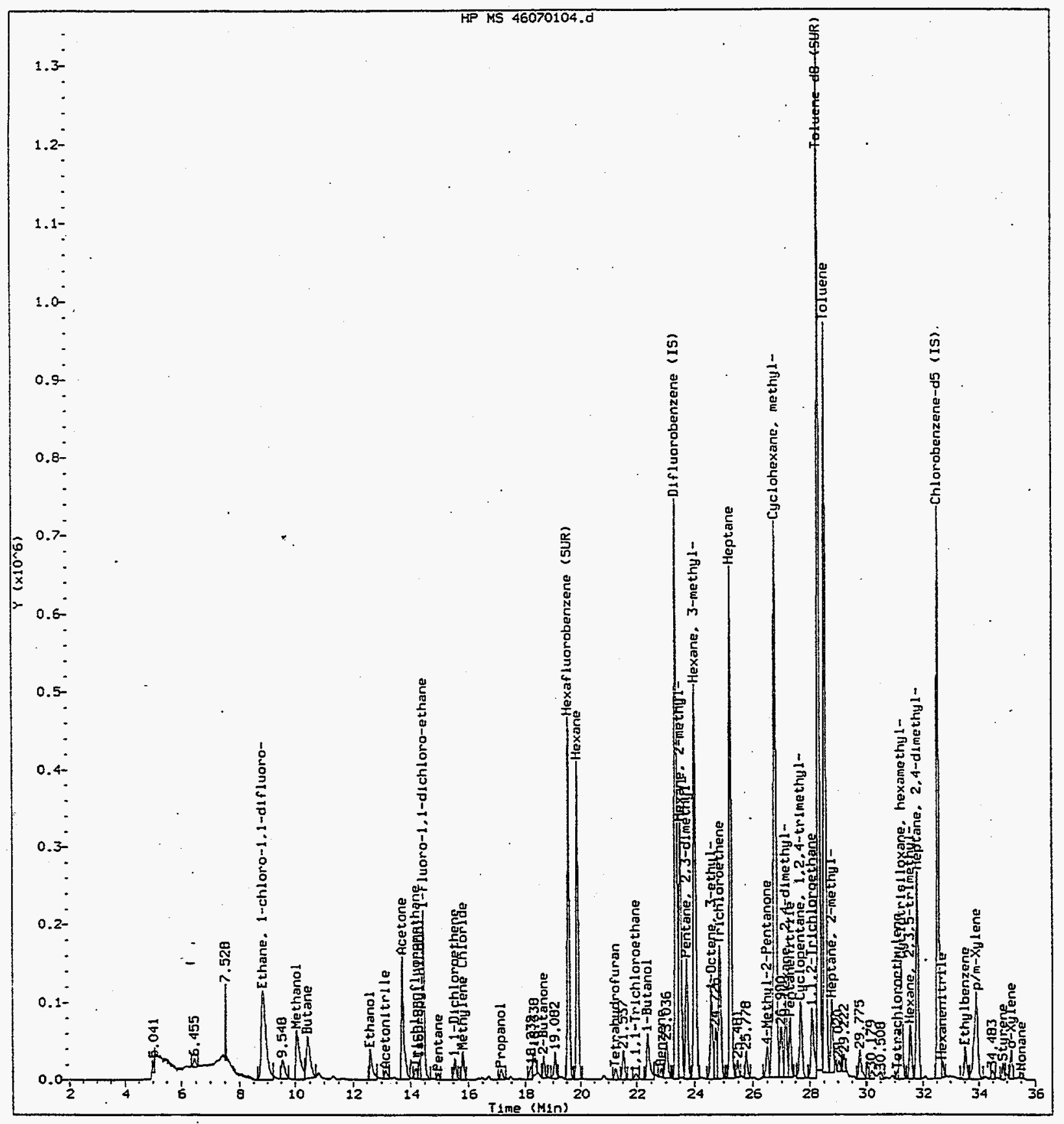

Figure E.1a Total Ion Chromatogram (2 - $36 \mathrm{~min}$ ) for Hanford Waste Tank S-103 Triple Sorbent Trap Sample S6060-A11-986 Collected on 6/12/96

E. 12 


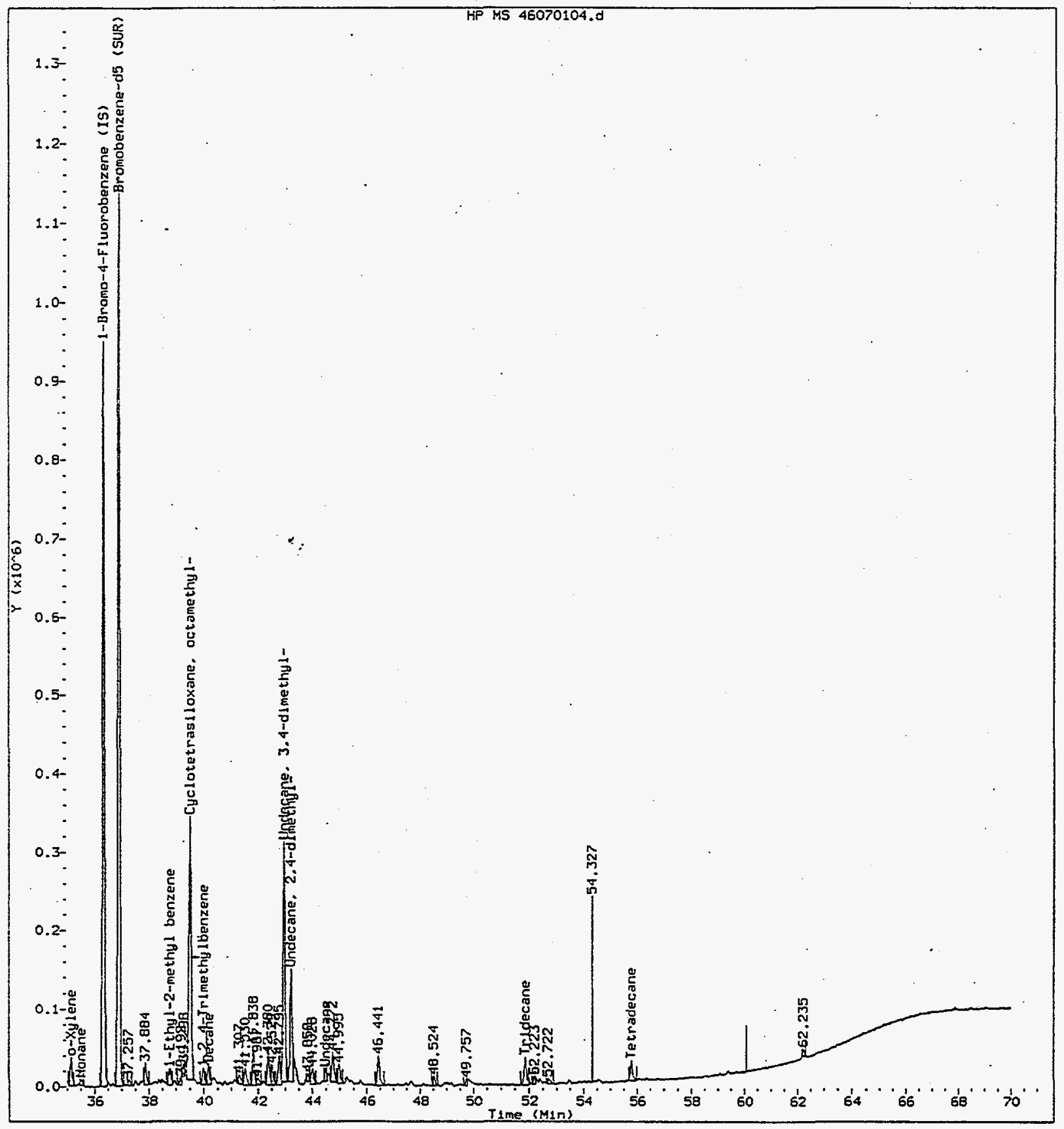

Figure E.1b Total Ion Chromatogram (36 - $70 \mathrm{~min}$ ) for Hanford Waste Tank S-103 Triple Sorbent Trap Sample S6060-A11-986 Collected on 6/12/96

E. 13 


\section{Appendix F}

\section{Tank Vapor Characterization:}

\section{Chain of Custody Sample Control Forms}




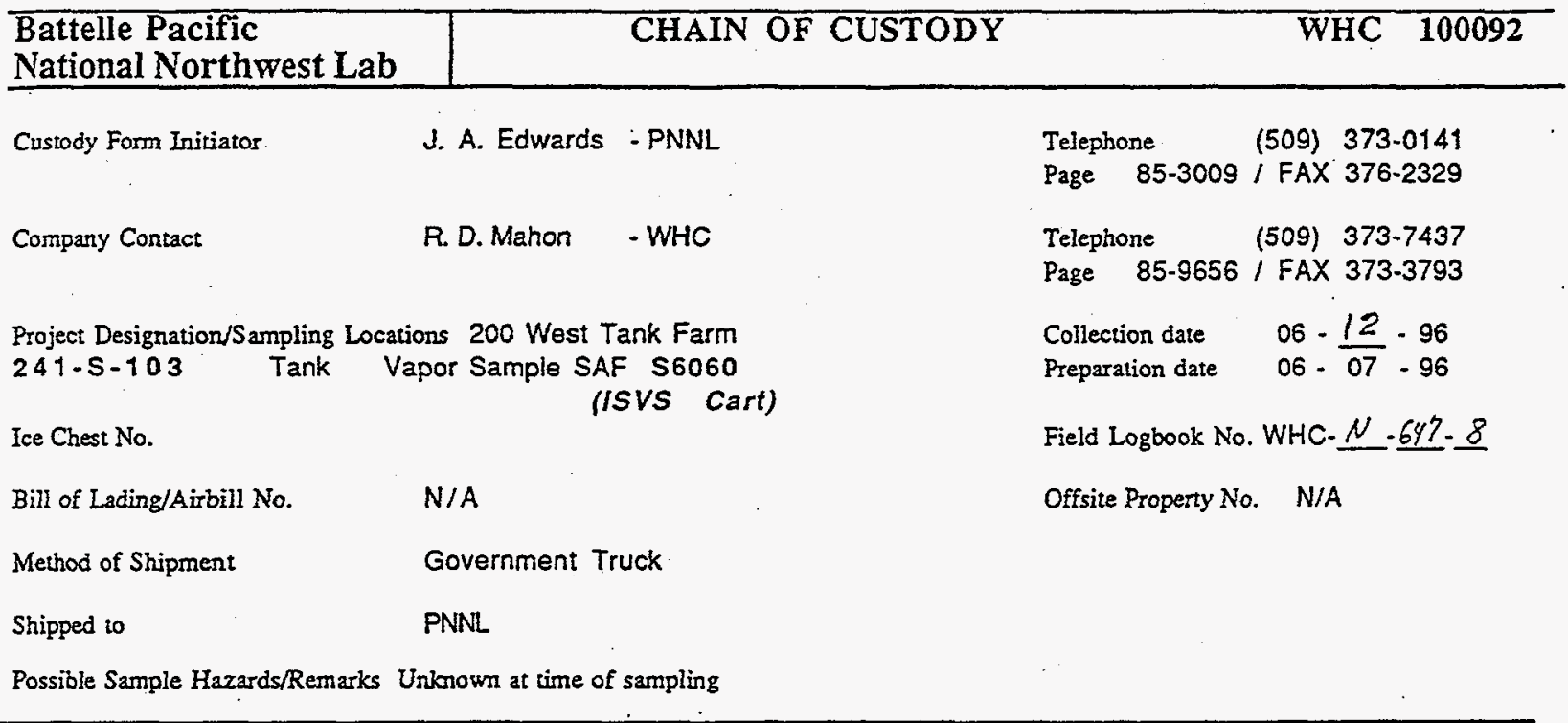

$\begin{array}{ll}S 6060-\mathrm{A} 07 . S 91 & \text { Collect } \mathrm{NH}_{3} / \mathrm{NO}_{\mathrm{X}} / \mathrm{H}_{2} \text { O Sorbent Trap } \\ \text { S6060-A08.S92 } & \text { Collect } \mathrm{NH}_{3} / \mathrm{NO}_{\mathrm{X}} / \mathrm{H}_{2} \text { O Sorbent Trap } \\ \text { S6060-A09.S93 } & \text { Collect } \mathrm{NH}_{3} / \mathrm{NO}_{\mathrm{X}} / \mathrm{H}_{2} \text { O Sorbent Trap } \\ \text { S6060-A10.S94 } & \text { Collect } \mathrm{NH}_{3} / \mathrm{NO}_{\mathrm{X}} / \mathrm{H}_{2} \text { O Sorbent Trap }\end{array}$

S6060 - A15 . S95 - Open, close and store $\mathrm{NH} / \mathrm{NO}_{\mathrm{X}} / \mathrm{H}_{2} \mathrm{O}$ field blank $\# 1$

S6060-A16. S96 - Open, close and store $\mathrm{NH}_{3} / \mathrm{NO}_{\mathrm{X}} / \mathrm{H}_{2} \mathrm{O}$ field blank $\# 2$

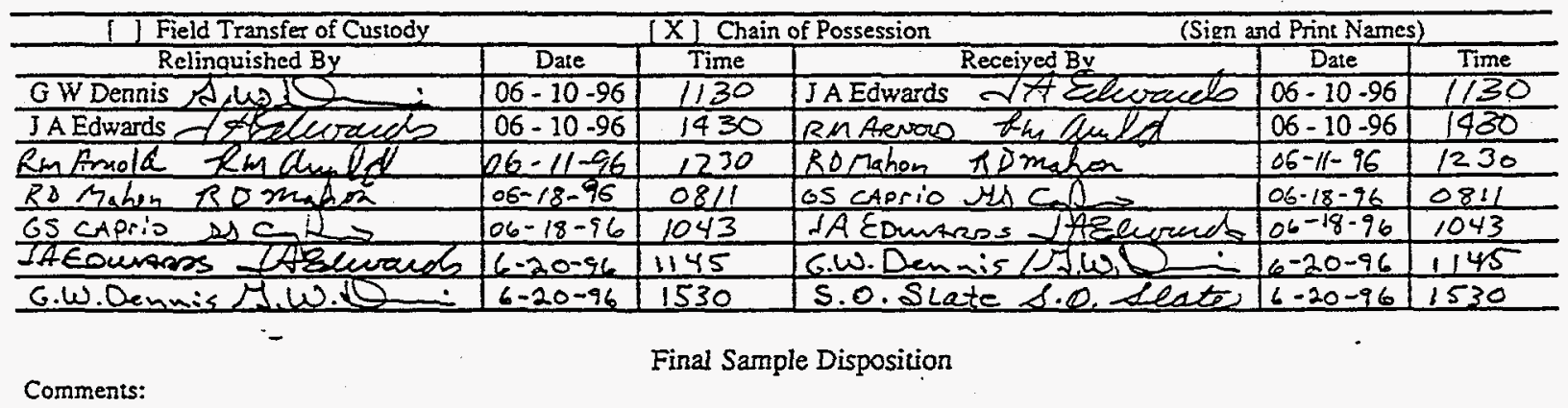

PNNL (only) Checklist Media labeled and checked? Letter of instruction? Media in good condition? COC info/signatures complete? Rad release stickers on samples? Activity report from 2225 ? RSR/release? ( $\leq 100 / 3 \leq 400 \mathrm{pCi} / \mathrm{g})$ COC copy for LRB, RIDS filed?

(WHC-SD-WM-TP-335, REV. 2, Table 2b) A-6000-407 (12/92) WEF061

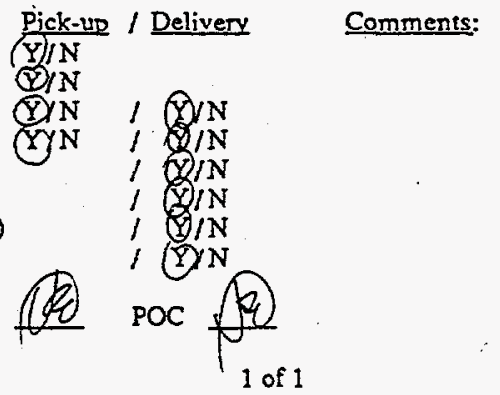

(Revised 05/30/96 PNNL) 


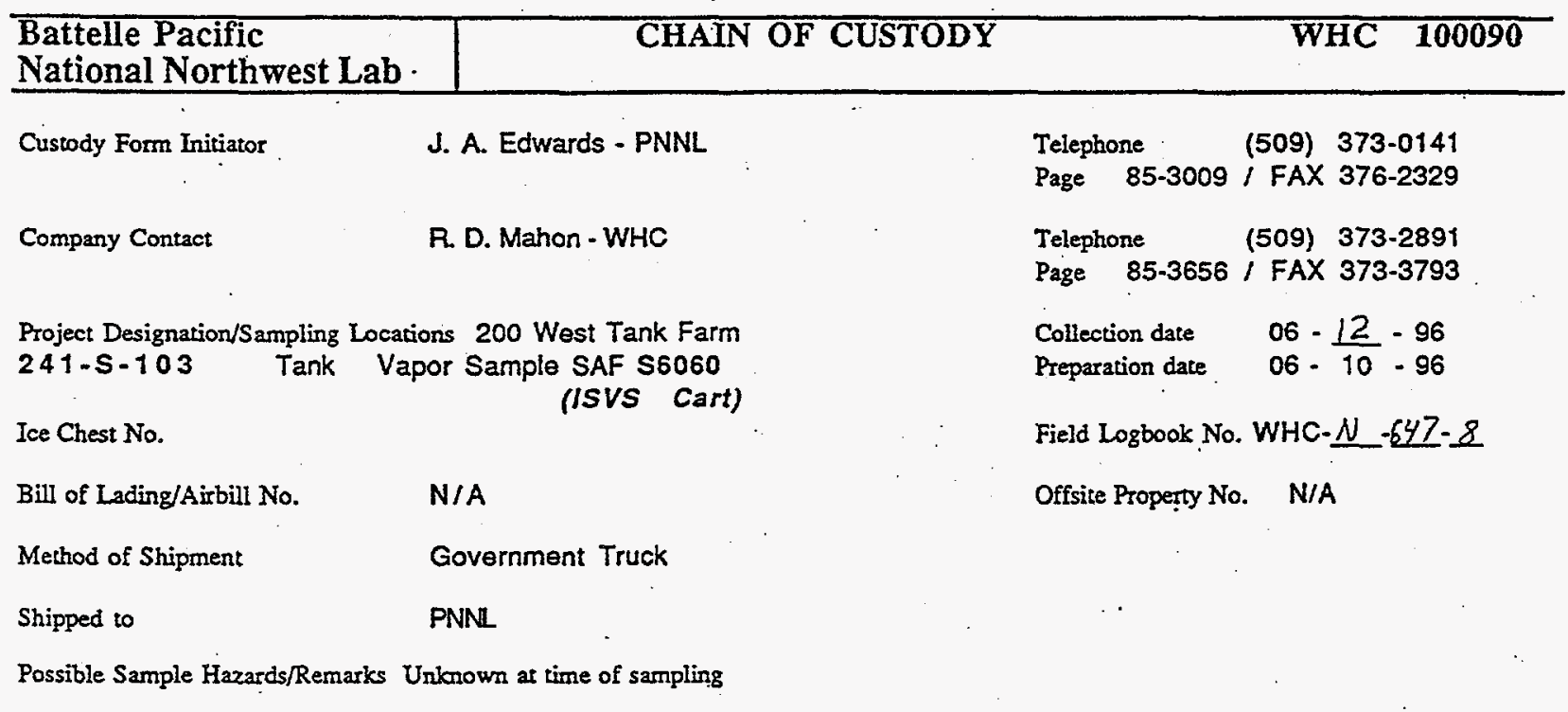

$S 6060-A 01.001$

$\mathrm{S} 6060-\mathrm{A} 02.010$

$S 6060$ - A04.080

$\mathrm{S} 6060-\mathrm{A} 05.082$

$\mathrm{S} 6060$ - A06.083
Collect Ambient Air Sample SUMMA \#1

Collect Ambient Air Sample SUMMA \#2 (through tube bundle)

Collect SUMMA \#3

Collect SUMMA \#4

Collect SUMMA \#5

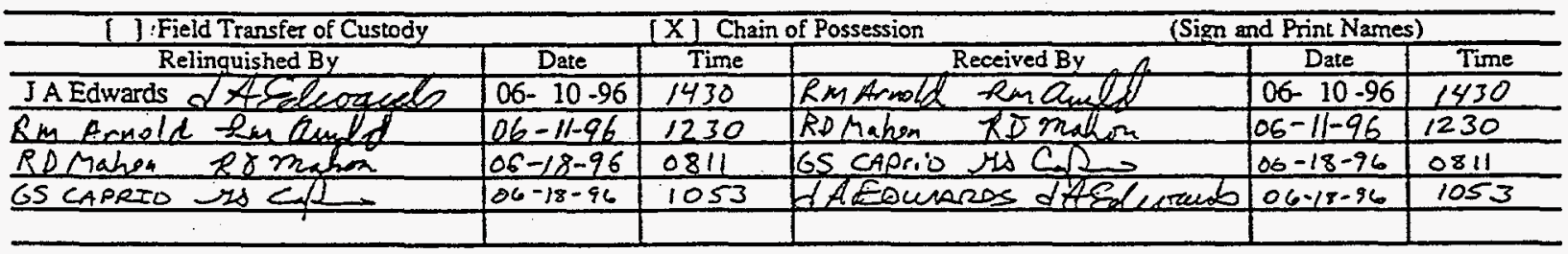

Comments:

Final Sample Disposition

PNNL (oniv) Checiklist Media labeled and checked? Letter of instruction? Media in good condition? COC info/signanures complete? $\mathrm{Rad}$ release stickers on samples? Activity report from 2225? RSR/release? (a $\leq 100 / B \leq 400 \mathrm{pCi} / \mathrm{g}$ ) COC copy for LRB, RIDS filed?

(WHC-SD-WM-TP-335, REV. 2, Table 2b) PO)

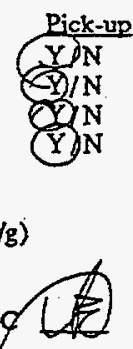

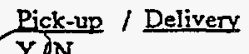

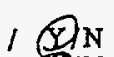

$1 \%$ N

$1 \mathrm{ON}$

$1 \mathrm{XN}_{\mathrm{N}}$

1 CON

in

Poc

Comments: 


\begin{tabular}{|c|c|c|}
\hline $\begin{array}{l}\text { Battelle Pacific } \\
\text { Northwest Laboratory }\end{array}$ & CHAIN OF CUSTODY & $\begin{array}{ll}\text { WHC } & 100091\end{array}$ \\
\hline
\end{tabular}

Custody Form Initiator

Company Contact

J. A. Edwards - PNL

R. D. Mahon - WHC

Project Designation/Sampling Locations 200 West Tank Farm 241-S-103 Tank

Vapor Sample SAF S6060

Ice Chest No.

(ISVS Cart)

Ertco Hillo thermometer No.

Bill of Lading/Airbill No.

Method of Shipronent

Shipped to

PNL-T 003

N/A

Government Truck

WHC-
Telephone
(509) 373-0141
Page 85-3009/ P8-08/FAX 376-0418
Telephone
(509) 373-7437
Page 85-9656 / S3-27 / FAX 373-7076
Collection date
$06 \cdot 12 \cdot 96$
Preparation date
$06 \cdot 07 \cdot 96$

Field Logbook No. WHC-N 647.8

Offsite Property No. N/A

Possible Sample Hazards/Remarks Unknown at time of sampling

Sample Identification

S6060 - A11 - 986 .

S6060-A12. 987 .

S6060 - A13 . 988 .

S6060 - A14 . 989 .

S6060 - A17 . 991 .

56060 - A18. 992 .

S6060 - A19 . 993 .

S6060 - A20 . 994 .
PNL Triple Sorbent Trap (TST) Sample \# 1

PNL TST Sample\# 2

PNL TST Sample \# 3

PNL TST Sample \# 4

Open, close \& store TST Field Blank $\# 1$

Open, close \& store TST Field Blank \#2

Store TST Trip Blank \#1

Store TST Trip Blank \#2

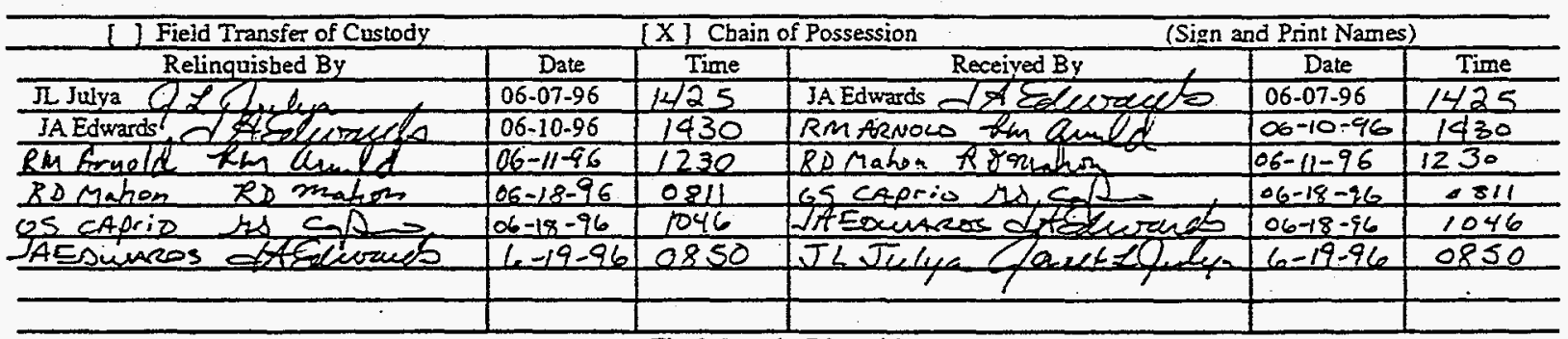

\section{Comments:}

PNL (onlv) Checklist

Media labeled and checked?

Letter of instruction?

Media in good condition?

$\mathrm{COC}$ info/signatures complete?

Sorbents shipped on ice? $\left(<5^{\circ} \mathrm{C}\right)$

HilLo thermometer - Keep upright!

$\mathrm{Hi} /$ Lo thermometer

Rad release stickers on samples?

Activity report from $222 S$ ?

COC copy for LRB, RIDS filed?

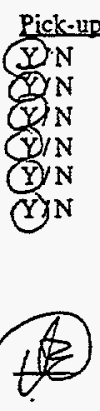

Final Sample Disposition

/ Delivery

Q $/ \mathrm{N}$

1 OIN

, OIN

$101 \mathrm{~N}$

$1 Q / N$

i $\theta / N$

POC
Comments:

1. Cooler Temperature Status

LHi $-15^{\circ} \mathrm{C} / \mathrm{LO}-15^{\circ} \mathrm{C}$ (pick up at PNL to WHC)

IHi ${ }^{\circ} \mathrm{C} /{ }^{\circ}{ }^{\circ} \mathrm{C}$ (delivery at WHC from PNL) ।

$1 \mathrm{Hi}-15^{\circ} \mathrm{C} / \mathrm{LO}{ }^{\circ} \mathrm{C}$ (at return to $\mathrm{PNL}$ from WHC)

Hi $-15^{\circ} \mathrm{C} / \mathrm{LO}+5^{\circ} \mathrm{C}$ (at deliverv from WHC to PNL)

(Revised 06/21/95 PNL) 


\section{PNNL}

Karl Pool

P8-08

Berta Thomas

P8-08

John Evans

K6-96

Khris Olsen

K6-96

Kurt Silvers

K9-08

Jon Fruchter

K6-96

Jim Huckaby

K6-80

Brenda Thornton

K6-80

Darlene Varley

K1-06

Katherine Savard

K9-04

Kris Walters

K6-80 (5 copies)

\section{Lockheed}

Larry Pennington

S7-21

Luther Buckley

R2-12

DOE-RL

Carol Babel

S7-54

Jim Thompson

S7-54 